San Jose State University

SJSU ScholarWorks

Master's Theses

Master's Theses and Graduate Research

1996

\title{
The use of Augmentative Alternative Communication (AAC) systems with the severely handicapped : a case study
}

\author{
Patricia E. Seyfried \\ San Jose State University
}

Follow this and additional works at: https://scholarworks.sjsu.edu/etd_theses

\section{Recommended Citation}

Seyfried, Patricia E., "The use of Augmentative Alternative Communication (AAC) systems with the severely handicapped : a case study" (1996). Master's Theses. 1263.

DOI: https://doi.org/10.31979/etd.ptrj-akb2

https://scholarworks.sjsu.edu/etd_theses/1263

This Thesis is brought to you for free and open access by the Master's Theses and Graduate Research at SJSU ScholarWorks. It has been accepted for inclusion in Master's Theses by an authorized administrator of SJSU ScholarWorks. For more information, please contact scholarworks@sjsu.edu. 


\title{
THE USE OF AUGMENTATIVE ALTERNATIVE COMMUNICATION (AAC) SYSTEMS WITH THE SEVERELY HANDICAPPED: A CASE STUDY
}

\author{
A Thesis \\ Presented to \\ The Faculty of the Department of Communication \\ Disorders and Sciences \\ San Jose State University
}

\author{
In Partial Fulfillment \\ of the Requirements for the Degree \\ Master of Arts
}

by

Patricia E. Seyfried

May 1996 
UMI Number: 1379378

\section{Copyright 1996 by \\ Seyfried, Patricia Elizabeth}

All rights reserved.

UMI Microform 1379378

Copyright 1996, by UMI Company. All rights reserved.

This microform edition is protected against unauthorized copying under Title 17, United States Code.

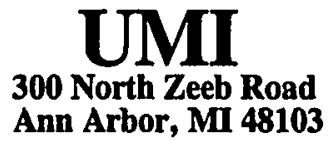


(C) 1996

Patricia Elizabeth Seyfried

ALL RIGHTS RESERVED 
APPROVED FOR THE DEPARTMENT OF

COMMUNICATION DISORDERS AND SCIENCES
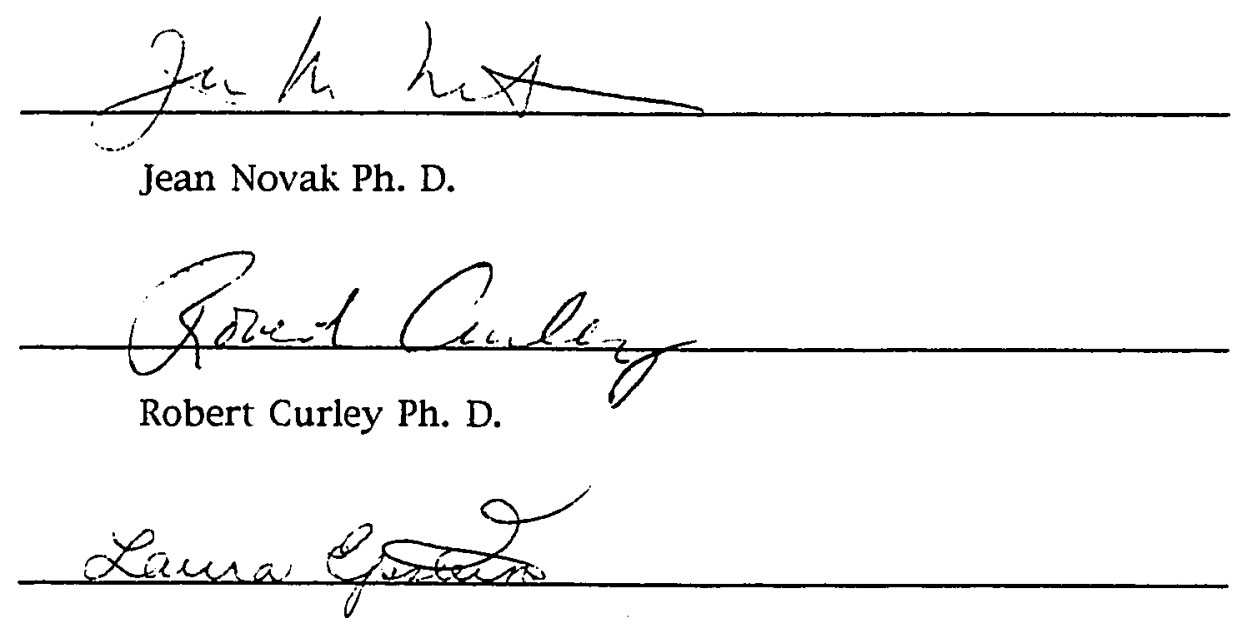

Laura Epstein Ph. D.

APPROVED FOR THE UNIVERSITY

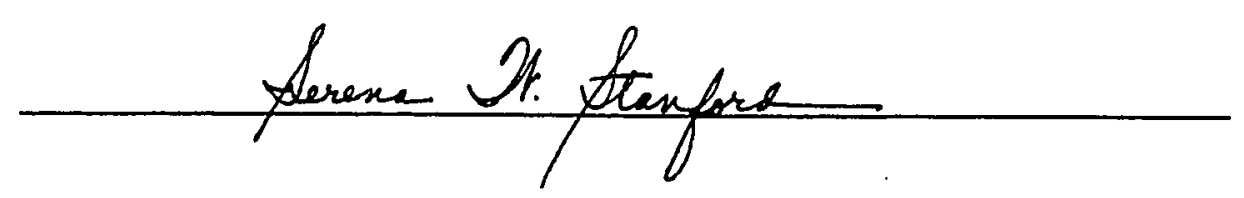




\section{ACKNOWLEDGMENTS}

My sincere appreciation is extended to my three committee members Robert Curley Ph. D., Laura Epstein Ph. D., and thesis chair Jean Novak Ph. D., for their contributions, both academic and emotional. Thank you for all your hard work and support.

I would like to thank my classmates for providing a wonderful support network, especially to those who participated in this study.

In addition, I would also like to express my sincere gratitude to Bette Kirkes, speech pathologist at the San Mateo School District and Cliff Begnal, teacher at Belmont High School.

An acknowledgment is also due for the love and support of my in-laws; Roberta Seyfried, who spent uncountable hours with me proofreading all of my many drafts, and William Seyfried, who unconditionally lent a helping hand.

Finally, I would like to thank my parents, Braulio and Dolores Best, who gave me the needed encouragement across the miles and who reminded me that a sense of accomplishment comes from overcoming challenges. 


\section{DEDICATION}

This thesis is dedicated to my husband, Scott Seyfried, whose love and encouragement helped to make this thesis possible. Scott had faith in my abilities even during the times when I was doubtful. Thank you for helping me through the work of this thesis and supporting me to the achievement of this success. 
TABLE OF CONTENTS

Page

LIST OF FIGURES..................................................................................................................viii

Chapter

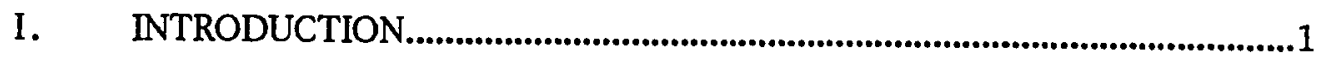

Implementation of AAC systems with the mild to moderate

handicapped population................................................................................2

Implementation of AAC systems with the severely handicapped

population...........................................................................................................3

Statement of Problem........................................................................................4

Purpose of Study............................................................................................4

Research Questions........................................................................................5

Statement of Significance............................................................................5

Limitations..................................................................................................6

II. IITERATURE REVIEW........................................................................

Defining Severe Handicaps..........................................................................7

The use of AAC systems with the severely handicapped...................11

Assessment Issues...........................................................................................13

Design Issues.............................................................................................20

Intervention Issues......................................................................................26

Summary........................................................................................................34

III. RESEARCH METHODOLOGY..................................................................

Subject...........................................................................................................

Materials, Devices and Procedures..........................................................39

Data Analysis...................................................................................................44 
TABLE OF CONTENTS cont.

$\begin{array}{lll}\text { Chapter Page } & \text { Pag }\end{array}$

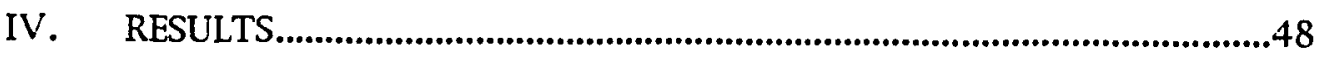

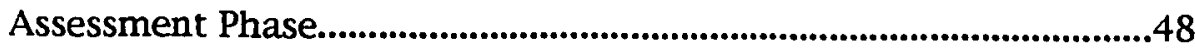

Intervention Phase......................................................................52

Post-Assessment Phase...................................................................55

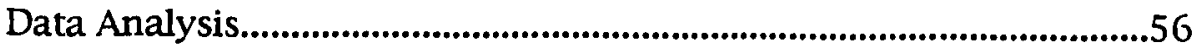

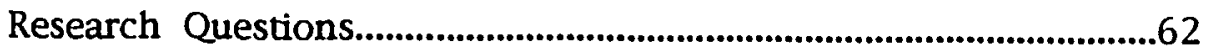

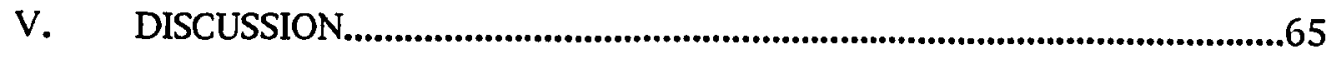

Contributions....................................................................................66

Limitations....................................................................................67

A Need for Future Research.............................................................68

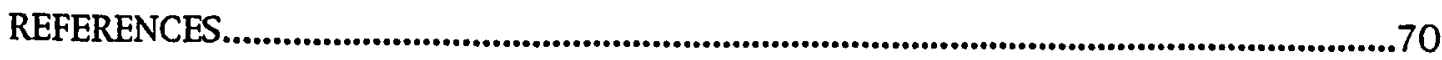

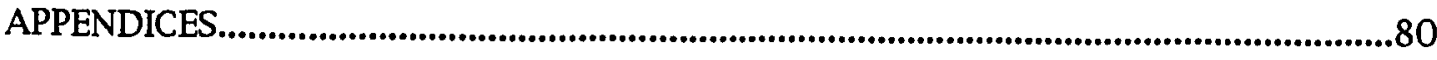

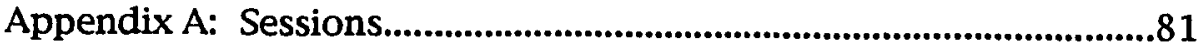

Appendix B: Description of the Communicative Interview.........124

Appendix C: Logs..........................................................................126

Appendix D: Philosophical Assumptions and Practical

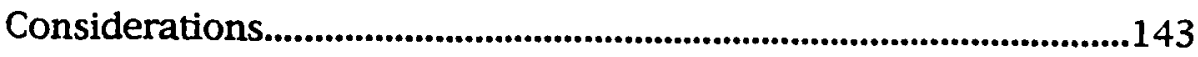




\section{LIST OF FIGURES}

Figure

Page

1. Nail biting behavior at vocational training site.............................57

2. Teeth clicking behavior at vocational training site.......................58

3. Rubbing genitalia behavior at vocational training site................59

4. Nose picking behavior at vocational training site..........................59

5. Nail biting behavior at subject's high school.................................60

6. Teeth clicking behavior at subject's high school............................60

7. Rubbing genitalia behavior at subject's high school....................61

8. Nose picking behavior at subject's high school..............................61 


\author{
ABSTRACT \\ THE USE OF AUGMENTATNE ALTERNATIVE COMMUNICATION (AAC) SYSTEMS \\ WITH THE SEVERELY HANDICAPPED: A CASE STUDY \\ by Patricia E. Seyfried
}

\begin{abstract}
Many individuals with severe handicaps have little or no functional speech which interferes with their ability to develop communication skills and effectively function in society. These individuals form a heterogeneous group which is in need of an individualized assessment and intervention in order to have their unique needs met. The first purpose of this study was to address the deficits of a severe communicatively handicapped student by designing and implementing an appropriate AAC system. The second purpose was to determine the functional gains made by the student after the intervention, and consider the maintenance and generalization of the system's use with different people and across different settings. Results demonstrated significant functional gains made by the student due to the intervention. Implications for speech-language pathologists on how to assess, establish and implement AAC systems with the severely handicapped population are discussed.
\end{abstract}




\section{CHAPTER I}

\section{Introduction}

Millions of people in the United States are suffering from severely handicapping conditions. These people may exhibit extreme deficits in intellectual functioning, visual, auditory or motor skills and communicative abilities (Fristoe \& Lloyd, 1978). Of these millions of individuals affected with severe handicaps approximately 1.5 million are non-speaking children and adults who require communication augmentation because of the severity of their communicative disability (Cohen \& Shane, 1982). This ability to communicate has long been seen as one of the fundamental characteristics that define us as human beings. Hence, if we truly believe in the basic humanity of people with severe disabilities, we must believe in their communicative potential and ability, no matter how severe their level of disability (Mirenda \& Iacono, 1990).

Everyone uses augmentative aids and techniques to communicate. For example, before children have access to speech they interact with their caregivers by means of nonverbal augmentative techniques such as eye gaze behaviors, differential vocalizations and smiles. Even after children acquire speech they continue to use both nonverbal and verbal augmentative communication techniques extensively (Vanderheiden \& Yoder, 1986). Those who need help with communication use Augmentative Alternative Communication (AAC) systems (Heward \& Orlansky, 1992). Research in the area of AAC systems involving individuals with mild to moderate handicaps have been addressed repeatedly (Keogh \& Reichle, 1985). However, research 
documenting the use of AAC systems with the severely to profoundly handicapped population is very limited (Romski, Sevcik, Robinson \& Bakeman, 1994).

The use of an AAC system potentially would allow the severely handicapped individual to communicate with others and play an active and functional role in society. In this thesis I will report on an AAC system designed and implemented to fit the communicative needs of a severely handicapped 16 year old nonverbal Mexican male who understands Spanish only. The assessment, design and intervention process utilizing an AAC system will be conducted entirely in Spanish in order to facilitate language comprehension.

Implementation of AAC systems with the mild to moderate handicapped population

For years controversy existed regarding the appropriateness of using augmentative communication techniques with individuals with mild to moderate handicaps who were thought to have some potential for developing speech (Vanderheiden \& Yoder, 1986). Concerns were expressed in regards to taking an either/or approach to the topic and the belief that the use of augmentative aids and techniques would impede or prevent the development and use of speech. Clinical experience has shown this not to be the case and there has been documentation of increases in functional speech potential (McDonal \& Schultz, 1973). Furthermore, the use of augmentative communication systems has been shown to increase both the number of vocalizations and the intelligibility for many individuals with mild to moderate 
handicaps. Through the use of communication aids and techniques these individuals were able to learn that they could communicate successfully. They also experienced the pleasure, the meaning, the feeling of being able to control their environment, and the power of effective communication (Vanderheiden \& Yoder, 1986).

Implementation of AAC systems with the severely handicapped population

Many individuals with severe handicapping conditions have little or no functional speech. This interferes with their ability to develop communication skills and effectively function in society. A wide range of disabilities could leave individuals without the adequate ability to communicate through the use of gestures, speech, and/or writing. Some of the conditions can be congenital, acquired or progressive neurological diseases. These conditions can be permanent or temporary (Vanderheiden \& Yoder, 1986).

AAC systems are not meant to be used as a substitute for any residual abilities that a severely communicatively impaired individual may have. Rather, they are meant to augment or increase those residual abilities so that those individuals could meet their communication needs (Silverman, 1980). The American Speech-Language-Hearing Association -ASHA- (1989) offered the following definition for AAC: "Augmentative and alternative communication is an area of clinical practice that attempts to compensate (either temporarily or permanently) for the impairment and disability patterns of individuals with severe expressive communication disorders (i.e., the severely speech-language and writing impaired)" (p. 107). With this definition ASHA (1989) granted its support for the utilization of AAC systems 
with the severely handicapped and although the body of literature in this area is not extensive, the researchers who focused their studies in the implementation of AAC systems with the severely handicapped recognized that AAC systems offer the strongest opportunity for this population to acquire a functional communication system (e.g., Beukelman \& Mirenda, 1992; Reichle, York \& Sigafoos, 1991; Romski \& Sevcik, 1992).

\section{Statement of Problem}

Individuals with severe handicapping conditions form a heterogeneous group which is in need of an intricate yet individualized assessment and intervention in order to have their unique needs met. Finding the most efficient application for providing communication for the severely handicapped through the use of AAC systems becomes a very important issue to be addressed and a problem to be solved. Otherwise, the severely handicapped will not be able to effectively participate in today's society. Research in the area of Augmentative Alternative Communication (AAC) indicates that without accessible communication students with severe communicative handicaps will remain isolated and segregated. However, with accessible communication, students who are limited or non-speaking will be empowered to reach their potential (Bloomfield, 1992).

\section{Purpose of Study}

The purpose of this case study is evaluate the communicative deficits of a severely handicapped nonverbal 16 year old student and design and 
implement an appropriate AAC system. Furthermore, this study is designed to determine the functional gains made by the child as well as the maintenance and generalization of the system's use by the child with different people and across different settings.

\section{Research Questions}

1. What was the overall impact of the intervention upon the subject's severe communicative handicaps?

2. To what extent did the AAC system facilitate the expansion and/or development of the behavioral characteristics the subject needed to learn in order to compensate for his severe communicative handicaps?

3. In what ways are the gains made by the subject directly related to the AAC intervention?

\section{Statement of Significance}

Research is needed to determine if significant improvement can be achieved in the communicative functioning of individuals with severe communicative disabilities due to their use of an AAC system. Results obtained can provide collaboration among professionals such as speech-language pathologists and special educators who work with this challenging population. 


\section{$\underline{\text { Limitations }}$}

This study is being designed as a case study. It will allow a comparison between a baseline (pre-treatment) performance and performance following treatment. This design is a close approximation to an experimental singlesubject design; however, it does not qualify as an experimental study because it does not include controls to rule out the effects of extraneous variables on the target behaviors during treatment. 


\section{CHAPTER II}

\section{Literature Review}

\section{Defining Severe Handicaps}

Students with severe handicaps are a heterogeneous group who frequently exhibit accompanying disabilities that include but are not limited to cerebral palsy, sensory impairments, or maladaptive behaviors. The term is generally used to refer to individuals with physical or sensory impairments who also have mental retardation (Wolery \& Haring, 1990). The differences among students with severe handicaps are greater than their similarities (Guess \& Mulligan, 1982). Heterogeneous profiles are obtained and reflecting

diverse communicative needs, and consequently, a range of communication intervention goals (Romski \& Sevcik, 1988). These heterogeneous profiles have also contributed to the difficult task of defining severe handicaps. In addition, no single widely accepted definition of severe handicaps has yet emerged. Most definitions have been based on tests of intellectual functioning, developmental progress, or the extent of educational needs. According to the system for classifying level of mental retardation, (used by the American Association on Mental Retardation) individuals receiving IQ scores of 40 and below are considered to have severe mental retardation; scores of 25 and below result in a classification of profound mental retardation. In practice, however, many individuals who score in the moderate level of mental retardation (i.e., IQ scores of 40-55) are only sometimes considered to have 
severe handicaps (Wolery \& Haring, 1990). Traditional methods of intelligence testing are virtually useless with many individuals who have severe handicaps. As Wolery and Haring (1990) explained, if these individuals are tested they tend to be assigned IQ scores at the extreme lower end of the continuum. To an educator knowing that a particular student has an IQ of 25 is of no value in designing an appropriate educational program. Furthermore, they questioned the appropriateness of giving an IQ test to students who might not be able to hold their heads up or point, let alone talk. Wolery and Haring (1990) also state that educators of students with severe handicaps focus on the specific skills a child needs to learn (i.e., getting from place to place independently, controlling bowel and bladder functions, self-feeding, and communicating with others) rather than on intellectual levels.

According to Wolery and Haring (1990) the most complete and useful definition of severe handicaps to date is the definition drafted by The Association for Persons with Severe Handicaps.

These people include individuals of all ages who require extensive ongoing support in more than one major life activity in order to participate in integrated community settings and to enjoy a quality of life that is available to citizens with fewer or no disabilities. Support may be required for life activities such as mobility, communication, self-care, and learning, as necessary for independent living, employment and self-sufficiency. (Lindley, 1990, p.1)

This definition refers to the level, duration, and focus of support needed by persons who are labeled as severely disabled, and it specifies the goals and expected outcomes of that support. Compared to some other areas of special 
education (i.e., mental retardation, learning disabilities, and behavior disorder in particular) there has been less concern and debate over the definition of severe handicaps. This is not an indication that professionals are not interested in defining the population of students they serve, but rather a reflection of two features inherent in severe handicaps. First, there is little need for a definition that precisely describes who is and who is not to be identified as severely handicapped. For example, the specific criteria a school district uses to define learning disabilities has a major impact on who will be eligible for special education services. Whether or not a student who may be labeled severely handicapped needs special education is seldom an issue. Second, because of the tremendous diversity of learning and physical challenges such students experience, a single descriptor such as severely handicapped is inadequate. On the other hand, complex statements incorporating the child's specific behavioral characteristics including deficits in life-skill or developmental areas are more meaningful (Sontag, Sailor, \& Smith, 1977).

No specific set of behaviors is common to all children with severe handicaps. Each child presents a unique combination of physical, intellectual, and social characteristics. Sailor and Guess (1983) describe several characteristics of children with severe handicaps. Almost all of these children are limited in their ability to express themselves and to understand others. Many cannot talk or gesture meaningfully or might not respond when communication is attempted. Cognitive limitations or retardation caused by brain damage will affect their cognitive ability which in turn will affect what they can learn and what can be taught to them. Their behavior and social skills will also be affected making it difficult for them to socialize with others 
(i.e., peers, adults, etc.) and others wanting to socialize with them. There are several consequences for children with severe deficits in communication skills. First, they encounter faulty transmission and/or perception of messages. This results in learning and social disadvantages and has a negative impact upon their emotional growth. Second, they experience impaired physical and motor development. Most of these children have limited mobility. Many cannot walk. Some cannot stand or sit up without support. Physical deformities are common and may worsen without consistent physical therapy. Third, they experience deficits in self-help skills. Some children are unable to care independently for their most basic needs (i.e., dressing, eating, exercising bowel and bladder control, and maintaining personal hygiene). To learn these basic skills they require special training involving prosthetic devices and/or adapted skill sequences. Fourth, they infrequently exhibit constructive behaviors and interactions. Most such children do not know how to play with other children, interact with adults, or seek out information about their surroundings. Finally, they often display inappropriate behavior. Many severely handicapped children do things that appear to have no constructive purpose and that interfere with teaching and with social acceptance. Some activities may be ritualistic (i.e., waving fingers in front of the face, twirling the body, rocking back and forth). Others are self-stimulatory and/or selfinjurious (i.e., scratching or biting oneself, head banging, hair pulling, eye poking, hitting, grinding the teeth).

Descriptions of behavioral characteristics such as these just mentioned can easily give an overly negative impression. Despite the immense challenges their disabilities impose upon them, students with severe handicaps may also have many positive characteristics including warmth, persistence, 
determination, sense of humor, sociability, and various other desirable traits (Forest \& Lusthaus, 1990). Many teachers find great satisfaction in working with students who have severe handicaps and in observing their progress in school, home, and community settings (Stainback \& Stainback, 1991).

\section{The use of AAC systems with the severely handicapped}

From 1970 to 1975 there was a dramatic increase in the use of nonspeech communication systems with individuals having severe communication impairments but essentially normal hearing (Lloyd, 1976). Research and intervention for individuals with severe handicapping conditions utilizing AAC systems however, did not advance significantly until the years 1983 to 1988 (Romski \& Sevcik, 1988). Although an extensive body of literature is not available in this area the existing body of research has documented that AAC systems have been used by individuals with severely handicapped conditions and that symbols have been mastered in an augmentative mode even when these individuals have not been successful at learning traditional spoken language (Romski, Sevcik, Robinson, \& Bakeman, 1994; Romski, Sevcik, \& Wilkinson, 1994). It has also been recognized in the literature that AAC systems offer the severely handicapped the strongest opportunity for effectively acquiring a functional symbolic communication system (Beukelman \& Mirenda, 1992; Reichle, York, \& Sigafoos, 1991; Romski \& Sevcik, 1992).

The past decade has been a time of increased attention to the challenge of facilitating communication between individuals with severe handicaps and significant others in their environment. Among the important evolutionary 
milestones achieved and reported in the body of research during this period of time has been a shift in assessment procedures. Until recently, assessment was used primarily to identify appropriate candidates who met a predetermined cognitive criteria for augmentative communication. Assessment is now a process which identifies appropriate AAC candidates based on the inclusionary principle that improved communication is possible to all persons with severe communicative handicaps regardless of their cognitive impairments (Kangas \& Lloyd, 1988). Another important milestone achieved was a shift in the goal of intervention from the development of specific isolated speech and language skills to the development of integrated functionally relevant communication abilities (Romski \& Sevcik, 1988). Finally there has been an increased understanding of the multimodal nature of communication (Reichle \& Karlan, 1985). These trends have been reflected in the communication literature as well as in practices currently employed in many school, community, home and vocational environments. These trends have also allowed the severely handicapped to have easier access to the use of AAC systems and therefore, an increase in the number of users has been documented (Mirenda \& Iacono, 1990). For example, a demographic study conducted in the State of Washington to determine the need for intervention using AAC with the severely handicapped indicated that persons with mental retardation comprise the largest percentage of the nonspeaking school-aged population. This study estimated that approximately $4 \%$ to $12 \%$ of school-aged children with mild to moderate retardation and $92 \%$ to $100 \%$ of children with severe to profound retardation were nonspeaking. Therefore, the use of AAC systems to provide these children with a functional means to communicate was warranted (Matas, Mathy-Laikko, Beukelman, \& Legresley, 1985). The trends reflected in the 
literature thus far have resulted in an acceptance of the belief that AAC services of some type should be delivered to communicatively handicapped individuals regardless of the degree of impairment (Romski \& Sevcik, 1988).

In order for a severely handicapped individual to be able to use an AAC system, careful consideration of assessment, design and intervention processes is necessary. These three processes are not exclusive of one another and should be integrated.

\section{Assessment Issues}

There has been considerable research on AAC with regard to persons with mild to moderate handicaps. Few studies however, have addressed concerns specific to children and adults with severe disabilities (Keogh \& Reichle, 1985). Some of the variables related to the successful implementation of AAC systems with both children and adults with severe handicaps have been identified and experimentally manipulated. These include: innovative teaching strategies, initiation of intervention at the level of the learner's extant skills, and service delivery focusing intervention in natural settings concentrating on functional activities which can promote generalization.

Until recently, however, research with this population was limited by the assumption that some prerequisite skills had to be in place before an individual could be considered a candidate for an AAC system (Chapman \& Miller, 1980; Shane, 1980; Shane \& Bashir, 1980). Three basic sets of decision rules for determining whether to implement a nonspeech communication system have typically been used (Chapman \& Miller, 1980; Shane, 1980; Shane \& Bashir, 1980). These decision rules are not exclusive of one another, often 
overlap and have a common focus: determining "when" it was advisable to use a nonspeech system of communication. All three sets of decision rules adhere to the same basic strategy of first setting up a certain severity of impairment that must be present, and subsequently apply the scrutinizing prerequisites required for entry into an AAC system. The prerequisite skills identified have included cognitive development at Sensorimotor Stage V (e.g., means-end) or Sensorimotor Stage VI (e.g., object permanence), intentional communicative abilities, and spoken language comprehension abilities. The rationale behind these prerequisite skills is that certain sets of skills are necessary for the development of other skills. This assumption is taken from the emergence of communication and language skills in the normally developing child which generally follows a predictable course (Bruner, 1983). This early sequence of communication and language acquisition was used as a framework for the development of the prerequisite skills. However, the body of literature suggests that the relationship between cognitive, communicative, and linguistic skills is not as predictable as it might have been viewed initially by child language investigators (Romski \& Sevcik, 1988). Rice and Kemper (1984) believe that no well defined necessary and sufficient cognitive skills for language development have been documented. Furthermore, they argue that the definition of AAC has been extended beyond formal linguistically based systems to include vocalizations, gestures, and other modes of communication to allow AAC intervention to begin at the point the learner is at rather than waiting for them to attain a certain skill. Nevertheless, since many of the individuals with severe intellectual disabilities did not meet the prerequisite's criteria, they were not considered to be "ready" to use or to benefit from communication intervention employing an AAC system. 
A number of reasons have been advanced for believing that individuals who do not meet these criteria may still benefit from AAC. Rogers (1977), for instance, documented the fact that a severely intellectually delayed population exhibited less homogeneity across cognitive subscales than normal children. For example a child with severe handicaps might be operating at Sensorimotor Stage V (12-18 months) in means-ends but Stage III (4-8 months) in motor imitation. Subsequent data continued to support the conclusion that individuals having severe handicaps are heterogeneous with respect to the level of cognitive development attained across several different areas of behavior at a given point in time (Karlan \& Lloyd, 1983). Consequently, when this heterogeneity is manifested across cognitive assessment scales, they cast doubt on the precision of an overall cognitive stage score. In spite of this evidence, a significant number of learners with severe disabilities were trapped in the middle of having a sufficiently severe impairment but failing to have the putative cognitive prerequisites necessary to be a candidate for an AAC system (Reichle \& Karlan, 1985).

Supporters of the decision rules argued that children begin using adults as agents to obtain access to desired objects and events during sensorimotor stage V (Bates, Benigni, Bretheton, Camioni, \& Volterra, 1979; Uzgiris \& Hunt, 1975) and that the acquisition of an adult as an agent is a critical prerequisite to communication referencing or naming. Therefore, children must have the attention of a speaking partner to reference. When the learner does not have the speaking partner's attention, the listener's attention must be obtained prior to the initiation of the message. Other studies argued the need for the use of "adult as agent" from Sensorimotor Stage $V$ as a prerequisite for AAC program entry stating that this prerequisite allowed only "self-initiators" to 
participate in augmentative communication training (Chapman \& Miller, 1980; Shane, 1980; Shane \& Bashir, 1980). An alternative point of view was presented by Keogh and Reichle (1980) suggesting that "adult as agent" represents a desirable entry skill but is not a prerequisite. Keogh and Reichle (1980) suggested that initial use of a communication board involves teaching the learner to use a symbol as a mediator to the desired objects/events. The use of an adult as an agent does not become a precondition to board use. Although the use of "adult as agent" may critically affect the learner's ability to initiate communicative behavior, it should not be considered a prerequisite for the implementation of a communication board. This logic can be supported in the following manner: First, a learner may be taught to use object mediators to obtain reinforcers prior to the use of persons as mediators. This argument is consistent with the emergence of language in normally developing children whose language develops through a communicative continuum from signals such as fussing or crying at one extreme to symbols such as words or manual signs at the other end of the continuum (Uzgiris \& Hunt, 1975). Second, it may be possible to teach a mediating response that could serve as a perlocutionary communicative function. For instance, Bates, Benigni, Bretheton, Camioni, and Volterra (1979) have described a perlocutionary communicative function as the production of an unintentional motor or vocal behavior that has the effect of an intentional one. For example, if a child cries with no intent of obtaining an adult but the adult interprets the child's cry as a call and responds by comforting the child, a perlocutionary communicative cycle has been completed. In support of Bates, Benigni, Bretheton, Camioni, and Volterra (1979) several investigators (Keogh \& Reichle; 1983; Mclean \& Snyder-Mclean, 1978) suggested that frequent participation in perlocutionary 
routines may set the occasion for the acquisition of "person as agent" attention getting strategies. If this occurs, Sensorimotor Stage $V$ "means-end" would not be required for early communication production training. Therefore it should not be required as a prerequisite to initiating an AAC system.

More support against the decision rules was presented in a study conducted by Reichle and Yoder (1985) where four preschoolers with severe disabilities, who functioned at Sensorimotor Stage IV, were taught to label 4 objects using a direct selection communication board with Pictogram Ideogram Communication (PIC) symbols. The conclusion of their study was that children at Stage IV could be taught rudimentary communication skills even though functioning at Sensorimotor Stage V has typically been considered a prerequisite for AAC use and development.

Another ability considered to be a prerequisite to the use of AAC systems has been spoken language comprehension skills. For individuals with spoken language comprehension skills, AAC systems may primarily serve as communicative output modes. For individuals with receptive and expressive communication/language impairments the AAC system would have to be used to receive information from, and convey information to, their communicative partners. This prerequisite emerges from the assumption that AAC systems should be use as output modes of communication instead of being used as dual teaching tools for communication. This assumption is based on the consistent difficulty learners with severe communicative disabilities have evidenced with the various dimensions of the speech input or output signals.

This prerequisite was also argued against by researchers. In a study conducted by Romski, Sevcik, and Pate (1988) it was reported that two nonspeaking young adult subjects with severe retardation, who also lacked 
spoken language comprehension skills, learned to request desired foods and objects using abstract graphic symbols on a computer-linked display panel. Their conclusion was that learning is possible once the system is established and there is no need for the spoken language comprehension skills to be present before intervention is started.

Another of the prerequisite skills that has been presented was the presence of intentional communicative abilities in the individual's actions. Researchers who were in opposition to this prerequisite skill used a pragmatic perspective derived from the Pragmatic Approach. Initially the Pragmatic Approach had been used in studies in early language acquisition with children who were not mentally retarded. First, researchers used a pragmatic framework to describe the functions of language in various contextually based communicative interactions (e.g., to request, to protest) because they believed it was the functions of language that affected the behaviors of other individuals participating in the social interactive context (Bates, 1976; Bruner, 1978). Later the Pragmatic Approach was extended in studies conducted with infants who were not mentally retarded with the purpose of analyzing their preverbal communication attempts. Results from these studies indicated that the normally developing infants successfully used a variety of preverbal behaviors to affect their environment at a time when expressive abilities were limited to a small set of nonverbal gestures such as reaching and pointing (Bates, 1976; Bates, Camaioni, \& Volterra, 1975). Later on when communication skills were studied the subjects, although mentally retarded, had been verbal, speaking, and/or with mild or moderate mental retardation (Owens \& McDonald, 1982; Owings \& McManus, 1980; Owings, McManus, \& Scherer, 1981). These studies increased the understanding of the language abilities of persons 
who are mentally retarded but could speak. However, there remained a lack of data and methodology that could describe the communicative abilities of nonverbal youths with severe-profound mental retardation from the pragmatic perspective that could be used in the assessment and effective treatment of their communication skills (McLean \& Snyder-McLean, 1978; Owings, McManus, \& Scherer, 1981). Therefore, Cirrin and Rowland (1985) conducted a study with the intent of developing a method for assessing nonverbal behaviors from a pragmatic perspective. They based their study on the assumption that nonverbal behaviors can be used as an effective means for fulfilling various social functions. They had 15 subjects with severeprofound mental retardation ranging in age from 10 to 18 years. All of the subjects were nonverbal and had been unresponsive to speech training. The primary goal of their educational program was the establishment of a basic functional communication system. Most of the subjects used nonverbal behaviors (e.g., reaching for objects, pushing) to have some control over their environment. The development of the assessment procedure consisted of samples of communicative behaviors from the subjects gathered over a 20 minute session. These sessions consisted of 15 routines involving highly motivating stimuli (e.g., food items, toys that moved or that made noises) and activities (e.g., making kool-aid, tickling) guided by a familiar adult. Opportunities for communication were set up by the adult who also provided a suitable pause at the critical moment for the subject to respond. The samples containing the communicative behaviors from the subjects were videotaped and coded for intentional nonverbal communicative behaviors and communicative functions. The results generated by their assessment process demonstrated that all 15 subjects had at least some comprehension of the role 
of adults as agents and the role of their own signals in affecting that agency. They concluded that even these individuals with severe cognitive and social handicaps had a social foundation of language to some degree and thus might benefit from the use of AAC systems.

All of these studies emphasized the need to reassess the issue of prerequisites and their role in communication service delivery to persons with severe intellectual disabilities. These studies were part of the movement that started the shift in assessment procedures from those which had been designed to identify "appropriate candidates" for AAC to those which opened the doors to include all individuals regardless of the level of their intellectual disability.

\section{Design Issues}

Once the assessment process is completed the next step is to design an appropriate communication system. The selection of an appropriate symbol system or symbol set for the heterogeneous population of individuals with mental retardation can not be predetermined based on IQ level, developmental age, or some other measure (Chapman \& Miller, 1980). Rather symbol set selection is a complex task that must be approached on an individual basis (Romski, Sevcik, \& Joyner, 1984). Investigators have advocated the use of a two-tiered process in which the need for an AAC system is quantified first, and then a specific system is chosen (Chapman \& Miller, 1980; Nietupski \& HamreNietupski, 1979; Shane, 1980; Shane \& Bashir, 1980). An alternative suggestion is to sample 2 augmentative modes with a learner before selecting a single augmentative system (Kiernan, 1981). 
AAC systems have been divided into unaided and aided systems. Unaided systems traditionally have been the choice for able-bodied children who exhibit other primary disabling conditions (e.g., mental retardation). Unaided systems do not require any aids or devices. They use the sender's face, head, hands, arms, and other parts of the body and are also frequently referred as manual systems (Karlan \& Lloyd, 1983). Examples of unaided systems are signed English, signing Exact English and American Sign Language (ASL). The use of manual signs is attributed to the following variables: First, manual signs require less sophisticated motor skills than speech and they are taught easily because some signs closely resemble the object and action they represent (Bellugi \& Klima, 1976). Second, manual signs can be held visually static providing a good model for imitation (Dennis, Reichle, Williams, \& Vogelsberg, 1982). Third, manual signs and gestures are portable requiring only the processing of temporal and spatial information and the use of the individuals own body to communicate.

Aided systems traditionally have been reserved for individuals with severe physical disabilities. Aided systems require some type of external assistance, or an aid or device such as paper, pencil, pictures, charts, communication boards, and in some cases electronic devices (Karlan \& Lloyd, 1983). There are two ways to use aided modalities: First, an aided modality can be use in correspondence with graphic symbols on manual communication board. Such systems could be set up to require a lesser degree of motor abilities depending on the needs of the individual (e.g., from manually pointing to an icon to using scanning devices and single switch activation to select an icon) and they can allow for total iconicity or they can be more abstract in their representation depending on the cognitive abilities of the 
user (Lloyd \& Fuller, 1986; Vanderheiden \& Lloyd, 1986). Also it has been reported that graphic symbols aid in memory recognition because they are static and therefore are easier to process (Mirenda, 1985). Second, an aided modality can be use in correspondence with electronic voice output communication aids (VOCAs) which are more expensive systems that allow for voice projection upon icon selection (Soto, Belfiore, Schlosser, \& Haynes, 1993).

It has been suggested that making a quick selection between signing and communication boards may create a false issue for the interventionist because many learners may benefit from the use of a "mixed" system; that is one that combines the use of some signs/gestures with other graphic symbols. Consequently, selecting a single augmentative system may not be the most critical initial issue within the designing process (Keogh \& Reichle, 1985). Many investigators have argued that systems should be selected based upon an individual's communicative strengths and weaknesses and their personal match to a system or systems rather than their accompanying physical disability alone (Keogh \& Reichle, 1985; Mirenda, 1985; Romski, Sevcik, \& Joyner, 1984). In any case, once the selection of an aided or unaided system or some combination has been made other issues have to be considered. For instance, when the design of a nonspeech communication system is under consideration, the individual's representational ability must be taken into account (Romski, Lloyd, \& Sevcik, 1988; Sevcik \& Romski, 1986). One of the problems in nonspeech communicative intervention with the severely handicapped population is the representational complexity of the symbols to be used. If a visual graphic symbol set is to be used, the arbitrary versus the pictographic nature of the symbols need to be evaluated (Luftig \& Bersani, 1985; Romski, Sevcik, \& Joyner, 1984). When normally developing children 
acquire language it is essential that they realize that symbols refer to environmental referents. Normally developing children are able to make a correspondence between physical realities and symbols so that they become internalized representations of the world (Bates, 1979; Bruner, 1974). Keogh and Reichle (1985) stated that little progress toward acquiring a symbolic and rule-governed communication system can be expected without the ability to match objects and events with some symbol form (e.g., photographs or line drawings). However, for individuals with significant oral language impairments and severe retardation the transition to representational cognition may be a difficult one (McLean \& Snyder-McLean, 1978; Romski, Sevcik, \& Joyner, 1984).

Iconic signs have been found to facilitate vocabulary learning in person with mental retardation (Dennis, Reichle, Williams, \& Vogelsberg, 1982; Griffith \& Robinson, 1980; Reichle, Williams, \& Ryan, 1981). Furthermore, iconic signs that visually represent the function of the referent, or action patterns evoked by the referent, appear easier to learn than signs that visually represent the static features of the referent (Knudson, 1980). Hurlbut, Iwata, and Green (1982) provided direct evidence about the relationship of iconicity to visual-graphic symbol learning for individuals with severe physical disabilities and mental retardation. Their research showed that iconic line drawings were acquired more rapidly, maintained longer, and generalized more frequently than arbitrary set of symbols. Similar findings from a number of studies with normally developing children (Ecklund \& Reichle, 1987; Mizuko, 1987) supported the conclusions from Hurlbut, Iwata, and Green (1982). 
Mirenda (1985) went a step lower in the representational symbol ladder and suggested that photographs require minimal symbolic ability (less than that needed for iconic signs) on the part of the learner and for this reason photographs may be the best choice of representational symbols for communication board users. Mirenda's study set out to describe the representational performance of 8 subjects with severe mental retardation. Objects, photographs and line drawings were presented as stimuli in identity and nonidentity matching tasks to examine the subjects' abstractive skills. In the identity matching tasks the stimuli were matched to themselves (e.g., object matched to object). In the nonidentity matching tasks, first the objects were paired to their matching photographs, then the objects were paired to their line drawing illustrations, and lastly the photographs were paired to the line drawing illustration of the same objects. The subjects in the study were divided into 2 groups based on their functional language use which was defined as a minimum vocabulary of 10 spoken words, manual signs, or visualgraphic symbols used spontaneously in both production and comprehension. The results indicated that in the identity matching the functional language group did better. However, the difference between them and the nonfunctional language group was slight except for the line drawing matching in which the difference was significantly higher for the group with functional language. In the non-identity matching there were significant differences on the performance by the two groups in all three matching categories. The more representationally complex the stimulus matches were, the more difficult they were for the subjects without functional language skills, especially the matches containing line drawing representations. 
The results of Mirenda's (1985) study not only indicate that photographs may be a good choice for novice communication board users, but also sheds light on two important issues. The first issue is that photographs and line drawings which hold a different representational value can be used to differentiate specific conceptual skills and/or symbolic abilities in individuals with severe cognitive and language impairments. Line drawings pose practical advantages over the use of photographs, such as ease of production and availability. Since a line drawing can be made by anyone without requiring artistic skills they can be prepared requiring minimal time. Also line drawings can allow for introduction of new items following a spontaneous or unprepared functional situation when conducting intervention in natural occurring settings. The second issue is that it is important to consider the individual's comprehension and production skills at the time of communication board instruction.

In addition to considering the individuals representational abilities when designing an AAC system, other issues must also be considered. For instance, Lloyd (1986) suggested that cognitive, linguistic, environmental, and perceptual factors also need to be considered. Many of these factors may interact to affect the way in which symbols are employed by individuals with severe retardation. For example, one important environmental consideration suggested by Lloyd is the ease of interpretation by communicative partners. This is because the way in which communicative partners respond to the symbols can affect the way in which they are employed by the AAC user. Another issue to consider is the integration of existing communication skills such as vocalizations and gestures, with manual signs; graphic symbols, and/or words for effective communication development. Hopper and Hemlick 
(1977) have suggested that AAC systems should be overlaid upon existing communicative skills.

According to Romski, Sevcik, Reumann, and Pate (1988) choosing an aided or unaided system and symbol set may be a relatively minor concern in teaching individuals with severe intellectual disabilities to communicate. A more primary concern may be the selection of teaching strategies that result in progress toward communicative competence for individuals with severe intellectual disabilities regardless of the mode employed. This leads us to the issues that must be considered during the intervention process.

Intervention Issues

For years professionals who work with severely handicapped individuals have had access to techniques for teaching a wide variety of skills, both in the classroom and in the community (Sailor, Wilcox, \& Brown, 1980). Due largely to the development of this teaching technology, those with severe learning handicaps are becoming increasingly able to participate in recreational, vocational, community, and school-related activities with nonhandicapped persons. Despite philosophical and technological advance, there remained a significant number of severely handicapped individuals who did not fully benefit because of their inability to generalize newly acquired skills to unfamiliar materials, environments and/or persons. These individuals include at least those identified as severely-profoundly mentally handicapped, trainable mentally handicapped, and autistic. For years, educators have been frustrated by the lack of generalization, and yet relatively few pertinent techniques were evident in classrooms and other 
treatment centers (Warren, Rogers-Warren, Baer, \& Guess, 1980). One explanation for this void can be found in the literature. A literature review in applied behavior analysis, conducted by Donellan and Mirenda (1983) revealed 150 journal articles pertaining specifically to generalization programming for the severely handicapped. However, the vast majority of the research investigated generalization with the nonhandicapped or mildly handicapped populations. Though several authors had called for additional research (Berler, Gross, \& Drabman, 1982; Drabman, Hammer, \& Rosenbaum, 1979), such research is still sparse with regard to severely handicapped students.

A number of studies have focused on establishing the AAC system and teaching communicative functions (i.e., requesting, rejecting, commenting and labeling) to individuals with severe cognitive and communicative disabilities (e.g., Reichle, Rogers, \& Barrett, 1984). However, few studies have assessed the process of detaching the symbol from its referent to allow/promote generalization of the acquired functions. The generalization of learned communicative functions continues to be an important issue that needs to be addressed in the research involving the severely handicapped. Two routes toward achieving this type of generalization have been reported in the literature. The first was presented by Keogh and Reichle (1985) who suggested teaching a "generalized request" in the form of "want" followed by the introduction and teaching of labels for specific items that are desired. This approach entails teaching combinatorial utterance skills (e.g., want + item) to request a specific item. In a study conducted by Reichle, Barrett, Tetlie, and McQuarter (1987) the effects of initial generalized requesting on the acquisition of object labels in two young adults with severe retardation and autism were examined. The generalized request instruction did not have a 
detrimental effect on the acquisition of subsequently taught object labels. Reichle et al. (1987) suggested that it is important to teach a broad repertoire of communicative functions. Otherwise, the individuals will only use the request function. The second route was presented by Romski, Sevcik, Reumann, and Pate (1988) by adapting findings from language-relevant non human primate model research, employing also the requesting function as an entry point to teaching symbol meaning. They had three institutionalized adults with severe retardation as subjects for their study and they taught them to request four foods. When a subject activated a symbol, the food that was paired with that symbol was obtained (e.g., symbol A was always paired with food A, symbol B with food B, and so on). Learning the conditional relationship between a symbol and its referent proved to be a difficult one for the subjects. However, once they had achieved this skill a decrease in the trials to achieve the criterion necessary for subsequent symbol request learning was documented. Labeling skills emerged, followed by comprehension, but only after the subjects learned to request 10 items using 10 different symbols. In addition, symbol meanings were learned more readily. Generalization is a critical issue in the early symbol acquisition process regardless of the route chosen. Direct comparison of these two routes to symbol acquisition has not, to date, been made.

Another issue that needs addressing is the generalization of the individual's use of the AAC system with other people and in different social contexts. Language production is the result of an interaction between the skills of the speaker and events in the environment. Although the two are tied, the language literature related to severely-profoundly handicapped individuals is replete with a concern for skill acquisition and a corresponding 
neglect of the role of the environment. The recognition of generalization problems (Guess, Keogh, \& Sailor, 1978; Harris-Vanderheiden, Brown, MacKenzie, Reinen, \& Scheibel, 1975; Mirenda \& Mathy-Laikko, 1989; Rincover \& Koegel, 1975; Warren, Rogers-Warren, Baer, \& Guess, 1980) has forced language researchers and practitioners to examine the role of the environment in language training. Training in one-to-one highly structured environments has produced successful skill acquisition (e.g., Hewett, 1965); however, corresponding skill display in everyday settings has been very disappointing. Researchers (Hart \& Rogers-Warren, 1978; Mirenda \& Iacono, 1990; Reichle \& Yoder, 1985; Rogers-Warren, 1975) analyzing this phenomenon have suggested that environmental conditions such as distracting stimuli, opportunities and consequences for language use, language directed to the individual, materials, and events play an important role in language acquisition. And while children's language skills do not change when they move from one setting to another, environmental conditions vary considerably. Training that occurs in a structured setting represents only a small portion of the child's language environment. As Rogers-Warren (1975) points out, language-delayed children may spend 30-60 minutes a day with a trainer, but they spend the remaining 23 hours in other, nontraining settings where language opportunities are unstructured and language use may not be encouraged. Because the reason for the concentrated, intensive teaching is to enhance and facilitate the language expression of handicapped children in their natural environment (i.e., the remaining 23 hours), language clinicians and researchers have expressed increasing concern with the problem of generalizing training skills to non-training settings (Guess, Keogh, \& Sailor, 1978; Harris-Vanderheiden et al., 1975; McQuarter, 1980; Mirenda \& Iacono, 
1990; Mirenda \& Mathy-Laikko, 1989; Reichle \& Yoder, 1985; Rincover \& Koegel, 1975; Warren \& Rogers-Warren, 1980).

According to Halle (1982), almost without exception, language training programs for moderately and severely handicapped individuals recommend use of structured sessions in distraction-free settings. Although these procedures may be necessary to teach some prerequisites of language, they may not facilitate generalization to the natural environment where language is actually used. It is recommended that early in the program the context of training be changed from a special training setting to the everyday setting (e.g,. home, school, ward). One potential solution to the generalization problem is the introduction of training in the natural environment. There are 4 reasons for adopting the natural environment as setting for language training and facilitation: (1) The problem of transferring stimulus control from the training setting to the natural environment is circumvented. (2) Persons who share the children's environment will be more likely to be involved in the training and facilitation of language even when formal training is not in effect. (3) Because the training and facilitation opportunities occur naturally in the everyday setting, they are bound to be functional, thus enhancing the probability of maintaining newly trained language. (4) Maintenance of newly traineci skills also can be improved by programming functional consequences for communication. If language displayed in the everyday setting results in consequences natural to the setting, then the generalization programming from artificial reinforcers used in training settings to natural consequences would be unnecessary (Halle, 1982). 
Three different, but overlapping training procedures have been developed and proven experimentally to produce language (talking) in the everyday setting/natural environment (Beukelman, 1987; Romski \& Sevcik, 1988). Although labels differ, they all refer to language training procedures that are (1) brief and positive, (2) carried out in the natural environment where opportunities for teaching functional language naturally occur and (3) occasioned by child interest in the topic to which training will relate. The first training procedure is Incidental Teaching which involves the naturally occurring interaction between a communicative partner and a learner in an unstructured situation where the communicative partner offers the learner opportunities to practice developing a skill (Hart \& Risley, 1975). The second training procedure is The Mand-Model Procedure, developed by Rogers-Warren and Warren (1980), which is a significantly simplified version of Incidental Teaching that allows the teacher to structure the interaction for the learner. It serves to facilitate the generalized effects of one-to-one language instruction by directly increasing the opportunities for individuals to display the skills they learned. The third training procedure is The Time Delay Procedure which has been described as a transitional method that advances the learner from a respondent's role to an initiator's role (Halle, Baer, \& Spradlin, 1981). Halle (1982) pointed out that the 3 procedures are highly compatible with each other. He reviewed them and provided an integrative model for them which promised substantial benefits. Halle's (1982) Integrative Model suggested that when employed in concert, these approaches may provide a route to competent communicative skills in individuals with severe communication/language disabilities. To date, however, these procedures have not been systematically applied to 
nonspeaking individuals with severe intellectual disabilities. Additional research is needed to determine the subject and procedural variables that affect their success with individuals with severe intellectual disabilities.

Alpert and Rogers-Warren (1983) examined the effects of training mothers of preschool-age language-delayed children to use The Mand-Model Procedure, The Time Delay Procedure, and The Incidental Teaching Procedure. All mothers learned to correctly apply each procedure, and by the end of the study they were using all 3 procedures to improve the intelligibility of their children's speech and to train new vocabulary and syntactic structures. They argued that because severely handicapped persons may require many opportunities to master a skill, a critical question to be addressed is whether "incidental" occasions for language instruction occur with sufficient frequency for learning. It is possible they stated that a "massed" trial approach that allows for a larger number of teaching opportunities might be effective. Perhaps "massed" trials may be necessary for initial acquisition of language form, but training should occur simultaneously in natural settings to teach language function.

According to the literature there are at least 3 prerequisites that must be satisfied before natural environment language training is initiated. First, there must be relevant content and motivation because children must have something about which to communicate and must have a desire to communicate (Mount \& Shea, 1982). The caregiver should identify reinforcers for each prospective trainee. Interviews with parents/caregivers as well as significant others in the child's life, are required in regard to the child's responses to different stimuli (e.g., foods, objects, activities that provide sensory stimulation, and self-selected activities) (Klein, Wulz, Hall, Waldo, 
Carpenter, Rathan, Myers, Fox, \& Marshall, 1981). Second, the social and physical environment must set the occasion for communicative performances (i.e., increase their probability of occurrence) and reinforce them when they occur. Several researchers have reported that caregivers or significant others may interact with handicapped children in ways that occasion behavior that is incompatible with language use (Halle, Baer, \& Spradlin, 1981; Mittler \& Berry, 1977). For example, Mittler and Berry (1977) speculate that underfunctioning in severely retarded individuals may be due to "the failure on the part of those working with retarded people to provide appropriate settings of demand, expectation, and opportunity for effective language performance" (p.245). Even when caregivers have expectations for communicative improvement, they are often unaware of the children's current behavioral repertoire or they are unskilled in training procedures. Thus, they may attempt to evoke communicative behavior that is inappropriate or impossible in light of the child's skill level, and they may not systematically model, prompt, elaborate, and reinforce appropriate communicative performances. Therefore, care givers are in need of skilled training so that they may be able to participate in more functionally appropriate interactions with their children. Third, the children must have an established communicative repertoire. To assess the children's repertoire the following three components must be considered: (a) Communicative function which for this population may be restricted to the display of pleasure and displeasure in response to particular stimuli. Mount and Shea (1982) suggest presenting an array of sensory stimuli to assess children's differential responses. The senses include sight, sound, touch, and smell. (b) Communicative form, which can be categorized in many different ways. For example, Mount and Shea (1982) 
grouped responses to sensory stimuli into positive and negative categories. Examples of forms that define positive responses are looks at teacher or object, points, turns head toward sound or object. Examples of negative responses are cries when object presented, pushes object or teacher's hand away, throws object. (c) Context of the communicative behavior, or the conditions under which the repertoire is displayed. An assessment may include occasions in which adults prompt children to verbally imitate or occasions in which natural environmental events serve as the functional cues for children's language initiations (Rogers-Warren, 1983).

In conclusion, communication training with young, severely impaired children need not, and should not, be confined to one-to-one therapy sessions. The highly constrained stimulus conditions in such training inhibit generalization of skills across materials, persons and contexts because children may not learn to discriminate the conditions operating in the training environment from those operating in real-world settings. Natural environment language teaching strategies offer an alternative or additional method of directly training communication skills when conducted in the child's natural environment by significant others (e.g., teachers, caretakers) and during occasions marked by high child interest.

\section{Summary}

AAC systems can be used as avenues by which to teach and/or facilitate communication skills and they can function as language teaching tools as well (Romski \& Sevcik, 1988). Reports suggest that individuals with severe cognitive and communication deficits can successfully acquire and use visual 
symbols for communication (Locke \& Mirenda, 1988; Mirenda, 1985; Romski \& Sevcik, 1992; Romski, Sevcik, \& Pate, 1988). Once a symbol vocabulary is established, the development of complex or multi-symbol communication is a natural extension by which AAC users can broaden the content, function, and power of their messages (Romski, Sevcik, \& Wilkinson, 1994). For individuals with spoken language comprehension skills, the AAC system may serve as communicative output mode. However, for individuals with more extensive expressive and receptive communication/language impairments the AAC system can be used to receive information from and convey information to their communicative partners (Romski \& Sevcik, 1988). Currently many severely handicapped individuals use AAC systems as their primary means of communication (Sevcik, Watkins, \& Deffebach, 1995). However, the notion persists that AAC instruction with this population should be conducted in highly structured, artificial settings until some arbitrary criterion is reached; only then is the individual exposed to natural situations where communication skills are actually required. Unfortunately, given the generalization difficulties common in person with mental retardation, this approach is usually futile. Therefore, when designing an AAC system one of the problems that must be addressed in the communication intervention is the lack of naturally occurring communication opportunities. Such opportunities can only exist when responsive communication partners interact with persons with mental retardation in real (nor artificial) home, school, and community settings. Natural communication opportunities will directly affect the vocabulary selected as well as the instructional techniques used, and must be considered an integral part of any AAC intervention (Mirenda \& MathyLaikko, 1989). 
The AAC intervention with the severely handicapped population should also take into consideration the skills and needs of potential communication partners. Often this could mean that symbols should be selected that can be understood by other nonreading individuals as well as literate adult partners. These considerations should be extended when the individual's partners speak a different language. Therefore, in order to maximize the use and understanding of the AAC system by the communicative partners the system should be presented bilingually. In addition, instructional strategies should be taught to facilitators with whom the individual comes in regular contact, in order to maximize communication across environments and contexts (Mirenda \& Mathy-Laikko, 1989). 


\section{CHAPTER III}

\section{Research Methodology}

\section{$\underline{\text { Subject }}$}

A 16-year old nonverbal severely retarded male (Victor) participated in this study. Victor was born and raised in Mexico and in 1993 came to the United States with his immediate family. The nature of Victor's disability has not been officially diagnosed. His mother reported that because of a breech delivery brain damage could have resulted from anoxia. Victor has never received any follow-up medical treatment to assess the extent of the brain damage. He spent the first five years of his life at home with his parents without receiving any type of services. Victor's admission into a public school in Mexico was denied due to low scores obtained on a non standardized test. It was recommended that Victor be kept at home because school officials felt he was mentally incapable of learning and would not benefit from formal education. Victor's parents could not afford to take Victor to a private school or to a specialized learning center. As a result, Victor stayed at home and never received any formal education or attended any kind of learning or social/recreational center in Mexico. He never learned how to read, write or use speech to communicate. The language in the home is Spanish and although Victor does not have expressive oral abilities, his parents reported that he has limited comprehension. They reported that Victor understands: "sit down", "come here", "yes" and "no" in Spanish. 
Upon his arrival in the United States, Victor started attending school on January 19, 1994. Victor's educational services were provided by the San Mateo School District. At the time of this study, Victor was attending a class for students with multiple handicaps located in a high school setting. In addition to Victor, eleven other retarded multiple handicapped learners ranging between the ages of fifteen and twenty years old were served by a teacher and two aides. All of the students and staff members spoke and understood English only. The focus of the classroom curriculum was to teach functional daily living activities as well as work-related skills to the students. All of the students in the classroom had been trained by a speech pathologist from the San Mateo County Office of Education to utilize an Augmentative Alternative pocket-size communication book. The system was being used by the students in the classroom as well as in their vocational training sites outside of school. This system however was designed in English and had no translations in Spanish.

An informal speech and language assessment was conducted utilizing the services of a translator from the community. The information obtained indicated Victor's status in fine motor skills, vision and hearing, cognition, speech and language and behavior (see Appendix A, Session A1). Based on the information provided by this informal assessment and additional behavioral information that had also been provided by Victor's classroom teacher (see Appendix A, Session A1) the school's Speech-Language Pathologist (SLP) developed specific educational goals for Victor's Individualized Educational Plan (IEP). Victor was going to refine his fine motor skills by learning to use scissors to cut dotted lines. He was going to learn to hold a pen, learn to write the first letter of his name and count to 10 . The SLP recommended speech- 
language therapy for Victor to be conducted in his primary language. The therapy would focus on increasing his receptive and expressive communication skills. She also recommended that Victor receive AAC intervention with the purpose of establishing the same pocket-size communication book with a Spanish translation so that Victor could use it with classroom peers and in the community.

Materials, Devices and Procedures

\section{Assessment Phase}

1. All research activities including the testing of Victor's abilities were conducted in native Spanish by the researcher. The Peabody Picture Vocabulary Test-R (PPVT-R) by Dunn and Dunn (1981) was selected by the Speech Language Pathologist who had Victor in her caseload. This examiner was asked to administer the test for two purposes. First, to obtain a baseline of Victor's Spanish receptive language and second, to incorporate the results in Victor's upcoming Individualized Educational Plan (IEP) revision and update. The testing was conducted in Victor's classroom. He was required to point to pictures in response to verbal prompts. Victor's behavior suggested that standardized testing was an inappropriate format from which to obtain baseline information regarding his communication skills (see Appendix A, Session A2). Rather informal observations and non-standardized tools such as the Communication Interview by Schuler, Peck, Willard, and Theimer (1989) were conducted and relied upon for valid baseline data (see Appendix B).

2. The experimenter requested to have a parent conference from which the following were obtained: A health and developmental history of 
Victor and a Communication Interview (Schuler, Peck, Willard, \& Theimer, 1989) based on Victor's linguistic abilities (see Appendix C, Log C11)

3. The experimenter also conducted informal observations at Victor's school and vocational training site, focusing on his current communication intents, use of gestures, and body language (see Appendix A, Sessions A1 through A6). Based on this information Victor's communication needs were determined in two environments: at school and at his vocational training site.

4. The following were also obtained: A Communication Interview (Schuler, Peck, Willard, \& Theimer, 1989) from the subject's teacher, from the school's Speech Language Pathologist and from this experimenter (see Appendix C, Log C11).

5. Since Victor did not have an available communication system that could help him interact and communicate with others an alternative communication or a system of communication for individuals who cannot speak but have a desire to communicate, appeared to be appropriate for him. Alternative communication was appropriate due to the fact that Victor exhibited the following characteristics: The use of pointing to real objects suggesting a desire to communicate; his ability to acquire new information through modeling of peers and adults; his desire to emulate peers to make himself a member of the group within the school setting.

6. Baumgart, Johnson, and Helmstetter (1990) have applied at least ten philosophic assumptions and five practical considerations when designing communication systems for individuals with severe disabilities. These assumptions and considerations were used as a guide for selecting and designing Victor's AAC system (see Appendix D). 


\section{Intervention Phase}

1. Based on the information obtained during the pre-assessment phase Victor's communicative status was determined. Consideration was given to Victor's intentional and functional communicative abilities. In order to address the abilities demonstrated by Victor, the Model of Communication Development (Prizant \& Wetherby, 1990) which is rooted in the study of pragmatics was used. This model looks at communicative intent as the way in which the individual who sends the communication signal intends for the message to affect the individual receiving the message in a specific way (i.e., "I'll throw the cup and maybe she won't make me drink the milk"). The model looks also at communicative functions as the way to the individual's goal (i.e., to protest). Prizant's and Wetherby's (1990) model is based upon the language description of normal developing children. The model progresses along two dimensions: First, the vertical dimension of intentionality which describes how intentionality emerges along a five level continuum from basic to complex. Second, the horizontal dimension of communicative means which looks at the outcome of the produced signal by the individual who had send it. The Communication Interview by Schuler, Peck, Willard, and Theimer (1989) was designed to assess the communicative means and functions of individuals with limited language (see Appendix B1). Communicative functions and means can be used as a guide when designing or expanding an individual's communication system. Utilizing both dimensions of this model the investigator was able to determine where Victor was within the continuum of intentional communication. This continuum was used as a framework and as a guide to determine the focus of the AAC intervention in regard to the 
following categories: First, behavioral regulations such as requesting objects, requesting actions and protesting; second, social interactions such as requesting a social routine, greetings, show off acts to attract another's attention to oneself and call acts which gain the attention of others to indicate that a communicative act is to follow; and third, joint attention by commenting on objects and commenting on actions.

A personalized communication system was devised for Victor with the intent to promote the development of his intentional communication skills. It was hypothesized that if Victor had a means to communicate he could develop more sophisticated functional communication. If that was the case then Victor's language development would have a great impact on his behavioral and social communicative skills which in turn would increase his overall school and job-training performance.

In order to concurrently address the establishment of the AAC system with the teaching of functional communicative skills the experimenter followed the guidelines established by other researchers in the field. For example, researchers (Goossens \& Crain, 1986) suggest the use of training hierarchies for implementing alternative communication systems. These hierarchies begin with teaching the students to make requests when offered choices among actual objects. This is followed by a series of training steps leading to the use of a picture symbol communication system which ultimately contains large numbers of vocabulary items. Initially the student may need to be prompted by the interventionist to execute the request. However, the ultimate goal is for the system to be utilized spontaneously by the student. 
2. Victor received intervention once a week for an average of two hours and was required to engage in therapy in an interactive manner. The researcher responded unconditionally to Victor's initiations/attempts to communicate during every therapy session. The intervention was conducted at the vocational training site chosen by the school district officials (see Appendix A, Sessions A7 through A18).

\section{Post-Assessment Phase}

1. The post-assessment phase involved repeating the use of observation and non-standardized measures.

These involved the following:
A. Another parent conference was conducted to record changes in the student's communication skills noted by his parents (see Appendix C, Log C11).
B. The experimenter observed Victor and recorded any changes in his communicative behaviors (see Appendix C, Log C11). completed changes in the subject's communicative behaviors (see Appendix C, Log C11).
C. Victor's classroom teacher and the school's SLP also

2. During this post-assessment phase the following areas were of particular interest:

A. Newly acquired, learned or developed communication skills (i.e., commenting, initiating conversations). 


\section{B. Victor's expansion of language knowledge and vocabulary use through the communication system. \\ C. Indications of current or future generalization of communicative skills used with various people, in different environments and in different contexts (see Appendix A, Sessions A19 through A22).}

Data Analysis

The data collected from the assessment/baseline phase will be compared to the data obtained from the post-assessment phase and will be depicted by graphs to allow a visual comparison. It was hoped that the results would indicate a significant decrease in the number of occurrences of the inappropriate behaviors. This investigator followed the guidelines offered by McReynolds and Kearns (1983) on how to design this case study. Singlesubject studies are descriptive, not experimental, in nature. An A-B case study can include a number of scientific components to approximate an experimental single-subject design which can evaluate treatment variables in a controlled manner. Case studies allow restricted statements concerning the effectiveness of proposed and applied treatment variables.

There are five scientific components that need to be taken into account (McReynolds \& Kearns, 1983). The first experimental component is control. Control is what distinguishes a case study of a single subject from a singlesubject experimental study. Because the design has only a baseline and treatment phase, the effect of other variables during treatment cannot be ruled out. It could be speculated that other variables could have been involved 
by being present at the same time of the treatment. To demonstrate the effect of the independent variable it is necessary to control such extraneous variables. An A-B study is not designed to control these extraneous variables because that is not the purpose of the study. Once data is gathered and pretreatment and post-treatment results are compared the researcher can only make tentative conclusions concerning the effectiveness of the treatment. The second experimental component is the dependent variable which is the behavior to be studied. The third experimental component is the independent variable which is the treatment to be used. The fourth component is the definition of training procedures. The fifth component is reliability which involves independent judgment measures.

Although this investigator cannot account for control on this case study the remaining four experimental components will be addressed as follows:

Dependent Variable. Four behaviors were being studied: nail biting, nose picking, teeth clicking, rubbing of genitalia. The number of occurrences prior to treatment was high for each behavior. These behaviors were exhibited at home, school and vocational training site.

Independent Variable. The AAC system was to be considered the independent variable and was only used during the treatment phase of the study. Although other variables such as the use of a naturalistic setting in which to conduct the intervention and the use of the subject's first language were also considered, they were ruled out because of their presence during the assessment phase of the study.

Training procedures for establishing the AAC system. The following questions were considered: 
a) What steps were followed in order to establish the AAC system? The system was established by teaching the subject how to "request". Later on the system evolved to the use of a schedule board which the subject was to follow in order to complete different tasks. The first step in the establishment of the system involved the use of real objects. The second step involved the use of color pictures and the final step involved the use of black and white line drawings.

b) What constituted a trial? The subject's identification of the object, picture or line drawing was considered a trial. The subject was given the command of "show me ___ or was asked "What do you need?" and if he was able to point to the appropriate icon then it was counted as a trial.

c) What was the number of trials per step and what was the criterion level to be reached at each step? Five trials were needed per step. The criterion level was $80 \%$ accuracy on the identification of the icons.

d) What constituted a training session? Every session averaged two hours. During this time AAC training took place as well as behavioral observations.

e) What kinds of cues were given to the subject? Three different kinds of cues were given: "Verbal+Visual+Gestural" which received a score of 3 when recorded. "Verbal + Visual" which received a score of 2 when recorded. "Verbal cues only" which received a score of 1 when recorded. When the subject used the system to request or to follow the activity with the schedule board spontaneously an "S" was recorded.

Reliability. Two out of the three post-assessment sessions at the Vocational Training Site were conducted by graduate students from the Communication Disorders Program at San Jose State University. During those 
two post-assessment sessions the investigator acted as a recorder along with one of the graduate students while the second graduate student acted as the interventionist. By obtaining the scoring from two different observers it was hoped to eliminate any possible scoring bias from the investigator. In addition, by having different interventionists in two of the three postassessment sessions it was hoped to establish that the subject's performance was system based/related and not interventionist related. This provided information about the generalization of the use of the system with different people. 


\title{
CHAPTER IV
}

\author{
$\underline{\text { Results }}$
}

\section{Assessment Phase}

Prior to initiating any type of assessments, Victor's teacher, the school Speech Language Pathologist (SLP), the Vocational training supervisor and this experimenter met to discuss his communication skills. At this meeting, it was agreed that his signs for "hello" and "thank you" would continue to be accepted as means to communicate. It was also determined that sign language was not readily understood by most people within his environment. Since he was going to be integrated into the community a recognizable and portable system was recommended. This picture system would be utilized in a greater number of varied environments, and lessen the dependence on an "interpreter" or someone to teach his system to others. Black and white icons from the same communication wallet Victor's peers were using in his classroom were preferred. Although the use of such a system was to be considered the ultimate goal for Victor, it was understood that a more iconic representational system would have to be establish first before transitioning Victor into a more abstract system such as the wallet communication book.

Prior to the design and implementation of the line drawing system, a number of additional questions were raised. In order to obtain the needed information to answer such questions, informal observations were obtained at Victor's school and vocational training site. In addition, a parent conference was conducted and communication interviews were completed by Victor's 
parents, school teacher, school SLP and the investigator. The information gathered from these tools provided answers to the following questions:

1. What was Victor's level of functioning in the areas of cognition, attention, receptive and expressive communication, hearing and vision, and fine motor abilities?

Victor's lack of cognitive assessments, his non-compliant behavior with standardized cognitive assessment procedures and the fact that he had never been formally assessed in Mexico made it difficult to evaluate his cognitive abilities. Victor was observed to be highly anxious during attempts at speech and language assessments resulting in fingernail biting to the point of bleeding. Information was therefore collected over six sessions of informal assessments in which Victor demonstrated the functional use of objects, object permanence, and basic problem solving skills. These abilities were indicative of readiness to use a symbolic communication system. As for attention span, Victor could not attend to instructional tasks without getting distracted and needed constant refocusing. His receptive comprehension in Spanish was minimal. He responded to simple one-step commands verbally given (i.e., "come here", "sit down"). Victor required verbal and visual cues in order to follow lengthier one step commands (i.e., "give me the book", "show me the apple"). He was also not able to point to real objects upon request. However, he was observed to gesture with his whole hand when pointing to people or to desired objects out of his reach. Victor was able to point with his index finger with modeling; however, he continued to use a whole hand when pointing spontaneously. He was not able to point to pictures upon request. Victor's expressive communication abilities were observed to be limited to two types of noises. To protest, Victor would produce a loud grunt and to approve or accept 
something Victor would produce a high pitched squeal usually accompanied by smiles, laughter or even dancing. No visual problems were evident to the educational staff and Victor's parents had reported that he had normal vision and hearing. Victor's preferred hand use was observed to be his right hand. He was observed to pick up objects always using his right hand regardless of the location of the object even when that meant crossing the midline to get an object or even if the object was closer to his left hand. Victor's fine motor skills were restricted to holding pencils or holding scissors. He was able to pick up and hold small objects and turn pages of books and magazines.

2. What were the goals (functions) of Victor's behavior? Through the use of the communication interview it was determined that Victor exhibited the same inappropriate behaviors at home, school and the vocational training site. This eliminated the possibilities of the environment being the cause of the behavior or the language used and his inability to understand it (English vs. Spanish being spoke to him). Therefore, it was determined that the cause that brought these behaviors about was the lack in his ability to expressively communicate with others and the necessity to have his wants and needs met. For example, rubbing of his genitalia or crotch was always exhibited when he wanted to use the restroom, and nail biting and teeth clicking were always present when confronted with new situations. These behaviors not only were inappropriate but were also disruptive to Victor's education and to other students in his classroom and his co-workers at the vocational training site. Victor's behaviors had a goal and a purpose; therefore, this demonstrated that he had developed a rudimentary way to communicate. It was hypothesized that if Victor was taught a different way to 
express these same goals/functions such inappropriate behaviors would be replaced by easily understood and socially accepted means of communication such as those provided by an AAC system.

\section{What was Victor's level of intentionality?}

There were signs that Victor's intentionality was only moderately developed. At school and at the vocational training site he consistently used the same behavior for a specific purpose, so it was evident that he had goals as well as plans for attaining it. He also was able to coordinate these plans, exemplified by rubbing genitalia, then waiting for a response. However, he was not able to use repair strategies or combine his behaviors when a communication breakdown occurred which would have been indicative of higher levels of intentionality. At home, Victor's parents had reported that he was coordinating the use of "noise + pointing" and "pulling other's hand + pointing" when requesting desired food/objects. It was hypothesized that these signs of further development would be transferred to the school and the vocational training site with the use of the AAC system, positive reinforcement, and incidental/naturally occurring teaching strategies.

\section{What were Victor's communication needs at home, school, and in the community?}

Victor lived at home with his parents and an older sister. His parents reported satisfaction with the way in which Victor communicated his needs with them and described him as being independent for daily living activities. At school and in his vocational training site, Victor's receptive communication needs related to compliance to requests that were involved in safety and the learning 
of new tasks. Stating his needs or requests (i.e., bathroom, food) in an appropriate way was the number one priority. Secondary priorities included social skills, such as acknowledging the presence of others (i.e., by greeting them). His primary communication partners at school were adult staff and peers who were disabled. In the vocational training site, Victor's communication partners included employees of the store, the vocational education supervisor and the investigator.

\section{Intervention Phase}

Intervention using the AAC system occurred at the vocational training site (10 sessions) and at the school site ( 2 sessions). Each intervention session averaged two hours and included naturally occurring situations related to vocational training or classroom activities.

The goals for the AAC system were:

a) to provide Victor with a formal system of communication that would readily be used and comprehended by different people (peers, adults, Spanish/English speaking), situations, and environments;

b) to provide him with a highly portable and socially acceptable system for use in the community;

c) to provide a method with which Victor could initiate requests and be readily understood eliminating the need for inappropriate behaviors and anxiety driven demonstrations;

d) to provide a method that could be readily expanded and revised. 
Vocational Training Site Intervention. Part of the initial instruction involved in the establishment of the AAC system required the use of highly motivational real objects (see Appendix C, Logs C3 and C4). Modeling the use of pointing with the index finger was used to establish "requesting" of desired objects/food. Victor was provided with tangible (i.e., the desired object/food itself), verbal (i.e., praising), and physical (patting on the back) reinforcements for participating in the task. Inappropriate behaviors were interrupted and he was prompted to use the system to request what he wanted. Every time he made an attempt to use the system he was given the attention of the researcher and his needs were met. Gesturing and pointing were encouraged. Reaching/grabbing desired object/food was interrupted and Victor was redirected to use the system to communicate. During structured training of the AAC system Victor was given five trials with each object, picture, or black and white icon. A minimum of $80 \%$ accuracy was needed in order for the use of a more abstract form of communication to take place. Victor exhibited a smooth transition between the use of real objects, color pictures and black and white line drawings. By the fourth intervention session Victor was already using the line drawings to request for food, activities of daily living (ADL), and work icons. The type of cue that Victor needed in order to fulfill the request was being recorded. Victor easily transitioned in more than $90 \%$ of the icons from needing "verbal + visual + gestural cues" to needing only "verbal cues" to point/identify icons. Two types of requests made by the researcher were under the category of "verbal only". The first was by asking "show me the ____" and the second was by asking "what do you need?" and Victor pointing to the appropriate icon. Unfortunately, 
towards the end of the intervention phase Victor was not utilizing the system spontaneously for more than 12 out of 28 icons from his AAC system and 0 out of 14 icons from his pocket-size communication book. Although spontaneity in the use of both systems was a desirable end result from the intervention, Victor was not able to, or chose not to use every icon spontaneously. As Victor progressed in the use of the AAC system a decline in the occurrences of the inappropriate behaviors was observed. A significant reduction of at least $50 \%$ on the occurrences of such behaviors was hoped for since Victor spontaneously was able to better use his AAC system to communicate week by week.

School Site Intervention. The intervention was conducted with the purpose of expanding the black and white line drawing communication system being used at the vocational training site to include items related to educational classroom activities (see Appendix C, Logs C5 and C6). These activities were deemed appropriate for Victor as part of fulfilling his Individualized Educational Plan (IEP). It was determined that Victor would benefit from a "schedule board" for the purpose of being more independent in the classroom. This type of board would allow the classroom teacher to select the activities he wanted Victor to be involved in for the day and it would allow Victor to execute each activity independently by following the schedule. Victor was already accustomed to the use of a "schedule board" since one had been also established for him at his vocational training site so that he would know what jobs he would be required to do for the day. Victor did not encounter any difficulties transferring or generalizing the purpose of the "schedule board" from his job to his classroom. It was also evident that Victor 
had transferred or generalized the use of the AAC system to satisfy his wants and needs. Therefore, a significant reduction in the number of occurrences of the inappropriate behaviors was exhibited. This decrease was also observed by the classroom teacher as well as the school's SLP.

\section{Post-Assessment Phase}

This phase had two purposes. The first purpose was to document generalization of the use of the system with different observers (see Appendix C, Logs C7 through C10). Two out of the three post-assessment sessions were conducted by different graduate students from the Communication Disorder's Program at San Jose State University (see Appendix A, Sessions A20 and A21). Victor was able to demonstrate an average performance during the AAC sessions conducted by the two graduate students. He also was able to use the system to regulate the occurrences of inappropriate behaviors. These results

provided the foundation for believing that Victor's performances were system based/related and not interventionist related. The second purpose of this phase was to assess the reduction in the number of occurrences of the four inappropriate behaviors. Every session consisted of a two hour observation time. A comparison between the average number of occurrences from the three assessment sessions and the three post-assessment sessions at the Vocational Training Site depicted a significant reduction on the occurrences of the four inappropriate behaviors. The following are the results from the comparison: Nail biting decreased from 14.67 to 1.3 occurrences. Teeth clicking decreased from 20 to 0 occurrences. Nose picking decreased from 8 to 1.6 occurrences. Rubbing genitalia decreased from 2 to 0 . Please note that 
Victor only rubbed his genitalia when he had to go to the bathroom. In each occasion he had to go twice.

During the intervention phase a total of 39 black and white icons had been introduced at the Vocational Training Site. During the post-assessment phase Victor was able to demonstrate the use of 4 icons spontaneously. He identified 26 icons requiring verbal cues only and identified 9 icons requiring verbal plus visual cues. During the intervention phase at Victor's High School 8 black and white icons were introduced. He was able to identify them at that time requiring only verbal cues. However, he was able to demonstrate the use of the 8 icons spontaneously during the post-assessment phase.

\section{Data Analysis}

During every session, consisting of a 2 hour observation, the four inappropriate behaviors exhibited by Victor were recorded. A total of eight graphs depict the number of accurrences of each behavior during each phase of the study. The first four graphs are related to the Vocational Training Site (see Figures 1 through 4) and the last four graphis are related to the subject's High School setting (see Figures 5 through 8 ). A considerable reduction on the number of occurrences of each behavior can clearly be observed on these graphs. This investigator attributes these reductions to the establishment and implementation of the AAC system. 


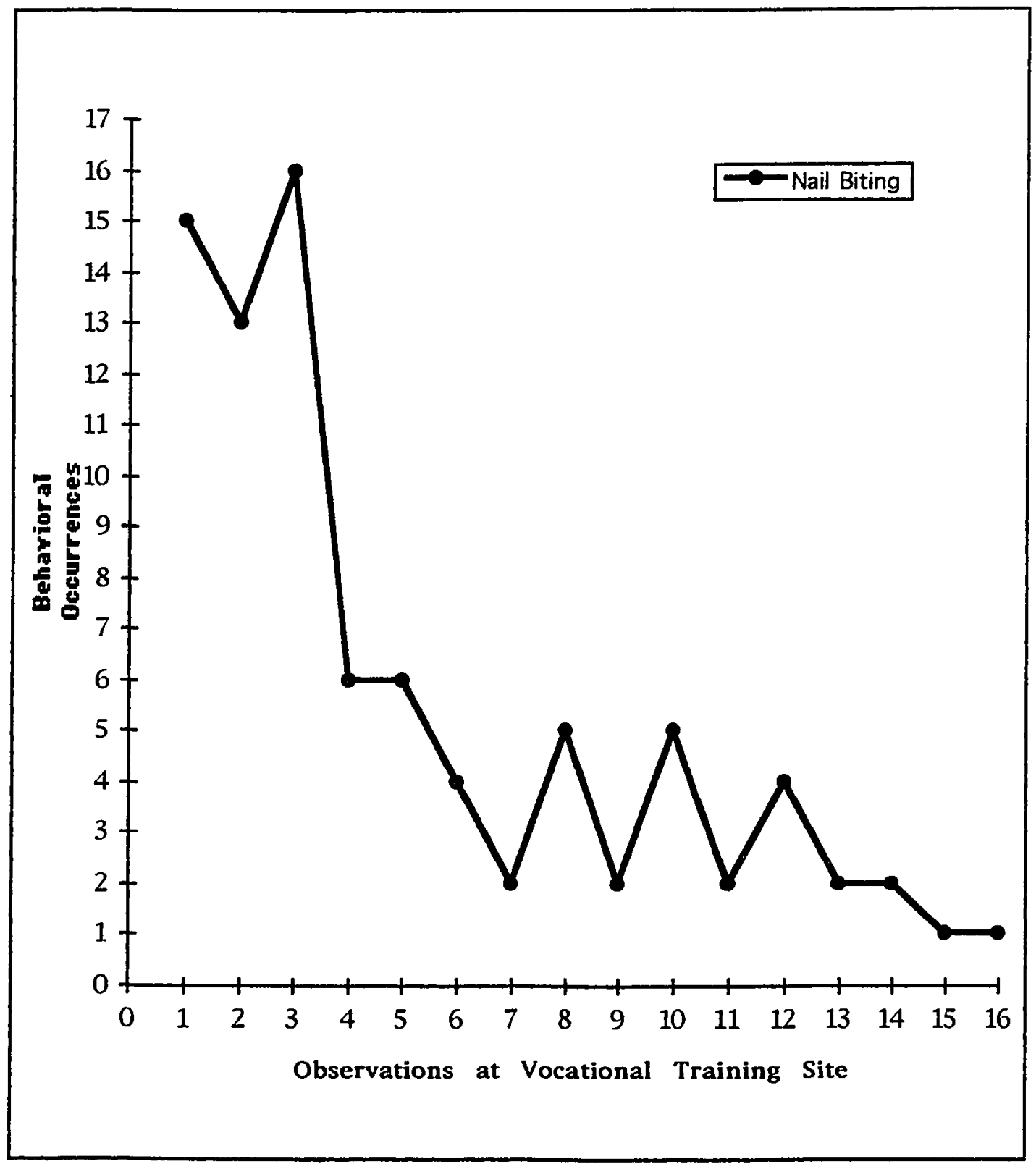

Figure 1. Nail biting behavior at vocational training site.

Observations 1-3 = Assessment phase; observations 4-13 = Intervention phase; observations 14-16 = Post-assessment phase. 


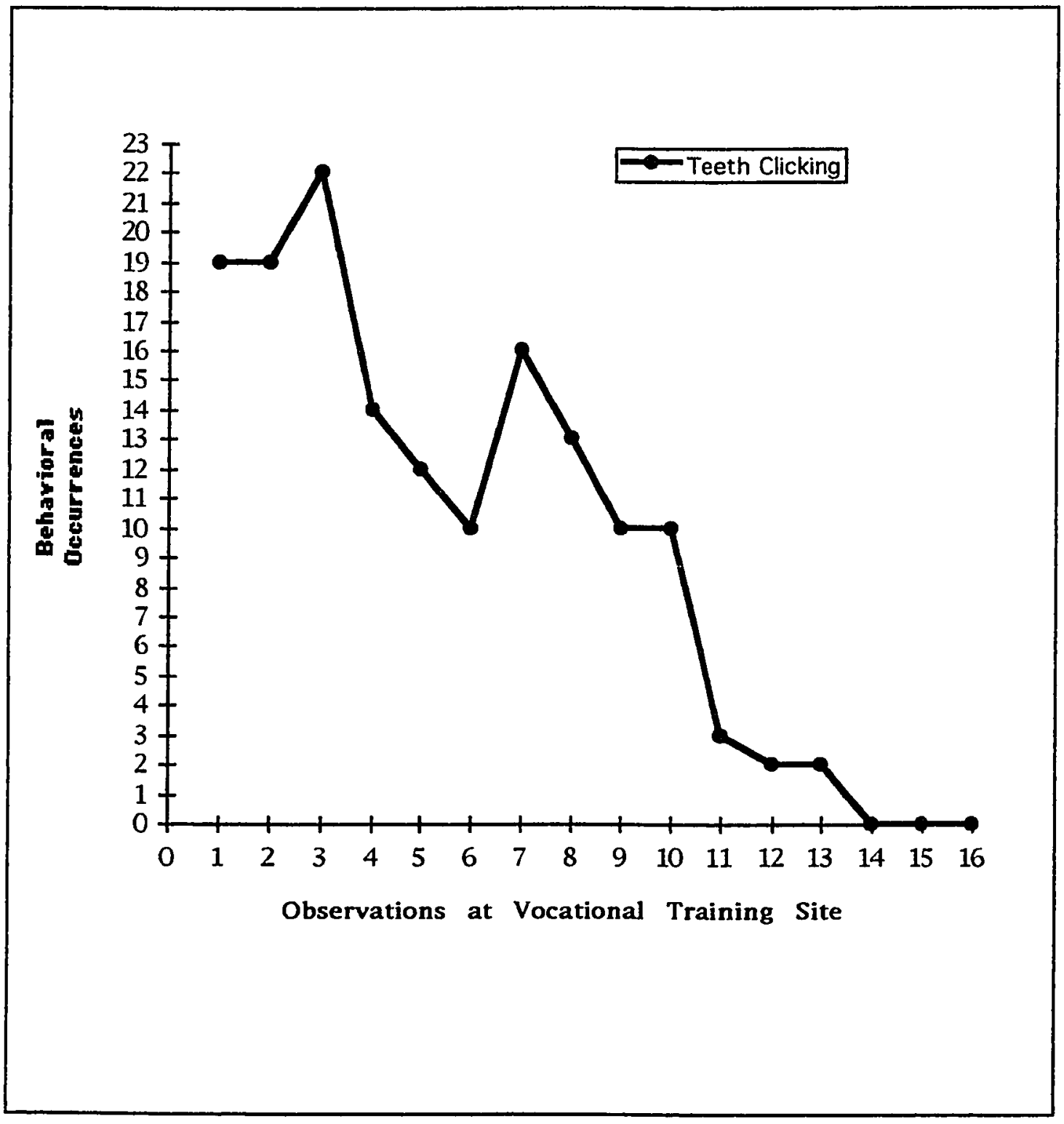

Figure 2. Teeth clicking behavior at vocational training site.

Observations 1-3 = Assessment phase; observations $4-13$ = Intervention phase; observations 14-16 = Post-assessment phase. 


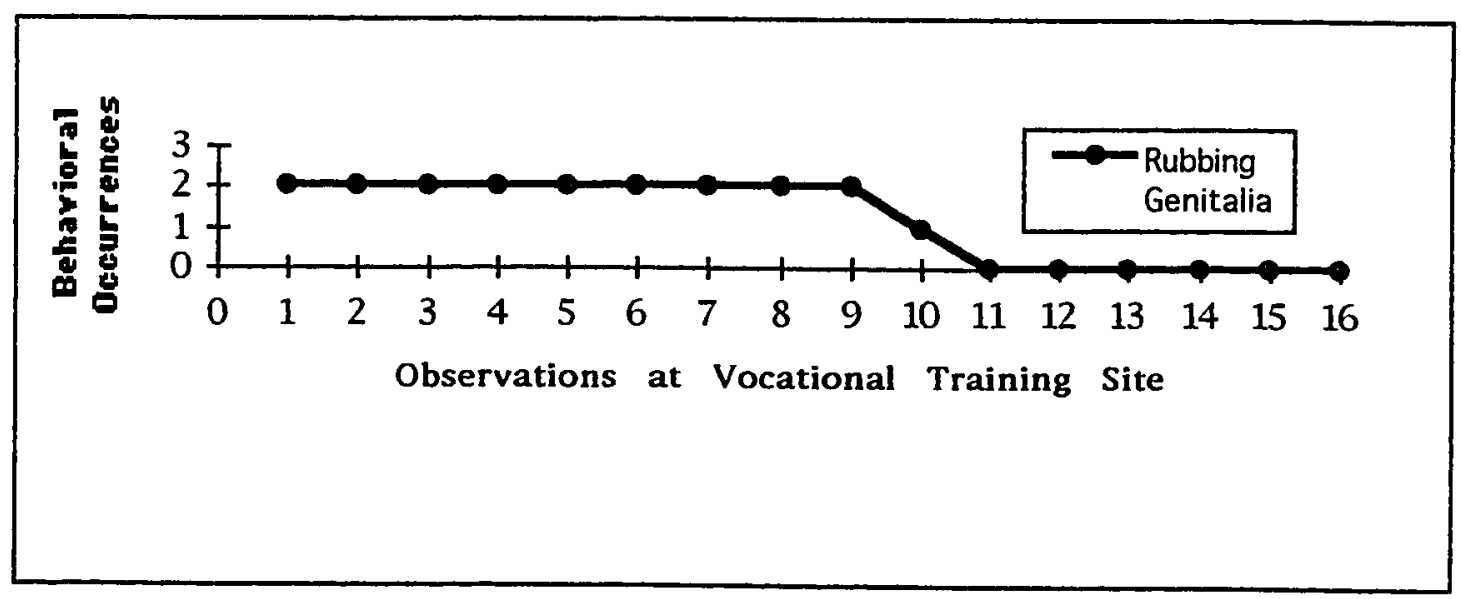

Figure 3. Rubbing genitalia behavior at vocational training site.

Observations 1-3 = Assessment phase; observations 4-13 = Intervention phase; observations 14-16 = Post-assessment phase.

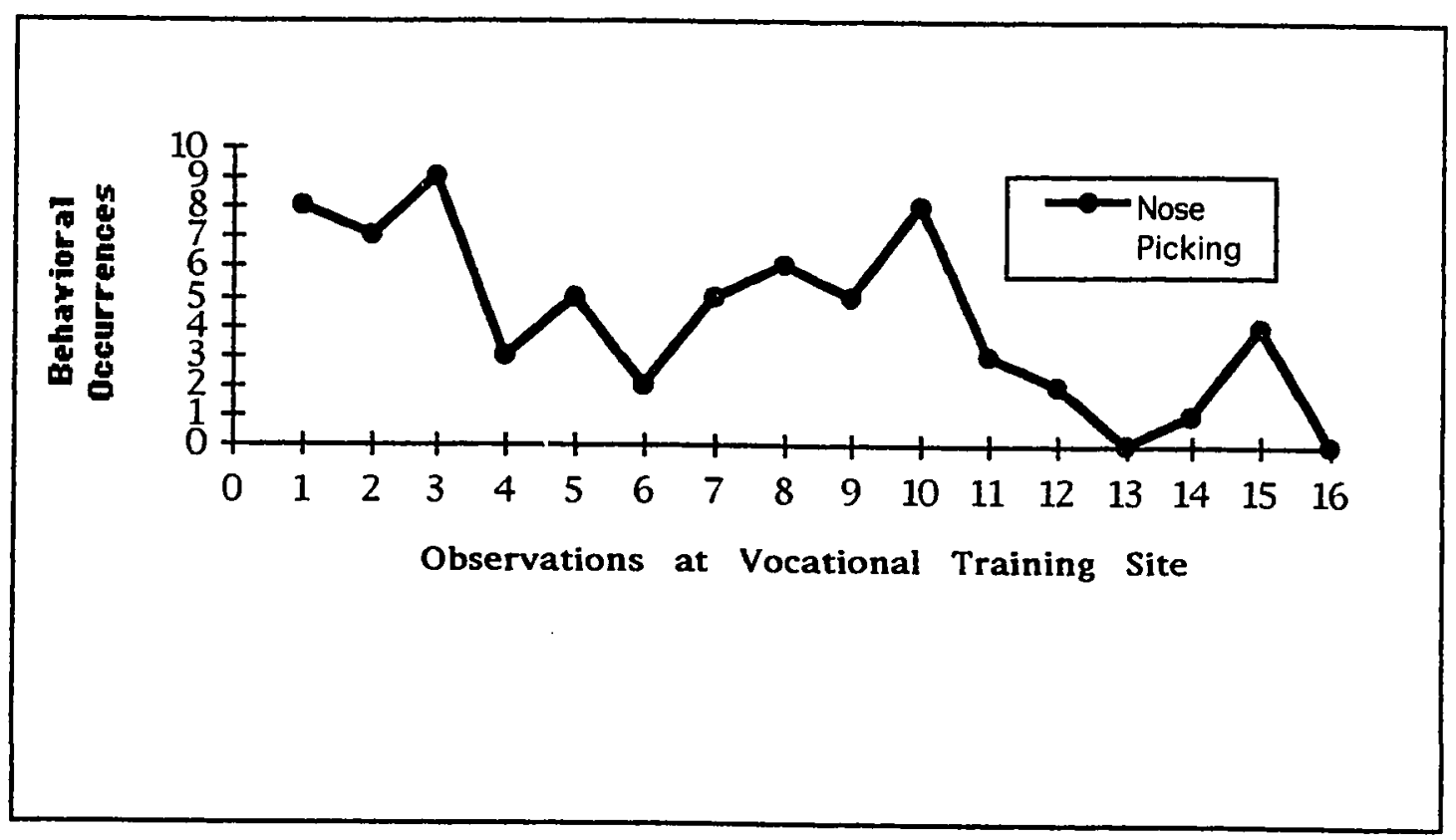

Figure 4. Nose picking behavior at vocational training site.

Observations 1- 3 = Assessment phase; observations 4-13 = Intervention phase; observations $14-16$ = Post-assessment phase. 


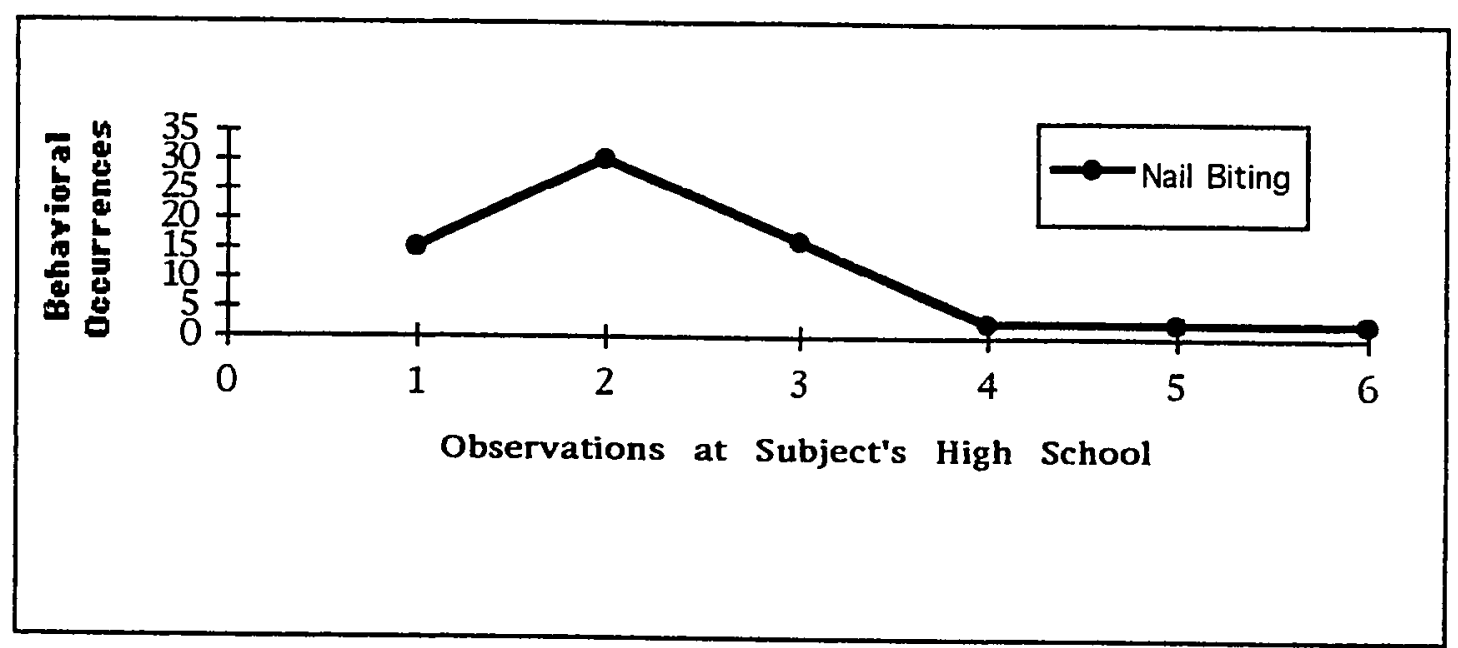

Figure 5. Nail biting behavior at subject's high school.

Observations 1-3 = Assessment phase; observations $4-5=$ Intervention phase; observation $6=$ Post-assessment phase.

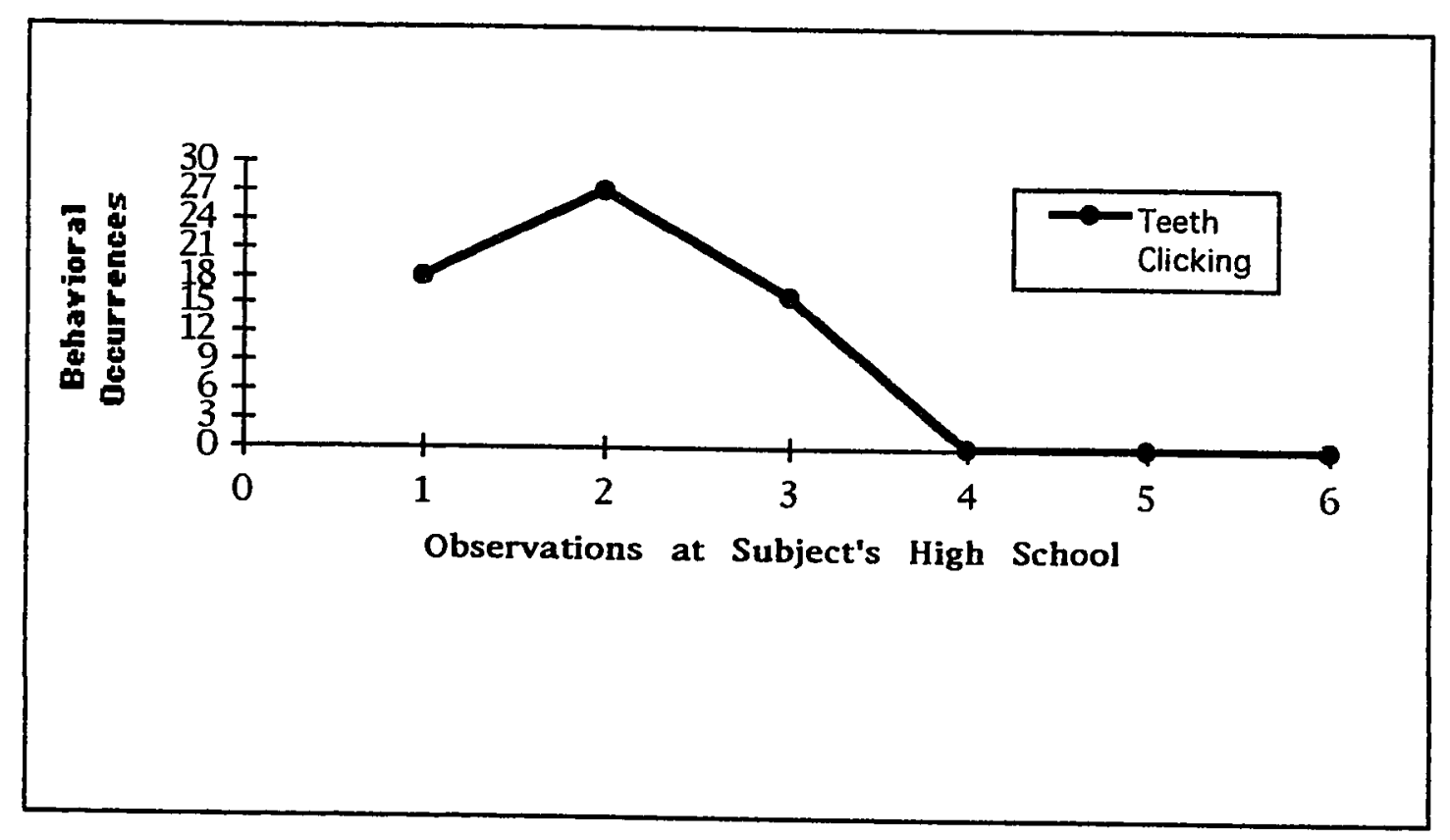

Figure 6. Teeth clicking behavior at subject's high school.

Observations 1-3 = Assessment phase; observations $4-5=$ Intervention phase;

Observation 6 = Post-assessment phase. 


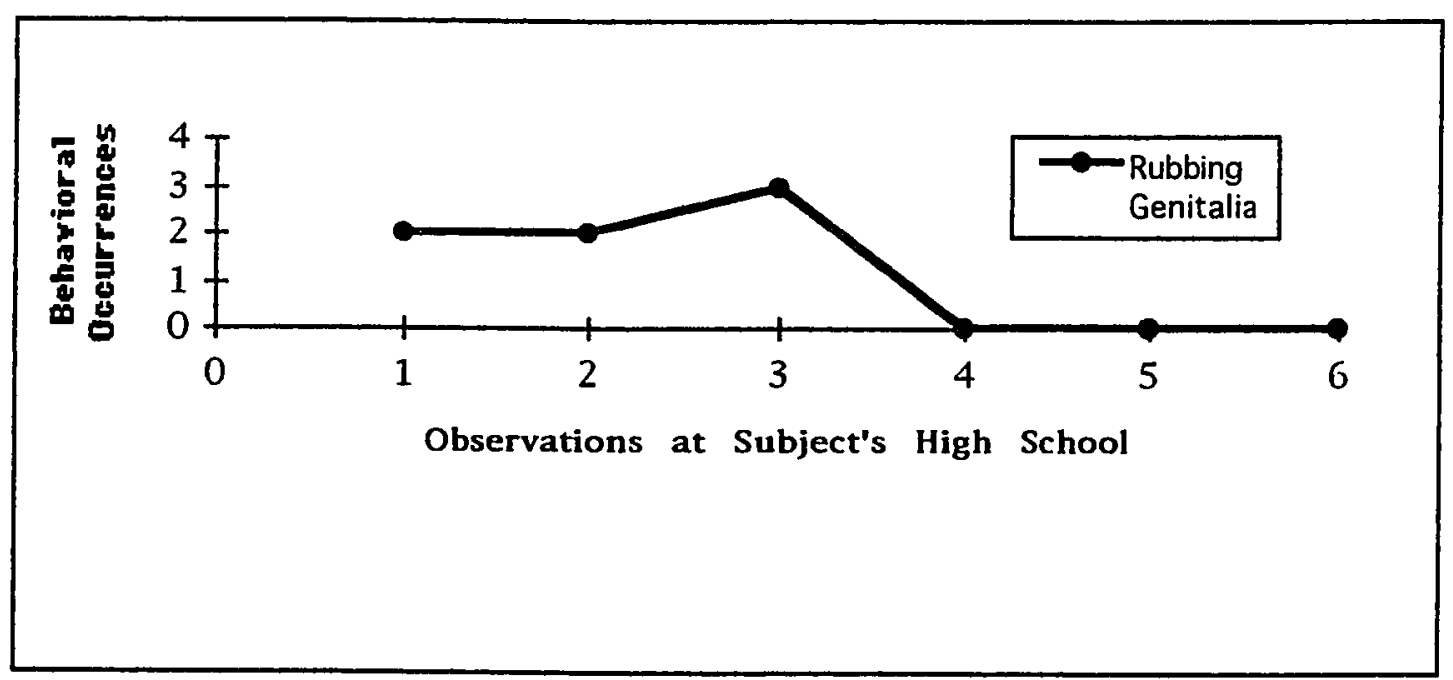

Figure 7. Rubbing genitalia behavior at subject's high school.

Observations 1- 3 = Assessment phase; observations 4-5 = Intervention phase; observation $6=$ Post-assessment phase.

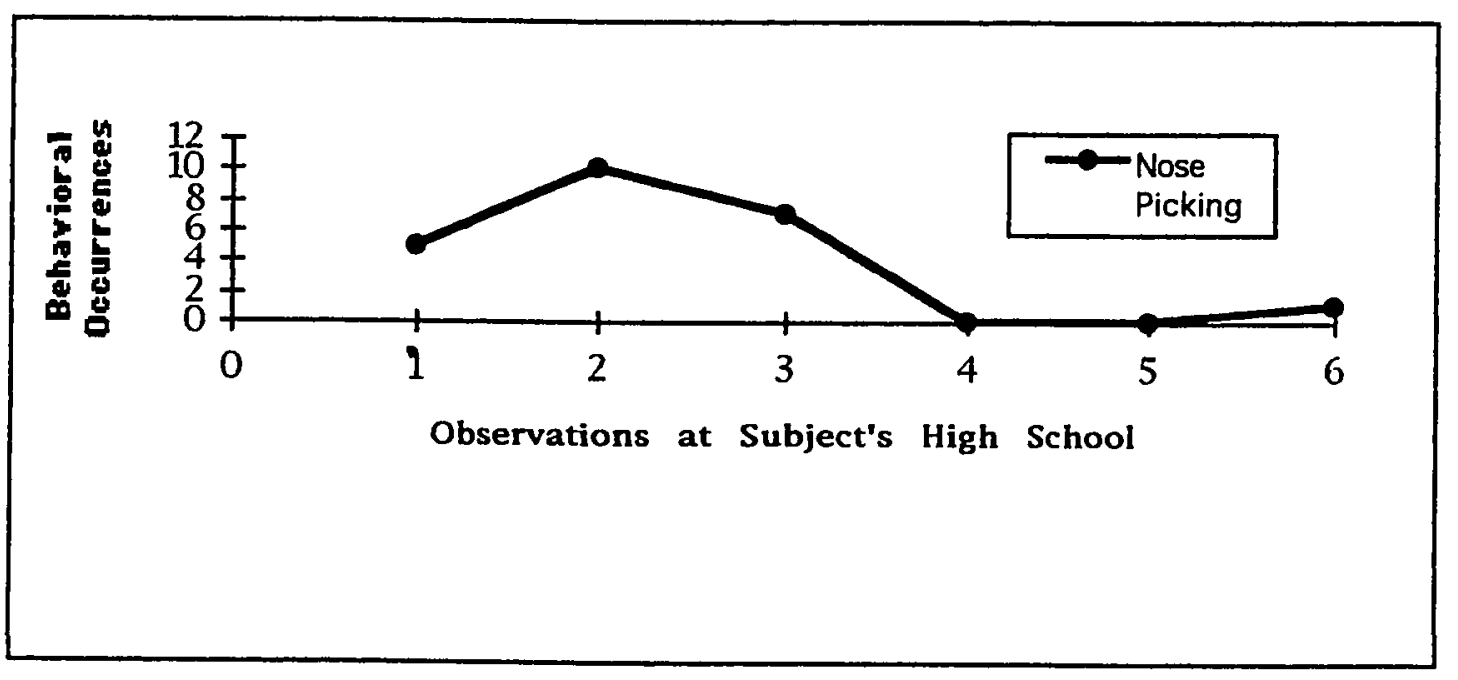

Figure 8. Nose picking behavior at subject's high school.

Observations 1-3 = Assessment phase; observations 4-5 = Intervention phase; observation $6=$ Post-assessment phase. 


\section{$\underline{\text { Research Questions }}$}

1. What was the overall impact of the intervention upon the subject's severe communicative handicaps?

Victor had found in the AAC system a method to communicate his wants and needs to others in his environment whether it was at home, school or at his vocational training site. Victor's interactions with adults and peers increased through the use of comments or declarative gestures that Victor would initiate to start a communicative exchange of information. Victor no longer solely relied on inappropriate behaviors to request for adult actions or to protest. Victor's intentional communication was further developed with the implementation of this system. He was now able to demonstrate higher developmental behavioral regulations, social interactions, joint attention in different communicative contexts and with a variety of people. More complex use of communicative means and functions were also evidenced by Victor. He coordinated a variety of means, including the AAC system, to deliver his requests or messages and was able to implement communicative repairs when a breakdown in communication occurred.

2. To what extent did the AAC system facilitate the expansion and/or development of the behavioral characteristics the subject needed to learn in order to compensate for his severe communicative handicaps? The AAC system provided Victor with a tangible and concrete tool he could use to communicate. The system gave him success at requesting and letting his wants and needs be known to others; therefore it provided him with the 
motivation he needed to continue to participate in the sessions. The system was established at a cognitive level which Victor could manage and the system was introduced in his native language which facilitated its comprehension. Victor was able to guide the progression of the system in regards to the presentation of the icons and their abstractness. Therefore, he was successful at all times and undoubtedly this increased his self-esteem and decreased his anxiety as evidenced by the decrease in the number of nail biting and teeth clicking exhibited by Victor.

3. In what way are the gains made by the subject directly related to the AAC intervention?

The AAC intervention was the independent variable in this study. There existed two other important variables which were the use of the Spanish language during the intervention and the fact that the intervention was being conducted in naturally occurring settings. These two variables were discounted as possible independent variables during the assessment phase of this study. During the six sessions in which Victor was observed, Spanish was used by the investigator at all times. In addition, every session was conducted in a natural occurring setting. Even though these two variables were in existence during the assessment phase, Victor exhibited the same inappropriate behaviors to communicate his wants/needs and protests. He reacted with the same levels of anxiety as evidenced by his teeth clicking and nail biting with as many number of occurrences as his parents, school teacher and school SLP had observed in the past. Therefore, it was determined that although these two variables were extremely important and necessary to complement the intervention process it was the AAC system that was going to 
be held responsible for any gains made by Victor. It is questionable whether Victor would have been able to comprehend the system if it had not been introduced in his first language. 


\section{CHAPTER V}

\section{Discussion}

The purpose of this case study was to evaluate the communicative deficits of a severely handicapped nonverbal 16 year old student and design and implement an appropriate AAC system. Of special interest was to determine whether the functional gains made by the student were maintained and generalized with different people and across different settings.

Four inappropriate behaviors were selected and targeted during the intervention. All four behaviors were exhibited by the student across different settings. Their occurrences were numerous as well as disruptive to the student's education, to other students in his classroom, and to his coworkers. Results indicated that all four behaviors were reduced in their occurrences after the AAC system was introduced. A decrease was evidenced

across different people (i.e., interventionists, co-workers, peers, teachers) and across different settings (i.e., at school, home and vocational training site). With these results it was determined that functional gains were maintained and generalized by the student.

The findings from this case study suggest that AAC systems can be used as communicative tools allowing the user to fulfill communicative functions in lieu of using expressive language. It had been hypothesized that if the student was taught a different way to express the same communicative functions, inappropriate behaviors would be replaced by the AAC system. The findings concurred with the hypothesis which in turn provides valid justification for wanting to implement AAC systems with students from this population. 
The findings also support the inclusionary principle that improved communication is possible to all persons with severe communicative handicaps (Kangas \& Lloyd, 1988). It also emphasizes the need to reassess the issue of cognitive prerequisites being evidenced during the assessment of a severely communicatively handicapped individual. This student's cognitive abilities had been underestimated. He was 16 years old and had never benefited from formal education because in Mexico his admission to a public school had been denied due to low scores obtained on a non-standardized test. Although AAC intervention occurred at age 16 and brought about functional gains in his communication skills, it is impossible to determine how he would have benefited if this intervention would have taken place sooner.

\section{Contributions}

This case study can provide several contributions to the field of SpeechLanguage Pathology in regard to the treatment of children with severe communicative handicaps. Speech-Language Pathologists have the difficult task of serving the severely communicative handicapped population and providing them with the means they need to communicate. This task can be extremely difficult because of the heterogeneous characteristics of the members in this population. Because of this heterogeneity, a preset "cookie cutter" approach to assessment and intervention would not bring the success wanted. It is also because of this heterogeneity that an experimental study could not provide valid data because with this population there cannot be a "homogeneous control group" to run such types of studies.

This present study provides other speech-language pathologists and special educators with the assurance that the following considerations should 
be taken when treating each and every one of our severely communicative handicapped children.

First and foremost, all clients must be provided with the opportunity to benefit from receiving intervention with an AAC system (aided or unaided) and not be excluded from qualifying by a "cognitive prerequisite" they can not meet. In other words their candidacy must be based in the "all inclusion, zero exclusion" belief. Victor is an example of someone who benefited from a treatment that he would have otherwise been excluded from. Second, all the interactions with the clients must be conducted in their first/native language. This is critical and should not be under-emphasized. Third, time must be given for a comprehensive assessment to take place and its importance must be validated in projecting therapeutic approaches from it. Fourth, implementing incidental teaching methods (not the one we prefer but the one our client is more responsive to) in naturally occurring communicative settings and not artificial clinic settings should occur. Fifth, the intervention must be "client centered" providing them with the tools that work for them and not the ones the therapist prefers. Sixth, in order to comprehensively understand the client's needs, a "collaborative approach" must be taken. The client's parents, teachers and other educators must be included as team members to complement the observations and assessment results obtained.

\section{Limitations}

This investigator is aware of the design limitations of this case study. Small sample size, limited amount of data, and without a formally developed reliability study to account for control are the limitations that need consideration. Because of the design of this case study the results and findings 
have to be considered "tentative" and not conclusive. However, the results and findings of this study are indicative of the positive effects that the AAC system had upon the functional communication of the subject. The data collected clearly exemplifies the functional gains made by the subject due to the AAC system.

To improve upon this case study and obtain conclusive results the investigator would implement the same treatment but under a different design. Instead of conducting a case study the investigator would conduct a single-subject experimental multiple-baseline design study. This type of design is useful when the behaviors being treated are irreversible or should not be reversed for ethical reasons. Control in a multiple-baseline design comes from a replication of treatment effects on another behavior, not a reversal or withdrawal of treatment of the first behavior. The design can be targeted across two or more behaviors and across different settings as to provide a generalization effect which would be the ultimate goal of the treatment. Statistical analysis can be computed to obtain quantitative data and the effectiveness of the treatment can be conclusive making of the results and findings a more valid and quantifiable source to support the implementation of AAC systems with the severely handicapped population.

\section{A Need for Future Research}

The current case study sheds light on the effectiveness of implementing an AAC system to increase the functional communication of a severely communicatively handicapped individual. However, further research is still necessary. The existing body of research focuses almost exclusively on the mild and moderate communicative handicapped population. More needs to be 
learned about facilitating communication for the severely handicapped population. Such research could be of tremendous benefit to speech-language pathologists and special educators in their efforts to provide individuals with severe handicaps with a vehicle for communication. 


\section{REFERENCES}




\section{References}

Alpert, C. L., \& Rogers-Warren, A. K. (1983, March). Mothers as incidental language trainers of their language-disordered children. Paper presented at the Gatlingurg Conference on Mental Retardation, Gatlingurg, TN.

American Speech-Language-Hearing Association. (1989). Competencies for speech-language pathologists providing services in augmentative communication. Asha, 31 (3), 107-110.

Bates, E. (1976). Language and Context. New York: Academic Press.

Bates, E. (1979). The emergence of symbols: Cognition and communication in infancy. New York: Academic Press.

Bates, E., Benigni, L., Bretheton, I., Camioni, L., \& Volterra, V. (1979). The emergence of symbols: Cognition and communication in infancy. New York: Academic Press.

Bates, E., Camaioni, L., \& Volterra, V. (1975). The acquisition of performatives prior to speech. Merrill-Palmer Quarterly, 21, 205-226.

Baumgart, D., Johnson, J., \& Helmstetter E. (1990). Augmentative and alternative communication systems for persons with moderate and severe disabilities. Baltimore, MD: Paul H. Brookes.

Bellugi, U., \& Klima, E. (1976). The faces of sign: Iconic and abstract. Annals of the New York Academy of Sciences, 280, 514-538.

Berler, E. S., Gross, A. M., \& Drabman, R. S. (1982). Social skills training with children: Proceed with caution. Journal of Applied Behavior Analysis, 15 , 41-54.

Beukelman, D. R. (1987). When you have a hammer, everything looks like a nail. Augmentative and Alternative Comm'nication, 3, 94-95.

Beukelman, D. R., \& Mirenda, P. (1992). Augmentative and alternative communication. Baltimore: Paul Brookes.

Bloomfield, B. C. (1992). Beginning requesting and choicemaking skillsa suggested strategy for introducing augmentative communication. San Jose, CA: Publication Intended.

Bruner, J. S. (1974). From communication to language- a phycological perspective. Cognition, 3 , 255-287. 
Bruner, J. S. (1978). On prelinguistic prerequisites of speech. In R. Campbell (Eds.), Recent Advances in the Psychology of Language (pp. 20-24). New York: Plenum Press.

Bruner, J. S. (1983). Child's talk: Learning to use language. New York: W.W. Norton \& Co.

Chapman, R., \& Miller, J. (1980). Analazing language and communication in the child. In R. C. Schiefelbusch (Ed.), Nonspeech language and communication: Acquisition and intervention (pp. 159-196). Baltimore: University Park Press.

Cirrin, F. \& Rowland, C. (1985). Communicative assessment of nonverbal youths with severe/profound mental retardation. Mental Retardation, 23, 52-62.

Cohen, C., \& Shane, H. (1982). An overview of augmentative communication. In N. Lass, L. McReynolds, J. Northern, \& D. Yoder (Eds.), Speech, language, and hearing (pp. 875-890). Philadelphia: W. B. Saunders.

Dennis, R., Reichle, J., Williams, W., \& Vogelsberg, R. T. (1982). Motoric factors influencing the selection of vocabulary for sign production programs. Journal of the Association for the Severely Handicapped, 7, 20-32.

Donnellan, A. M., \& Mirenda, P. L. (1983). A model for analyzing instructional components to facilitate generalization for severely handicapped students. The Journal of Special Eduacion, 17 (3), 317-331.

Drabman, R. S., Hammer, D., \& Rosenbaum, M. S. (1979). Assessing generalization in behavior modification with children: The generalization map. Behavioral Assessment, 1, 203-219.

Dunn, L. M., \& Dunn, L. M. (1981). Peabody Picture Vocabulary TestRevised. Circle Pines, MN: American Guidance Service.

Ecklund, S., \& Reichle, J. (1987). A comparison of normal children's ability to recall symbols from two logographic systems. Language, Speech, and Hearing Services in Schools, 18, 34-40.

Forest, M., \& Lusthaus, E. (1990). Everyone belongs with the MAPS action planning system. Teaching Exceptional Children, 22 (2), 32-35.

Fristoe, M., \& Lloyd, L. L. (1978). A survey of the use of non-speech systems with the severely communication impaired. Mental Retardation, 4 , 99-103.

Goossens, C., \& Crain, S. (1986). Augmentative communication: Intervention resource. Lake Zurich, IL: Don Johston Developmental Equipment. 
Griffith, P., \& Robinson, J. (1980). Influence of iconicity and phological similarity on sign learning by mentally retarded children. American Journal of Mental Deficiency, 85, 291-298.

Guess, D., Keogh, W., \& Sailor, W. (1978). Generalization of speech and language behavior: Measurement and training tactics. In R. L. Schiefelbusch (Ed.), Bases of language intervention. Baltimore: University Park Press.

Guess, D., \& Mulligan, M. (1982). The severely and profoundly handicapped. In E. L. Meyen (Ed.), Exceptional children and youth: An introduction (2nd ed.), pp. 76-82. Denver: Love.

Halle, J. (1982). Teaching functional language to the handicapped: An integrative model of natural environment teaching techniques. Journal of the Association for the Severely Handicapped, 7, 29-37.

Halle, J., Baer, D., \& Spradlin, J. (1981). Teacher's generalized use of delay as a stimulus control procedure to increase language use in handicapped children. Journal of Applied Behavior Analysis, 14, 389-409.

Harris-Vanderheiden, D., Brown, W., MacKenzie, P., Reinen, S., \& Scheibel, C. (1975). Symbol communication for the mentally handicapped. Mental Retardation, 13, 34-37.

Hart, B., \& Risley, T. (1975). Incidental teaching of language in the preschool. Journal of Applied Behavior Analysis, 8, 411-420.

Hart, B., \& Rogers-Warren, A. (1978). A milieu approach to teaching langauge. In R. L. Schiefelbusch (Ed.), Language intervention strategies. Baltimore: University Park Press.

Heward, W. L., \& Orlansky, M. D. (1992). Exceptional children: An introduction survey of special education (4th ed.), New York: Merrill.

Hewett, F. (1965). Teaching speech to an autistic child through operant conditioning. American Journal of Orthopsychiatry, 35, 927-936.

Hooper, C., \& Hemlick, R. (1977). Nonverbal communication and the severely handicapped: Some considerations. AAESPH Review, $2,47-52$.

Hurlbut, B., Iwata, B., \& Green, J. (1982). Non-vocal language acquisition in adolescents with severe physical disabilities: Blissymbol versus iconic stimulus formats. Journal of Applied Behavior Analysis. 15, 241-258.

Kangas, K., \& Lloyd, L. (1988). Early cognitive skills as prerequisites to augmentative and alternative communication use: What are we waiting for? Augmentative and Alternative Communication, 4, 211-221. 
Karlan, G. R., \& Lloyd, L. L. (1983, June). Examination of recall comprehension learning bv moderately retarded individuals responding to oral and manual cues. Paper presented at the 107th Annual Meeting of the American Association of Mental Deficiency, Dallas, TX.

Keogh, W., \& Reichle, J. (1980). Excerpts from the Vermonst early communication curriculum. Burlington, VT: University of VermontBurlington, Center for Developmental Disabilities.

Keogh, W., \& Reichle, J. (1983). Excertpts from the Vermont early communication curriculum. Unpublished manuscript, University of Minnesota.

Keogh, W., \& Reichle, J. (1985). Communication intervention for the "difficult-to-teach" severely handicapped. In S. Warren \& A. K. RogersWarren (Eds.), Teaching functional language (pp. 157-194). Baltimore: University Park Press.

Kiernan, C. C. (1981). A strategy for research on the use of nonvocal systems of communication. Journal of Autism and Developmental Disabilities, $11,139-151$.

Klein, M. D., Wulz, S. N., Hall, M. K., Waldo, L. J., Carpenter, S. A., Rathan, D. A., Myers, S. P., Fox, T., \& Marshall, A. M. (1981). Comprehensive curriculum communication guide. Lawrence, KS: Early childhood Institute, University of Kansas.

Knudson, C. A. (1980). Rate of enactive vs. iconic manual sign acquisition by retarded learners. Unpublished master's thesis, University of Kansas, Lawrence.

Lindley, L. (1990, August). Defining TASH: A mission statement. TASH Newsletter, 16 (8), 1.

Lloyd, L. L., (Ed.). (1976). Communication Assessment and Intervention Strategies. Baltimore, Maryland: University Park Press.

Lloyd, L. L. (1986, September). Augmentative and alternative communication symbols: Recent developments and research issues. Paper presented at the Fourth International Conference on Augmentative and Alternative Communication, Cardiff, Wales.

Lloyd, L. L., \& Fuller, D. (1986). Toward an augmentative and alternative communication symbol taxonomy: A proposed superordinate classification. Augmentative and Alternative Communication, $2,165-171$. 
Locke, P. A., \& Mirenda, P. (1988). A computer-supported communication approach for a nonspeaking child with severe visual and cognitive impairments: A case study. Augmentative and Alternative Communication, $4,15-22$.

Luftig, R., \& Bersani, H. (1985). An investigation of two variables influencing Blissymbol learnability with nonhandicapped adults. Augmentative and Alternative Communication, 1, 32-37.

Matas, J. A., Mathy-Laikko, P., Beukelman, D. R., \& Legresley, K. (1985). Identifying the nospeaking population: A demographic study. Augmentative and Alternative Communication, $1,17-31$.

McDonald, E., \& Schultz, A. (1973). Communication boards for cerebral palsied children. Journal of Speech and Hearing Disorders, 38, 73-88.

McLean, J., \& Snyder-McLean, L. (1978). A transactional approach to early langauge training. Columbus: Charles Merrill.

McQuarter, R. (1980). Milieu language training: A functional alternative to traditional remediation strategies. Unpublished master's thesis, University of Kansas.

McReynolds, L. V., \& Kearns, K. P. (1983). Single-subject experimental designs in communicative disorders. Baltimore, MD: University Park Press.

Mirenda, P. (1985). Designing pictorial communication systems for physically able-bodied students with severe handicaps. Augmentative and Alternative Communication, 1 , 58-64.

Mirenda, P., \& Iacono, T. (1990). Communication options for persons with severe and profound disabilities: State of the art and future directions. Journal of The Association for Persons with Severe Handicaps, 15 (1), 3-21.

Mirenda, P. \& Mathy-Laikko, P. (1989). Augmentative and alternative communication applications for persons with severe congenital communication disorders: An introduction. Augmentative and Alternative Communication, 5, 3-13.

Mittler, P., \& Berry, P. (1977). Demanding langauge. In P. Mittler (Ed.), Research to practice in mental retardation: Education and training, Vol. 2. Baltimore: University Park Press.

Mizuko, M. (1987). Transparency and ease of learning of symbols represented by Blissymbols, PCS, and Picsyms. Augmentative and Alternative Communication, 3, 129-136.

Mount, M. \& Shea, V. (1982). How to recognize and assess prelanguage skills in the severely handicapped. Lawrence, KS: H \& H Enterpreises. 
Nietupski, J., \& Hamre-Nietupski, S. (1979). Teaching auxiliary communication skills to severely handicapped learners. AAESPH Review, 4, 107-124.

Owens, R., \& McDonald, J. (1982). Communicative uses of the early speech of nondelayed and Down's Syndrome children. American Journal of Mental Deficiency, 86 (5), 503-510.

Owings, N., \& McManus, M. (1980). An analysis of communicative functions in the speech of a disinstitutionalized adult mentally retarded client. Mental Retardation, December, 309-314.

Owings, N., McManus, M., \& Scherer, N. (1981). A deinstitutionalized retarded adult's use of communicative functions in a natural setting. British Journal of Disorders of Communication, 16 (2), 119-128.

Prizant, B. M., \& Wetherby, A. M. (1990). Toward an integrated view of early language and communication development and socioemotional development. Topics in Language Disorders, 10 (4), 1-16.

Reichle, J., Barrett, C., Tetlie, R., \& McQuarter, R. (1987). The effect of prior intervention to establish generalized requesting on the acquisition of object labels. Augmentative and Alternative Communication, 3, 3-11.

Reichle, J., \& Karlan, G. (1985). The selection of an augmentative system in communication intervention: A critique of decision rules. Journal of the Association for the Severely Handicapped, 10, 146-156.

Reichle, J., Rogers, N., \& Barrett, C. (1984). Establishing pragmatic discriminations among the communicative functions of requesting, rejecting, and commenting in an adolescent. Journal of the Association for the Severely Handicapped, 9, 31-36.

Reichle, J., \& Yoder, D. (1985). Communiction board use in severely handicapped learners. Language, Speech, and Hearing Services in the Schools, 16, 146-157.

Reichle, J., York, J., \& Sigafoos, J. (1991). Implementing augmentative and alternative communication: Strategies for learners with severe disabilities. Baltimore: Paul Brookes.

Reichle, J., Williams, W., \& Ryan, S. (1981). Selecting signs for the formulation of an augmentative communication modality. The Journal of the Association for the Severely Handicapped, 6 , 48-56.

Rice, M., \& Kemper, S. (1984). Child language and cognition. Baltimore: University Park Press. 
Rincover, A., \& Koegel, R. (1975). Setting generality and stimulus control in autistic children. Journal of Applied Behavior Analysis, 8, 235-246.

Rogers, S. (1977). Characteristics of the cognitive development of profoundly retarded children. Child Development, 48, 837-843.

Rogers-Warren, A. (1975). Methods for analyzing language environments. Paper presented at the Symposium on Language Intervention, Lawrence, Kansas.

Rogers-Warren, A. (1983). Assessing skill prerequisites for incidental language teaching. Unpublished manuscript, Department of Special Education, Peabody College of Vanderbilt University, Nashville.

Rogers-Warren, A., \& Warren, S. (1980). Mands for verbalization: Facilitating the display of newly trained language in children. Behavior Modification, 4, 362-382.

Romski, M. A., Lloyd, L. L., \& Sevcik, R. A. (1988). Augmentative and alternative communication issues. In R. L. Schiefelbusch \& L. L. Lloyd (Eds.), Language perspectives: Acquisition, retardation and intervention (2nd ed., pp. 343-366). Austin, TX: Pro Ed.

Romski, M. A. \& Sevcik, R. A. (1988). Augmentative and alternative communication systems: Considerations for individuals with severe intellectual disabilities. Augmentative and Alternative Communication, 4 (2), 83-93.

Romski, M. A., \& Sevcik, R. A. (1992). Augmented language development in children with severe mental retardation. In S. Warren \& J. Reichle (Eds.), Causes and effects of communication and language intervention (pp. 113-130). Baltimore, MD: Paul Brookes.

Romski, M. A., Sevcik, R. A., \& Joyner, S. (1984). Nonspeech communication systems: Implications for language intervention with mentally retarded children. Topics in Language Disorders, $5,66-81$.

Romski, M. A., Sevcik, R. A., \& Pate, J. L. (1988). The establishment of symbolic communication in persons with severe mental retardation. Iournal of Speech and Hearing Disorders, 53, 97-107.

Romski, M. A., Sevcik, R. A., Reumann, R., \& Pate J. L. (1988). Youngsters with moderate or severe retardation and severe oral language impairments I: Home and school communicative patterns. Unpublished manuscript: Georgia State University. 
Romski, M. A., Sevcik, R. A., Robinson, B. F., \& Bakeman, R. (1994). Adult-directed communications of youth with mental retardation using the system for augmenting language. Journal of Speech and Hearing Research, 37, 617-628.

Romski, M. A., Sevcik, R. A., \& Wilkinson, K. M. (1994). Peer-directed communicative interactions of augmented language learners with mental retardation. American Journal on Mental Retardation, 98, 527-538.

Sailor, W., \& Guess, D. (1983). Severely handicapped students: An instructional design. Boston: Houghton Mifflin.

Sailor, W., Wilcox, B., \& Brown, L. (Eds.). (1980). Methods of instruction for severely handicapped students. Baltimore: Paul H. Brookes.

Schuler, A. L., Peck, C. A., Willard, C., \& Theimer, K. (1989). Assessment of communicative means and functions through interview: Assessing the communicative capabilities of individuals with limited language. Seminars in Speech and Language, 10 (1), 51-62.

Sevcik, R. A., \& Romski, M. A. (1986). Representational matching skills of persons with severe retardation. Augmentative and Alternative Communication, 2, 160-164.

Sevcik, R. A., Watkins, R. V., \& Deffebach, K. P. (1995). Adult partneraugmented communication input to youth with mental retardation using the system for augmenting language (SAL). Journal of Speech and Hearing Research, 38, 902-912.

Shane, H. (1980). Approaches to assessing the communication of nonoral persons, In R. L. Schiefelbusch (Ed.), Nonspeech language and communication: Analysis and intervention (pp. 197-224). Baltimore: University Park Press.

Shane, H., \& Bashir, A. (1980). Election criteria for the adoption of an augmentative communication system: Preliminary considerations. Journal of Speech and Hearing Disorders, 5, 408-414.

Silverman, F. (1980). Communication for the speechless. Englewood Cliffs, NJ: Prentice-Hall.

Sontag, E., Sailor, W., \& Smith, J. (1977). The severely/profoundly handicapped: Who are they? Where are we? The Journal of Special Education, $11(1), 5-11$.

Soto, G., Belfiore, P., Schlosser, R., \& Haynes, C. (1993). Teaching specific requests: A comparative analysis on skill acquisition and preference using two augmentative and alternative communication aids. Education and Training in Mental Retardation, June, 169-177. 
Stainback, S., \& Stainback, W. (Eds.). (1991). Teaching in the inclusive classroom: Curriculum design, adaptation and delivery. Baltimore, MD: Paul H. Brookes.

Uzgiris, I., \& Hunt, J. McV. (1975). Ordinal scales of development in infancy. Champaign-Urbana: University of Illinois Press.

Vanderheiden, G. C., \& Lloyd, L. (1986). Communication systems and their components. In S. E. Blackstone (Ed.), Augmentative communication: An introduction (pp. 49-161). Rockville, MD: American Speech-LangaugeHearing Association.

Vanderheiden, G. C., \& Yoder, D. E. (1986). Overview. In S. Blackstone \& D. Bruskin (Eds.), Augmentative communication: An introduction (pp. 1-28). Rockville, MD: American Speech-Language-Hearing Association.

Warren, S. F., \& Rogers-Warren, A. (1980). Current perspectives in language remediation. Education and Treatment of Children, 3 , 133-153.

Warren, S. F., Rogers-Warren, A., Baer, D., \& Guess, D. (1980). Assessment and facilitation of langauge generalization. In W. sailor, B. Wilcox, \& L. Brown (Eds.), Methods of instruction for severely handicapped students (pp. 102-117). Baltimore: Paul H. Brookes.

Wolery, M., \& Haring, T. G. (1990). Moderate, severe, and profound handicaps. In N. G. Haring \& L. McCormick (Eds.), Exceptional children and youth (5th ed.) (pp. 239-280). Columbus, OH: Merrill. 
APPENDICES 


\section{APPENDIX A}

Session A1

Date: 9-16-94

Location: Subject's High School

Assessment Phase

Today I met Victor for the first time. I arrived at his High School in Belmont and met the school's SLP at the classroom and Victor's teacher. The classroom was crowded. There were at least 11 other students sharing the classroom with Victor. As soon as we started to talk about Victor I noticed that a student turned around and gave me a big smile. Sure enough that was Victor. He was sitting at his desk doing some kind of matching exercise.

First I decided to observe Victor working and relating to other students in the classroom. He complied with the teacher's requests. He was friendly to the other students and was looking around trying to keep up with the activities around him.

Victor's teacher explained to me that Friday's are the "relax" days. The children's schedule remains loose and they have activities such as watching videos and playing games. The teacher likes to do this on Fridays as a reward for the student's good behavior during the week. The room became kind of noisy and there was a lot of activity going on.

Eventually I introduced myself to Victor. I started speaking Spanish to him and he gave me a big smile as a greeting. I pulled up a chair and he moved his body around to give me enough space to sit down. He was already putting a puzzle together. During this exercise he had trouble fitting the 
pieces twice. When the pieces did not fit right in he became frustrated and made a "loud grunt".

Once the puzzle was complete, I congratulated him but he was not interested in my approval. He walked to where his teacher was and tapped his shoulder and when his teacher turned around Victor smiled at him and made another sound. This time the sound was kind of a high pitched laugh/squeal. His teacher congratulated him and they shook hands. Victor seemed very pleased and proud.

After I helped Victor put away the puzzle pieces, he picked up the box and took it to a shelf and then came back bringing another box. This time the box contained survival signs. He placed the box on the table and looked at me. I said nothing. I was trying to see how he would get me involved in the activity. He pushed the box all the way across the desk until it touched my hand. He opened the box and handed me one of the signs. I said in Spanish "do you want me to help you with these signs?" and he nodded "yes". I presented Victor with 4 cards to match. Two of the cards had red writing on them and two had green writing on them. I gave Victor one card at a time and he started matching them almost immediately. I was surprised that he could do the task that fast. Throughout both activities I noticed that Victor clicked his teeth constantly but more so when he was frustrated or felt under pressure (i.e. making a decision or trying to solve a problem). I also observed Victor biting his nails constantly.

Results from informal speech-language assessment:

Fine motor skills: $\quad$ Victor could not utilize scissors or hold a pencil. 


\author{
Vision and hearing: No acuety problems were noted in the report. \\ Victor's parents had reported that his vision and \\ hearing were normal. \\ Cognition: $\quad$ Victor demonstrated to have the concept of 1 , but no \\ other numbers beyond. \\ Speech and language: Receptively, Victor was able to touch most body \\ parts. He was able to imitate the signs for "hello" \\ and "thank you" but could not produce them \\ spontaneously. Victor could not follow simple \\ commands and could not read. \\ Expressively, Victor was able to utter noises and use \\ body language to communicate. Victor did not know \\ how to write. \\ Behavior: Victor was described as having a social and likeable \\ personality. He was observed to test adult's \\ authority in the classroom. He responded positively \\ if Spanish was spoken to him. Victor was observed \\ to click his teeth, rub his genitalia, bite his nails \\ and pick his nose constantly.
}

Behavioral information provided by the classroom teacher: Victor's classroom teacher reported the following observations of Victor's behavior in the classroom: Victor spent most of his time wandering around the classroom, looking out the window and getting distracted by anything that occurred outside. He was also very impatient and could not sit for periods longer than 5 minutes at a time. Victor constantly made a clicking noise that could be heard 
by everyone in the room. He was also seen biting his nails constantly even to the point of bleeding at which time the teacher or one of his aids would have to intervene and make Victor stop.

Victor's behavior started changing within the second week of his school attendance. His teacher reported that he started sweeping up the floor utilizing the classroom's broom and he also was retrieving the other student's jackets from their cabinets and placing them on each corresponding chair at the end of each school day. Victor was a master in handling the broom and dirt pan cleaning every inch of the classroom as well as matching the jackets and the owners correctly every day. These activities appeared to make Victor more at ease and he seemed to want to do them because they provided him a sense of confidence of knowing what to do and how to do it. Victor's teacher also reported that within the second month he was able to sit at his desk for most of the school day and was interested in working with puzzles and matching activities. He noticed that Victor was able to pick up a task soon after it had been shown to him and that Victor would continuously improve in his performance by practicing the same task over and over. Victor was described by his teacher as a child who has a happy personality, is friendly, is eager to learn and eager to please authority figures. Victor was also described as someone who takes pride in his work and loves recognition. 


\section{APPENDIX A}

Session A2

Date: 9-23-94

Location: Subject's High School

Assessment Phase

Today I had planned to give Victor an assessment focusing on his receptive language. I had pre-selected the following battery of tests:

The Toronto Test of Receptive Vocabulary

The Bicultural Test of Nonverbal Reasoning

The Brigance Diagnostic Inventory of Basic Skills

The Del Rio Expressive/Receptive Screening Tool

The Receptive One-Word Picture Vocabulary Test

After arriving at the high school and talking to the school's SLP she informed me that maybe I could take 1 or 2 tests from my battery and try to administer those to Victor, but in her opinion Victor did not test well and she doubted that he could even go through 1 test. At her request I administered the Receptive PPVT (Peabody Picture Vocabulary Test). The SLP told me that the San Mateo School District needed the results from that test in particular in order to develop the appropriate IEP addressing speech/language. I administered the PPVT to Victor and had to stop on item \#24 out of 175 items. Unfortunately, Victor did not respond in a positive manner to the testing situation. He became very tense and withdrawn. He was unable to point to the pictures. He seemed 
to not know how to use his index finger to point. Victor clearly could not understand what was being required of him or what the task at hand was. He seemed very nervous and confused. He started biting his nails and the test had to be discontinued. His anxiety level appeared to have been raised perhaps due to the fact that this testing experience was new to him. The administration of the PPVT was concluded.

Right at that time the children were getting ready to watch a video and Victor sat down to watch it also. He seemed preoccupied, anxious, and he continued to bite his nails. After about $1 / 2$ an hour I noticed that Victor had blood on his t-shirt. His teacher proceeded to clean him up and we looked to see where the blood was coming from. It appeared to us that it came from his fingernails. It seems that Victor had bitten his fingernails to the point of bleeding.

By observing Victor handling different tasks in the classroom I feel that he is capable of doing matching and sorting tasks. I feel that Victor has not been exposed to testing circumstances enough and so he feels threatened and uncomfortable during a test. He does not know how to scan for the answers and he does not point consistently. For the most part Victor was placing his hand on the right side of the page and only for certain items he point/placed his hand correctly in the middle or left side. I feel that testing is not the appropriate way of finding out what Victor knows and is capable of doing. A dynamic assessment can prove much more beneficial and fruitful. I feel that Victor is a fast learner and he uses a visual modality to learn. He imitates well and he is able to do a task if presented with a model. 
APPENDIX A

Session A3

Date: 9-30-94

Location: Subject's High School

Assessment Phase

After writing Victor's IEP with the school's SLP, I decided to see what Victor was working on. He was sorting bottle corks and plastic washers and putting them in 2 different buckets. It looked to me that this activity was so easy for him, he practically wasn't even looking or paying much attention to what he was doing and still he wasn't making any mistakes. I decided to increase the complexity of the task. I placed two strips of masking tape on the table and showed Victor once how to place a nail on each piece of tape and then take an envelope and place the 2 nails inside and put the envelope in a tray. He watched me do it once and was able to do it correctly on his own. The task was still too easy for him so I increased the items he needed to put inside the envelope to 4. By then he was picking up the items from their containers one by one and was skipping the step of putting them first on the table. He put each item inside the envelope correctly. When he was half way through the activity he noticed that everyone was getting ready to leave the room. His teacher asked me if we would join them at the track. I said that we will get there as soon as Victor finishes his task. Victor wasn't happy about that and he tried to get up and walk away. His teacher called him and said "sit down and finish your job" with a firm voice. He did. As a matter of fact, he finished his job so fast that I was amazed by his speed and coordination. 
We joined the group and walked to the track field and Victor began running with the rest of the kids. Victor has poor posture. When he runs he has good coordination however, he leaves his arms loose and they kind of flap as he runs and the palm of this hands are visible from behind him. Victor enjoyed being with the other children and tried to belong with the group. All the children talk to him and include him in all the activities. Even though the other children don't receive any verbal feedback from Victor they still interact with him and look at his behavior/gestures to get his responses. INFORMATION FROM VICTOR'S IEP

Test performance: The PPVT Spanish translation was administered. Victor attended to the tasks. He did not scan for the correct answer. Mostly he pointed to one plate to give his answer. However, he pointed to his own body parts instead of the plate in the test in cases such as: hand, elbow, knee, etc. Following Directions: Victor is able to follow one level directions consisting of a simple sentence without visual/gestural cues in Spanish. However, he requires both visual and gestural cues if he needs to follow directions in English. Expressive Language: Victor has exhibited two different types of noises/sounds. When Victor is trying to get someone's attention, the sound he makes varies in low pitch intonations. On the other hand, when he wants to express content or happiness the sound is more like squealing sound with high pitch intonations. Oral Motor: Victor was observed to eat and drink utilizing only one side of his mouth. He drinks on the right side of this mouth while moving his jaw to the left side. Victor clicks his teeth together when he is under pressure. Victor bites his fingernails constantly. He bites them occasionally to the point in which they bleed. Victor tends to mouth objects seemingly in an attempt to explore or learn about them. Informal 
Observations: Victor attempts to follow the classroom's routine although he displays high distractibility. Victor desires recognition of his task as is evident by his searching out of staff members to display what he has done. 


\section{APPENDIX A}

\section{Session A4}

Date: $10-07-94$

Location: Vocational Training Site

Assessment Phase

Today was the first time Victor and I worked together at his vocational training site. I met the Voc Ed Specialist and who is in charge of arranging for Victor's transportation from the school to the training site and back. Victor arrived at the store around 10:30 a.m. He seemed happy and excited to be there. I think he recognized me because he gave me a big smile. He brought his lunch bag and I told him that he should put it inside the refrigerator until lunch time. He followed me to the back of the store and when he saw the refrigerator he opened it and placed his lunch bag inside.

I was introduced to the manager of the store and she informed me of the first activity for Victor which had to do with sorting books by sizes and placing them on shelves. Victor and I worked in this activity for about 15 to 20 minutes. I showed Victor the three different sizes that we had to sort and he was able to separate the big from the little books and put them in different piles. However the medium size books were more problematic for Victor. He kept on grouping them with the big books. During this activity Victor's attention span was very short. He kept on looking out the window, looking around the room, and looking at the people shopping at the store. Victor's attention had to be refocused at least 10 different times. His overall attitude towards this activity was negative. He did not like sorting the books. One of the 
things that bothered Victor the most was the fact that he needed to wear gloves during this activity because of his constant nail biting. The gloves being used at this time did not fit him correctly because they were too small for him.

The second activity that we worked on was at the men's clothing section of the store. Victor was supposed to pick up hangers from a shopping cart (100 hangers) and put them in a special hanger collector that the store uses. I showed Victor how to pick up 1 hanger and put it in the collector. He looked at me and proceeded to pick up about 5 hangers together and placed them in the collector. The first time that Victor did not place the hangers correctly in the collector he continued gathering more and I had to call his attention to his error. He continued with the activity and in two other occasions the hangers did not fit in the collector correctly and Victor noticed it by himself and fixed them. Victor seemed to like this activity a lot. His attention span was longer although he got distracted about three times. This activity lasted 15 minutes. During this activity Victor did not wear gloves. I had told him that if he continued biting his nails and putting his fingers in his mouth and nose I would put the gloves back on. During this activity he seemed more relaxed and only in one occasion he put one finger inside his mouth and as he was doing it he looked at me and immediately stopped as if he remembered what I had told him. I took a pair of gloves and gave them to him. He put them on and about two minutes later he wanted to take them off. I reminded him of what would happen if he did it again. About five minutes later he started to move his hand towards his mouth and looked at me and stopped before his finger reached his mouth.

The third activity that we worked on was picking up clothes from around the store and placing them inside a shopping cart. I told Victor to look around 
for the clothes that did not have a hanger. I showed him how to look on the floor to see if there were any clothes there. This activity was difficult for Victor. He did not want to look around for misplaced clothes. His attention span was very short and he got completely distracted looking around the store. I ended up picking up most of the clothing from the floor and he followed me but maybe only picked up four garments while I picked up about twenty.

The fourth activity was done at the men's pants section where we had to look for pants that were hanging from hangers only from one side, or were almost ready to fall off, or pick up some pants that were already on the floor. I showed Victor how to look at how the pants were hung and when a pair of pants that needed to be re-hung was seen, I showed him how to take it out and put it back in the rack in the right way. Victor liked this activity. He found about 25 pairs of pants that needed to be re-hung. I had to call his attention four times when he skipped a pair of pants that needed to be re-hung. We finished this activity in about twenty minutes.

We took a lunch break and walked to McDonald's to get my lunch. As we walked I noticed that Victor did not look for cars in the street, he did not seem to be aware or worried of the dangers of the street. He did notice his reflection in a store window and he stopped and smiled at his own reflection. I ordered food to go and purposely purchased the "Mega Meal" so that I could share it with Victor upon our return to the store. I got an extra glass for him and poured half of my diet coke and gave it to Victor. When we got back two other employees were having lunch at the table so we sat and joined them. I warmed up Victor's lunch in the microwave and we started to eat. I asked Victor if he would want some of my French fries and he reached for them instead of nodding "yes" or "no". This took me by surprise and bothered me so I asked 
him not to do it again. If I asked him a question I wanted him to answer it "yes" or "no" instead of grabbing the food. During one of our short brakes Victor had seen one of the employees turn on the fan when she was hot so during our lunch evidently he got hot and stood up and plugged in the fan and turned it on. I asked Victor if he wanted half of my chocolate cookie and this time he nodded "yes". He ate it and stood up and turned the fan off and reached for the cassette player and turned it on, but noticed that the tape was not playing so he pressed eject, turned the tape around, put it back in and hit play and proceeded to move to the music and smile.

Our fifth activity was to sort out clothes by their tag color (yellow, blue, white). I tried to explain to Victor what to do but he did not have the concept of colors so we could not perform this activity.

The sixth activity involved taking clothes off from two different types of hangers, putting the clothes inside a Salvation Army bag and putting the hangers inside a shopping cart. Victor did fine with this activity right after seeing me do it only ONE time. The only time he had a problem was when he was trying to get a shirt off the hanger without unbuttoning it. I showed Victor once how to unbutton the shirt and he was able to do it then and two other times.

At the end of the day the manager of the store told me that in the future she would want Victor to be able to work every Friday on two or three of the six activities that she gave us for today. She encourage me to pay attention to the activities that Victor enjoyed and the ones that he was able to perform the best so that he could be trained on those activities and become more proficient at them. 


\section{APPENDIX A}

Session A5

Date: $10-14-94$

Location: Vocational Training Site

Assessment Phase

Victor remembered where the bathroom was. He even remembered where the key to the bathroom was kept. He remembered the tasks that needed to be done. Victor remembered what to do with the books but still had trouble with the medium size. He took clothes off of the hangers and remembered what to do with them. He was able to take the hangers back and placed them inside the big carrier sorting them in the process.

Victor's inappropriate behaviors were still present. He continued biting his nails, picking his nose, and rubbing his genitalia to indicate he needed to use the bathroom. 


\section{APPENDIX A}

\section{Session A6}

Date: $10-28-94$

Location: Vocational Training Site

Assessment Phase

Victor came to the store but he was sick. He had a cold. His nose was runny, he was sneezing and he seemed very warm to me as if he had a fever. Victor's work stamina was very low and that was understandable. I called his teacher and asked him why was Victor sent to school if he was obviously sick. He told me that he had tried to reach Victor's mother the day before to tell her to keep Victor at home when he was sick. Victor's teacher told me that Victor had been sick since that Wednesday and got progressively worse.

Victor got around doing his work but at a much slower pace. We took long breaks and sat by the portable heater to warm up a couple of times. We only worked on putting the two types of hangers in the big hanger carrier. There were about three hundred hangers that needed to be placed inside a big carrier. So that was the only activity we had for the day.

I continued observing Victor and as part of my assessment I was paying attention at the following: Victor's receptive English/Spanish language skills, visual and kinesthetic orientations. Also I was paying attention at the activities that he seemed to enjoy and perform well. 


\section{APPENDIX A}

\section{Session A7}

Date: $11-18-94$

Location: Vocational Training Site

Intervention Phase

Introduction of AAC with real objects. Placed inside clear sandwich bags and individually wrapped I took six different items for Victor: blocks, pennies, noodles, miniature chocolate chip cookies, a small container of apple juice and chocolate covered raisins. Each bag had velcro in the back. The first item I introduced was the chocolate chip cookies. I place the bag on the communication board (had six divided places) and waited to see Victors reaction. He smiled and had a curious look on his face. I touched the bag with my index finger and I took a cookie from a bag that was hidden and ate it. Victor smiled again and then touched his chest with his hand (he was telling me that he wanted one) so I took his hand and had his index finger touch the bag and immediately gave him a cookie. That was the only time I had to show Victor how to point to an item utilizing his index finger. He consistently pointed to the bag with cookies on different parts of the board. After 5 trials I introduced the second item which was the pennies. He looked interested and touched the bag with his index finger and I gave him two pennies. He looked at them and put one on top of the other one and then returned them to me. He immediately touched the cookies again. I introduced the juice and he selected it and we went back and forth between the juice and the cookies two times before he requested the pennies again. This time I gave him about six pennies 
and he made a tower of six and returned them. I introduced the blocks, the chocolate covered raisins, and the noodles. Victor was able to scan for the item he wanted in all positions of the board. He picked mostly the cookies, juice and blocks. With the blocks he liked to make towers and he demonstrated good fine motor skills. 


\section{APPENDIX A}

Session A8

Date: 12-02-94

Location: Vocational Training Site

Intervention Phase

AAC with real objects. As soon as the communication board was on the table Victor became very happy and excited. He saw me placing one of the items on the board and he took two more items and attached them himself. We went through the process of requesting again. Victor remembered what to do in order to get what he wanted. Out of the twenty times that he requested the items: he requested five times the cookies, five times the juice, five times the blocks, three times the raisins, one time the pennies and one time the noodles. I had changed the items around four times.

Victor was able to point/identify 3 of the real objects when asked verbally. He identified cookies, juice and blocks with $100 \%$ accuracy in 5 trials. 


\section{APPENDIX A}

\section{Session A9}

Date: $12-16-94$

Location: Vocational Training Site

Intervention Phase

AAC with color pictures of the objects. I introduced pictures of the items in order to make the activity more complex for Victor. He had a smooth transition from the real objects to their pictures. I eliminated the pennies and the noodles and I introduced bubbles instead. Every time Victor requested juice I gave him about 3oz. which seemed very little for him so he requested it again. However the fourth time he requested the juice he looked at me and he seemed upset at the small amount of juice in his glass. The next request he tapped his index finger three times at the picture and made a point that he wanted more. I gave him three times as much juice and I counted it as three requests. He then looked at me and smiled pleased to see more juice in his glass. I am aware that Victor does not know how to count, however he knew that the equivalency of one request was not pleasing him so he tried to request more by tapping his finger repetitively. With the bubbles Victor did fine. As soon as I gave him the bottle he gave it back to me so that I could show him how. After I blew a couple of bubbles I gave him the bottle and he also was able to blew a few bubbles. All three times that he requested the bubbles we had this playful interaction. The same thing happened when Victor requested the blocks. He handed me a couple so that I would build 
something. He initiated these actions, twice building a tower we took turns and Victor followed the routine fine. He waited his turn and gave me a turn. 


\section{APPENDIX A}

Session A10

Date: 01-20-95

Location: Vocational Training Site

Intervention Phase

Victor arrived at 9:50 a.m. at the store. He seemed very happy and exited to be there. All the employees said "hello" to him and Victor shook hands with all of them ( 6 employees). I had the communication board ready with the colored pictures and as soon as Victor saw it he pointed to cookies and juice. Since it was obvious to me that Victor remembered how to use the system and had not regressed I decided to change the colored pictures for black \& white icons after he had completed five trials.Victor pointed to all of the icons with $100 \%$ accuracy and the transition was smooth.

At the table there was a box containing doughnuts. One of the employees moved the box away when Victor arrived at the table but he was able to see the doughnuts. From previous experience I knew he liked doughnuts a great deal. I did not have a color picture of a doughnut so I drew a doughnut with a black marker and I introduced it as a new item.

As soon as Victor saw the doughnut icon he pointed to it and I gave him half of a doughnut. He then requested juice and pointed to the doughnut icon again so I gave him the remaining half of the doughnut. Since he had had enough to eat I asked him to get his hands washed. I showed Victor three new icons: wash hands, dry hands and wipe face in that order. When he was finished drying his hands I told him to look at the pictures and I said "you 
washed your hands" and pointed to the icon, "you dried your hands and now you should wipe your face" and I pointed to the icon. He looked at the icon and picked up a paper towel got it a little bit wet with water and wiped off his face. At the end of the day we went through the same activity and Victor followed all three steps by himself without me saying anything.

I had a hanger and a line drawing of one. I also had a line drawing of a shopping cart and I had brought one next to the table. I did the same with the hanger carrier, the bags, and the clothes hanging. As soon as the five items were displayed on the communication board Victor pointed at the icon of the shopping cart and then pointed to the real shopping cart and smiled. He then pointed to the hanger and I gave him the hanger. The same happened with the other icons. Then I introduced other items such as: plate, spoon, knife, napkin, fork, glass and refrigerator, eat, and drink; all of which he has to use during lunch time. I verbally requested each object and he pointed at the icons and at the real objects.

The first activity involved the shopping cart. I showed him the icon and asked him if he knew what to do and he nodded yes. He started taking the clothes off of the hangers and placing the hangers inside the shopping cart and also putting the clothes inside the bag. He did this activity with $100 \%$ accuracy. The next activity involved the hangers themselves so I showed him the icon and again he knew what to do. We walked to the back room and he started sorting out the hangers and placing them in the big metal carrier. Only twice he mixed one of the hangers within a group where it did not belong. However, he sorted and hung more than 100 hangers correctly. My overall impression of this day was that Victor has good long term memory skills. He did not regress and I know that he was not using the system 
during the time he had not seen me. Victor pays attention to everything around him and stops constantly to look and observe. He has demonstrated smooth transition abilities with the use of the Mayer Johnson line drawings and I have no doubt in my mind that he will be able to increase his vocabulary and eventually use the more abstract drawings that the school's SLP had made .

I plan to speak with Victor's teacher to find out what items will be needed in the schedule board that Victor is going to have for his use at school. It is important at this point that he gets to use the system 5 days a week and not only on Fridays when he is with me. In regards to the intervention at home Victor's mother told me that at home he does everything by himself in regards to turning on/off the radio and television, getting food from the refrigerator and eating and doing the dishes. He also dresses himself but still does not know how to tie his shoes but asks his mom or dad for help. Victor's mom also manifested that she wants a system that Victor could use at work and at school but that at home she does not want a system because Victor is very independent and she does not want to change the dynamics of how the family interacts with him. Even after I had explained the benefits of implementing the system at home in order to integrate all three environments Victor's mom did not want at home intervention. Later on she explained to me that they were living under very poor living conditions. The whole family was living in a garage and she felt embarrassed to have me visit to do any kind of intervention. I respected her wishes and decided to concentrate on giving the intervention at school and at work. I am not sure of the consequences of not implementing the system at home. I feel that generalization will be harder but it is too early to know how much it is going to be affected. 


\section{APPENDIX A}

\section{Session A11}

Date: 01-27-95

Location: Vocational Training Site

Intervention Phase

Victor arrived at the store at 9:45 a.m. Upon approaching the table he saw the communication board and pointed to "drink" and made the appropriate gesture for drinking. Then he pointed to "eat" and when presented with the choices of: candy, cookie, and doughnut, he first picked cookie and then doughnut. When choosing between eat or drink he chose eat and cookie. He then pointed to the drink icon and I gave him apple juice. For the first time today we were going to use a schedule board. As the first activity the board was set up to have the shopping cart because the first activity revolves around a shopping cart. The second icon shows a hanger because Victor has to hang hangers in a big metal hanger carrier.

I pointed out our first activity. Victor knew what to do by looking at the first icon. We walked to the place where the shopping cart was full with the clothes that Victor had to take off of the hangers. Victor worked through this activity and one time he pointed to me as if asking for help so I showed him the "help" icon and he pointed to it and helping him we completed the activity. When Victor finished he was happy and clapped his hands. I showed him the board and modeled for him the way to take the shopping cart icon and place it in the "all done" envelope. After having asked him what to do with the 
icon I took the icon from the board and gave it to him. Then he proceeded to place it in the "all done" envelope.

We did not work on the second activity because the hangers were not ready to be placed inside the big metal carrier. We went back to the table and one of the Spanish speaking ladies who works at the store asked me in Spanish if it was time for Victor to be picked up. Right then Victor tapped my watch with his finger and I told him that it was not time to go yet.

As a final activity I started showing Victor some pictures. I showed him a picture of his teacher, his mom, his dad, and a picture with me in it as well as two pictures with him in them. When I showed Victor my picture he pointed to me. When I showed the picture where he was drinking he pointed at himself and gestured drinking. When I showed him the picture of his mother and teacher he got excited. When I showed him his father's picture he said "papapapapa". I had never heard Victor say anything like that, so close to the word papa (dada/father). I had never heard Victor say anything period. I proceeded to place all the pictures on the table and asked Victor to point to his mom, teacher, Patty, Victor, Victor drinking, and his father and once again spontaneously he said "papapapa". I worked with him trying to say "papa" but he kept on saying "papapapa". Then we worked on "mmmmmmm" for "mama" but he said "papapapa". For the first time Victor spontaneously had vocalized a word approximation. Never before had he even tried to imitate sounds or words with me or with his teacher.

I called his mother on Tuesday to find out if he had done this at home. His mother told me that he had done it before but sporadically since he was about 6 or 8 years old. I asked her why she had told me that Victor had never said anything if he had said papapapa before. She told me that papapapa is not 
a word so they did not count it as such. She said that it was only used once in a while but only with his father. When I asked her a couple of months ago if he had ever said anything she had told me that Victor had not said anything at all not even babbled when an infant. However, when I asked her on the telephone the same question once again she said that once about 8 years ago her sister said that Victor said two words clearly while she was baby-sitting but Victor's mom did not believed her and did not remember what those words were. 


\section{APPENDIX A}

Session A12

Date: 02-3-95

Location: Vocational Training Site

Intervention Phase

Victor arrived at 9:30 a.m. at the store. He was very happy and smiling a lot. He signed hello "V" to the manager in response to her greeting. We went to the break room and on the way he stopped and uttered sounds to make me look at him. He lifted up his sweater and pointed to his T-shirt and smiled. I commented on his T-shirt and he then pointed to his pants and I commented on them too. This was very nice and spontaneous of Victor. He initiated a conversation between us. Victor and I took a walk to Mc Donald's. I took the communication board with me and pointing to the eat icon I asked him what he would like to eat. He pointed to item \#3 from a picture in the menu on display at the restaurant and it was a combo-meal with: sausage and eggs Mc Muffin sandwich, hash browns and coffee. I ordered coffee for myself. When the food arrived I took the tray and he took the communication board. I asked him where he wanted to sit and he pointed to a table where we sat. I showed him the board and he pointed to the eat icon. I gave him his Mc Muffin sandwich and he opened the wrapping very delicately. He then proceeded to eat his sandwich slowly and properly without picking little pieces or making a mess. When he finished he pointed to drink and I gave him his coffee. I asked him if he wanted something else and he pointed to eat again and then pointed to the hash browns. I gave him 1/4 of them. We went back and forth 
requesting for the coffee and hash browns until he finished it. When he finished his coffee he showed me his empty cup and smiled. I asked him to place all the garbage in the tray and then I got up. He picked up the tray, found a garbage, disposed the garbage and placed the tray on the counter where we ordered the food. The lady behind the counter received it and I thanked her and Victor signed thank you also.

Coming from the restaurant I asked Victor in which direction we should walk and he pointed towards the store. We walked back and he stopped at the store recognizing it without problem. The first activity involved the following: shopping cart, clothes, hangers that needed to be placed in small carriers, and large bags which have to be turned inside out to put the clothes in (store regulation). Victor only had one small carrier for hangers but two types of hangers. When he started putting one kind of a hanger in the carrier and found the other kind of hanger he did not know what to do with it because he did not have a second hanger carrier to use. He opted for leaving one type of hanger inside the cart and only putting one type of hanger in the carrier. He continued working and I left to go converse with the manager of the store who wanted to show me something. I was checking on Victor's work and I saw that he started putting the second kind of hangers on the handle of the cart so that they would not be in his way inside the cart. This was very clever of him. He solved his own problem. When I returned he showed me where he was putting the second kind of hangers and he smiled at me. When we had to use a second bag I handed it to Victor and it took him a little while to find the opening of the bag. Then I showed him how to turn it inside out and let him do it. When he had to use a third bag he pointed to the one that was full but I did nothing until he pointed (spontaneously) to the bag icon on the board. Then I 
gave him the bag and he remembered what to do. Victor did not spontaneously put the icons inside the "all done" pocket.

The last activity was to look at the pictures and once again he recognized everyone and spontaneously said "papapapa". We once again worked on "mmmmmmmm" but Victor was only able to do "papapapa". I tried working on oral motor exercises but Victor could not imitate them. Victor could not imitate individual sounds or consonant-vowel approximations. 
APPENDIX A

Session A13

Date: $02-17-95$

Location: Vocational Training Site

Intervention Phase

Victor arrived at 9:40 a.m. at the store and he had a cold. Victor's nose was runny and he seemed to be tired. My father-in-law taped our therapy today for the first time. I introduced him to Victor and they shook hands. Victor did not seem bothered by my father-in-law or the video camera. He did seem distracted a couple of times when he looked at the camera during therapy but that reaction was expected. Victor requested a drink when he saw the "drink" icon on his communication board. He then requested "eat" and chose to have a "cookie".

We worked on identifying the pictures of : mom, dad, teacher, Patty, Victor drinking, Victor tired, Victor. Victor identified all of the pictures. For my picture he pointed at me. For his father's picture he kissed it and I said "papa" and he said "papapapapa". After two times of repeating "papa" Victor said it correctly. He said for the first time the word "papa". We also worked on "mama" and he approximated the sound.

We worked first with the shopping cart, hangers, bag, and clothes on hangers. He performed his task appropriately. He remembered to turn inside out the bag before putting the clothes in. He also seemed tired and lethargic due to his cold. One time I offered my help and Victor immediately accepted. However, I wanted him to point to the "please help me icon" on his board 
spontaneously. I asked him to tell me when he wants my help and he pointed at both of us as if saying "lets do it together". I said "show me the picture from your board "and he pointed to the right icon. After 10 minutes or so I left Victor working by himself and I was hoping that he would point to the icon once again to get me to help him. However, he did not point to it until I said "I would help you if you asked me to". Then Victor immediately pointed to the icon without saying anything else.

Until today Victor was required to put away the clothes from the shopping cart in the bags and sort the two kinds of hangers during this activity. However, I introduced the last phase of this activity which involves putting away or taking the shopping cart, bags full of clothes and the hanger carriers to the back room of the store. Victor was able to do this last phase. First I showed him the shopping cart icon and I said "Victor, take the shopping cart to the back room". I had to repeat the request and then Victor took the cart. Upon his return I showed him the icon still on his board and I told him he was finished with the shopping cart. "What do you do with it if you are done?" Victor did not do anything so I took his hand to the icon and said "take the picture". He did and I said "now what do you do?" and he put it inside the "all done" envelope. Exactly the same happened when he was finished putting away the three bags full of clothes. However, when he came back from putting the hangers away, he spontaneously took the hanger icon and placed it inside the "all done" envelope. 


\section{APPENDIX A}

Session $\mathrm{A} 14$

Date: 02-24-95

Location: Vocational Training Site

Intervention Phase

Victor arrived at the store at 9:40 a.m. Victor still had a cold. His nose was extremely runny. Victor chose to "drink" instead of "eat" when presented with the choices. He requested apple juice. His other choices for beverages were Hawaiian Punch and coffee.

Victor does not spontaneously initiate requests except when the request has to do with food or beverages. I feel that one of the causes of this problem is that the use of the communication board and book is only occurring once a week when Victor is at the vocational training site.

Victor had to work putting the hangers from their small carrier into a metal rack that later is placed inside the big metal hanger carrier. When Victor finished with the hangers I asked him what he was going to do with the icon of the "hanger" and the one of the "hanger carrier". He did not know. What I wanted was for him to take the icon and place it inside the "all done" envelope. But he needed me to direct him the first time with the "hanger" icon and he did it on his own with the "hanger carrier" icon.

The last activity of the session involved photographs. Victor once again said "papapapa" when he saw the photo of his dad and we worked on "papa" a couple of times (4). Victor did say "papa". He said "bababa and papapa" when 
he had his mother's photo. At this time Victor was extremely tired. He was yawning and was distracted because in the same room some co-workers were making a great deal of noise. The session ended abruptly because the bus driver showed up early and walked into the room at which point Victor saw her and started putting the photographs inside the box signaling the end of the session. 


\section{APPENDIX A}

\section{Session A15}

Date: 03-3-95

Location: Vocational Training Site

Intervention Phase

Today when we worked with the shopping cart Victor did not remember to turn the bag inside out and he did not point to the "please help me" icon spontaneously. I told Victor that if he wanted my help he should point to the picture. Only then did he pointed to it. During this activity I also had to redirect his attention back to work at least 3 times.

Victor was able to figure out that he should use another bag to put more clothes into when the first bag was full. He pointed to the full bag and I asked him to point to the board for what he needed. Victor pointed to the "bag" icon and I gave him another bag. He once again forgot to turn it inside out.

Victor commented on the rain. He pointed to the window and made a gesture as to wiping of water from his head. This gesture was identical to what he did when he came into the store in the morning and he was wet from the rain. 


\section{APPENDIX A}

Session A16

Date: 03-17-95

Location: Vocational Training Site

Intervention Phase

Victor arrived at the store at 9:30 a.m. today. We worked on stimulation exercises for the words "mama" and "papa". We also worked on imitation exercises for the lips etc. Victor commented on his t-shirt by showing it to me, smiling and moving his arms as if he was dancing. Victor moves his arms that way frequently at school when he is happy and relaxed (by teacher report).

The first activity involve putting clothes already out of the hangers inside plastic bags and taking them to the back room once the bags were full. Victor remembered to turn the bags inside out $2 / 4$ times. Also $2 / 2$ times he was able to recognize that he needed another bag because the bag he was using was full of clothes. He also pointed to the "please help me" icon when he needed my help to move the full bag to the back room. Victor was able to pick up another bag 3/3 times from the box where they were located. At the end of the activity I asked him "What do we do now?" and he put the icons inside the "all done" envelope.

The second and final activity of the day involved hanging the hangers in the big metal carrier located in the back room of the store. As soon as we arrived at the location Victor took the hanger and started working. After awhile, Victor showed me that he needed to have another metal rack in which to hang the hangers. I told him that we had to find the male employee so that 
he could place the metal rack inside the carrier for us. I told Victor to find him and then I followed him throughout the store until he did. Victor stood next to him and said nothing. I told Victor "Tell him what you need". Victor then started pointing towards the back room. The employee understood that there was something that Victor wanted concerning the back room, so he started walking in that direction. When we got there Victor pointed to the carrier and then to the metal racks on the shelve out of his reach. The employee said "I see you need a rack" and Victor smiled and nodded yes. Victor finished the third activity on time before 12:00 just with enough time to wash his hands. Before I said anything he walk to the table and reached for the "bathroom" board which contains different icons such as: toilet, wash hands, soap, dry hands. He pointed to the "wash hands" icon and smiled and we walked together and washed our hands. 


\section{APPENDIX A}

Session A17

Date: 03-24-95

Location: Subject's High School

Intervention Phase

Today I went to see Victor and to establish the following icons:

matching shapes, matching colors, matching numbers, cutting, sorting, workshop, book, system 80, all done, please help me, men's bathroom, all done envelope. A schedule board was provided along with all of the icons so that Victor could use them 4 days per week while attending school.

I worked with Victor on identifying which icon went with the corresponding activity and then I was able to observe Victor working on the activity. I was able to observe Victor while sorting and matching shapes and colors and he was able to do it with $100 \%$ accuracy. However, when matching numbers and letters Victor only had 60\% accuracy. Also, tracing and cutting are still in the developmental stages. Victor continues to have problems holding the pencil and staying within the lines. Victor had problems holding the scissors accurately and cutting properly.

Victor's teacher told me that he will work on using the schedule board every day with Victor and that he will let me know of the progress Victor is making. Although right now Victor is able to follow the classroom routine just fine, his teacher agreed that being able to use a schedule board will give him more independence and it would reinforce the use of the communication 
system by having Victor use it Monday through Thursday at school and then on Fridays with me at the vocational training site. 


\section{APPENDIX A}

Session A18

Date: 03-31-95

Location: Subject's High School

Intervention Phase

Today I went to Victor's classroom to train him to use his schedule board with icons for matching shapes, matching colors, matching numbers, cutting, sorting, workshop, book, system 80, all done, please help me, men's bathroom, and the "all done" envelope. Victor's teacher reported that Victor had been using the schedule board successfully in the classroom. He also stated that Victor was not placing the icons inside the "all done" envelope spontaneously. Overall, Victor did pretty well using his scheduling board. He seemed very comfortable using it. I tried focusing on using the "all done" envelope and Victor needed verbal cueing before using it. 


\section{APPENDIX A}

Session A19

Date: 04-07-95

Location: Vocational Training Site

Post-Assessment Phase

Today Victor worked on hanging hangers on the big metal carrier. He was able to put in practice problem solving skills when he needed to place the hangers in the carriers and they were tangled. Victor asked for my help using the "Please help me" icon twice. I conducted a post-assessment session in which I tried to assess how many icons Victor was able to ID from his working routine, activities of daily living, communication wallet, etc. 


\section{APPENDIX A}

\section{Session A20}

Date: 04-28-95

Location: Vocational Training Site

Post-Assessment Phase

Today a bilingual graduate student from SJSU attending the Communication Disorders Program conducted the post-assessment session with Victor. Another bilingual graduate student was also present as a recorder (to obtain two measures of responses and behaviors observed for independent judgement purposes). A check list with the tasks that Victor had to perform was provided and I explained to both of them the way in which to prompt for his responses and how to record them.

Unfortunately, Victor was sick today. He had a cold and seemed very uncomfortable. Victor had a runny nose and sneezed many times during the therapy session. This is not the first time that Victor attended school and the vocational training site when he was ill and should have stayed home. 


\section{APPENDIX A}

\section{Session A21}

Date: 05-12-95

Location: Vocational Training Site

Post-Assessment Phase

Today a bilingual graduate student from SJSU attending the Communication Disorders Program conducted the post-assessment session with Victor. Another bilingual graduate student was also present as a recorder (to obtain two measures of responses and behaviors observed for independent judgement purposes). A check list with the tasks that Victor had to perform was provided and I explained to both of them the way in which to prompt for his responses and how to record them. Fortunately, Victor was in much better health today. He was responsive and he was not as distracted as other times. I believe his performance was average. 


\section{APPENDIX A}

\section{Session A22}

Date: 05-12-95

Location: Subject's High School

Post-Assessment Phase

I conducted this post-assessment session just to see how much Victor was able to do after only two training sessions with me. He did very good. I believe that what makes a difference in his performance with this system in the classroom is the fact that he uses it four days per week versus the one system at the vocational training site which he uses only once per week. However, I believe the icons related to his behavior (e.g., like requesting for the bathroom) are successfully used in the classroom because of the training received at the vocational training site. 


\section{APPENDIX B \\ Description of the Communicative Interview}

The Communication Interview (Schuler, Peck, Willard, \& Theimer, 1989) evaluates communicative behaviors in individuals functioning at a prelanguage level. It also provides relevant information about the development of instructional programs and overall program decisions. The interview examines 5 basic communicative functions that normally tend to appear early in the repertoire of children: requests for affection/interaction, request for adult action, requests for objects/food/etc., protests, and declaratives/comments. While the functions sampled draw primarily from the domain of behavior regulation, they also touch upon social interaction and joint attention. Three important factors were being evaluated. First, the range of communicative means demonstrated by the subject as well as which means are most prevalent (23 means ranging from crying to using complex signs). Second, the range of communicative functions, as well as which contexts are most facilitative of communicative competence. Third, the use of multiple communicative means and communicative repairs. 


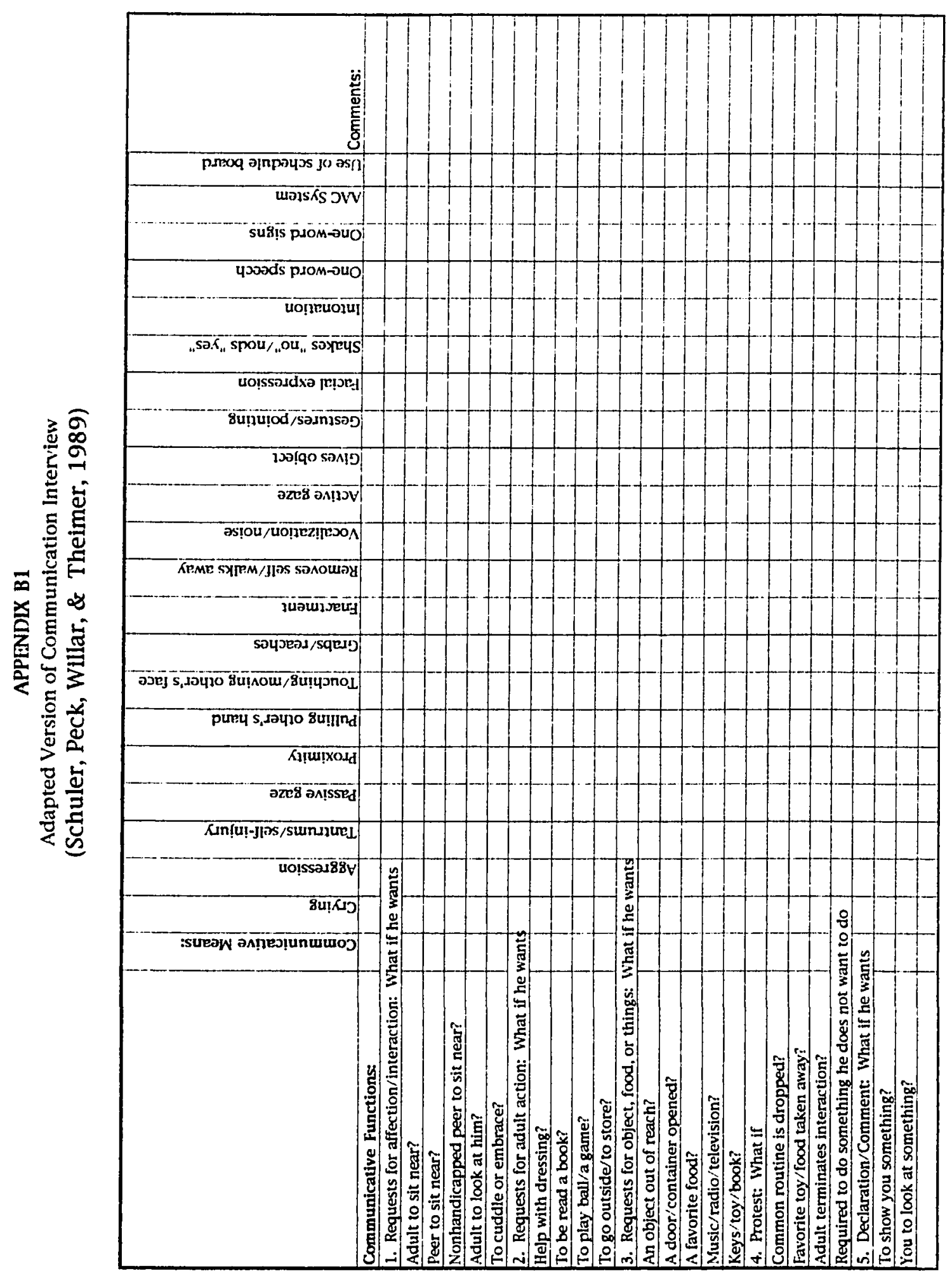




\begin{tabular}{|c|c|c|c|}
\hline \multicolumn{4}{|c|}{$\begin{array}{l}\text { Appendix C - Log C1 } \\
\text { Assessment Sessions } \\
\text { Swhiect's High_School }\end{array}$} \\
\hline & $9 / 16 / 94$ & $9 / 23 / 94$ & $9 / 30 / 94$ \\
\hline \multicolumn{4}{|l|}{ Behavioral Regulations } \\
\hline \multicolumn{4}{|l|}{ Request Objects Spontaneously } \\
\hline \multicolumn{4}{|l|}{ Request Actions Spontaneously } \\
\hline \multicolumn{4}{|l|}{ Social Interaction } \\
\hline \multicolumn{4}{|l|}{ Request Social Routine } \\
\hline Greets & 1 & 1 & 1 \\
\hline \multicolumn{4}{|l|}{ Show off } \\
\hline \multicolumn{4}{|l|}{ Call acts } \\
\hline \multicolumn{4}{|l|}{ Joint Attention } \\
\hline \multicolumn{4}{|l|}{ Comment on object } \\
\hline \multicolumn{4}{|l|}{ Comment on action } \\
\hline \multirow{2}{*}{\multicolumn{4}{|c|}{ Inappropriate Behaviors }} \\
\hline & & & \\
\hline Nail biting & 15 & 30 & 16 \\
\hline Teeth clicking & 18 & 27 & 16 \\
\hline Rubbing genitalia & 2 & 2 & 3 \\
\hline Nose picking & 5 & 10 & 7 \\
\hline \multicolumn{4}{|l|}{ Other Behaviors Observed } \\
\hline \multicolumn{4}{|l|}{ Word approximations } \\
\hline \multicolumn{4}{|l|}{ Use of problem solving skills } \\
\hline Acted distracted = task interrupted & 12 & 13 & 12 \\
\hline & & & \\
\hline & & & \\
\hline & & & \\
\hline & & & \\
\hline & & & \\
\hline & & & \\
\hline & & & \\
\hline & & & \\
\hline & & & \\
\hline & & & \\
\hline & & & \\
\hline $\begin{array}{l}\text { Note: Numbers indicate how many times t } \\
\text { subject within two hours of observations. }\end{array}$ & behaviors $\mathrm{n}$ & xhibited b & \\
\hline
\end{tabular}




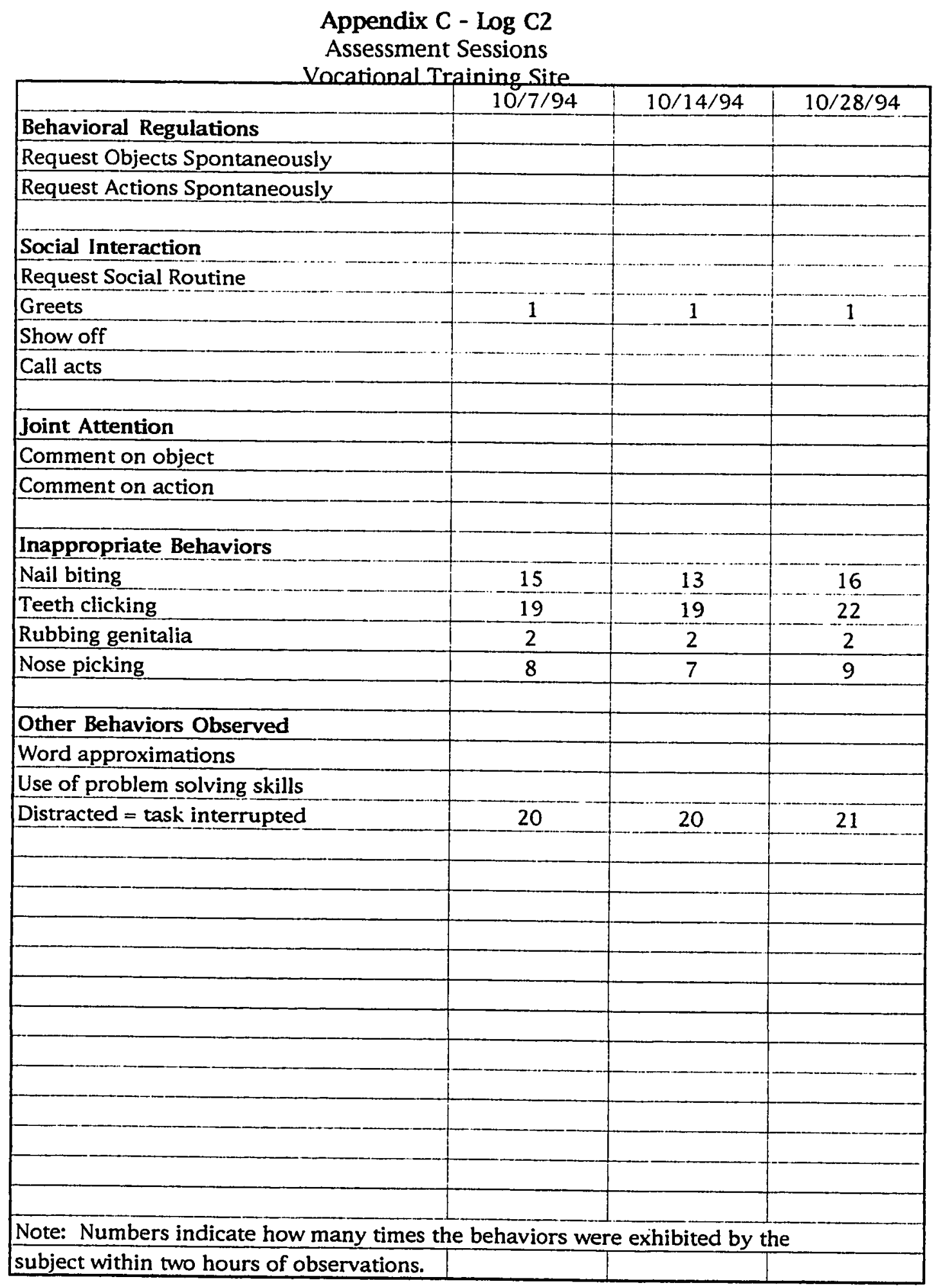




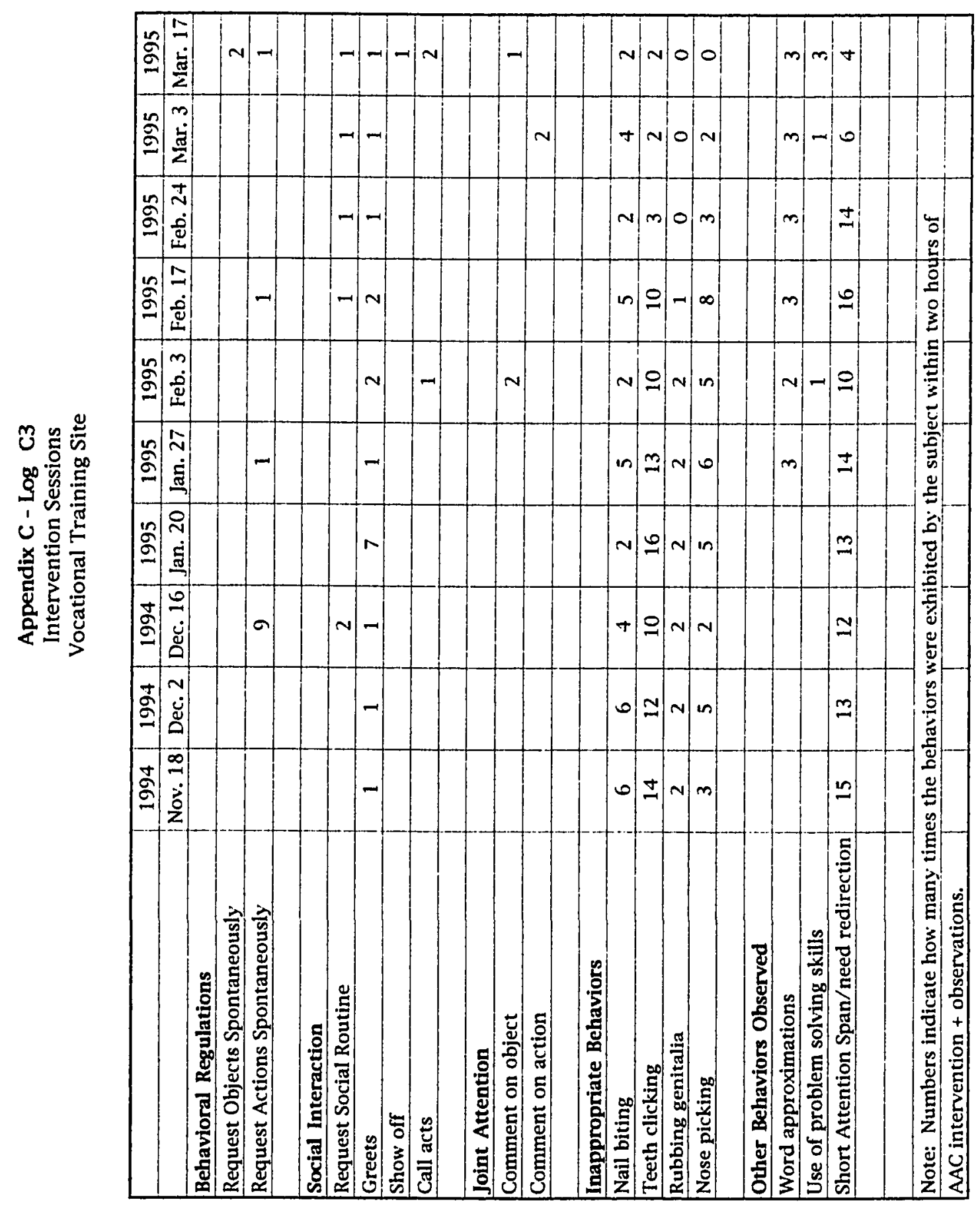




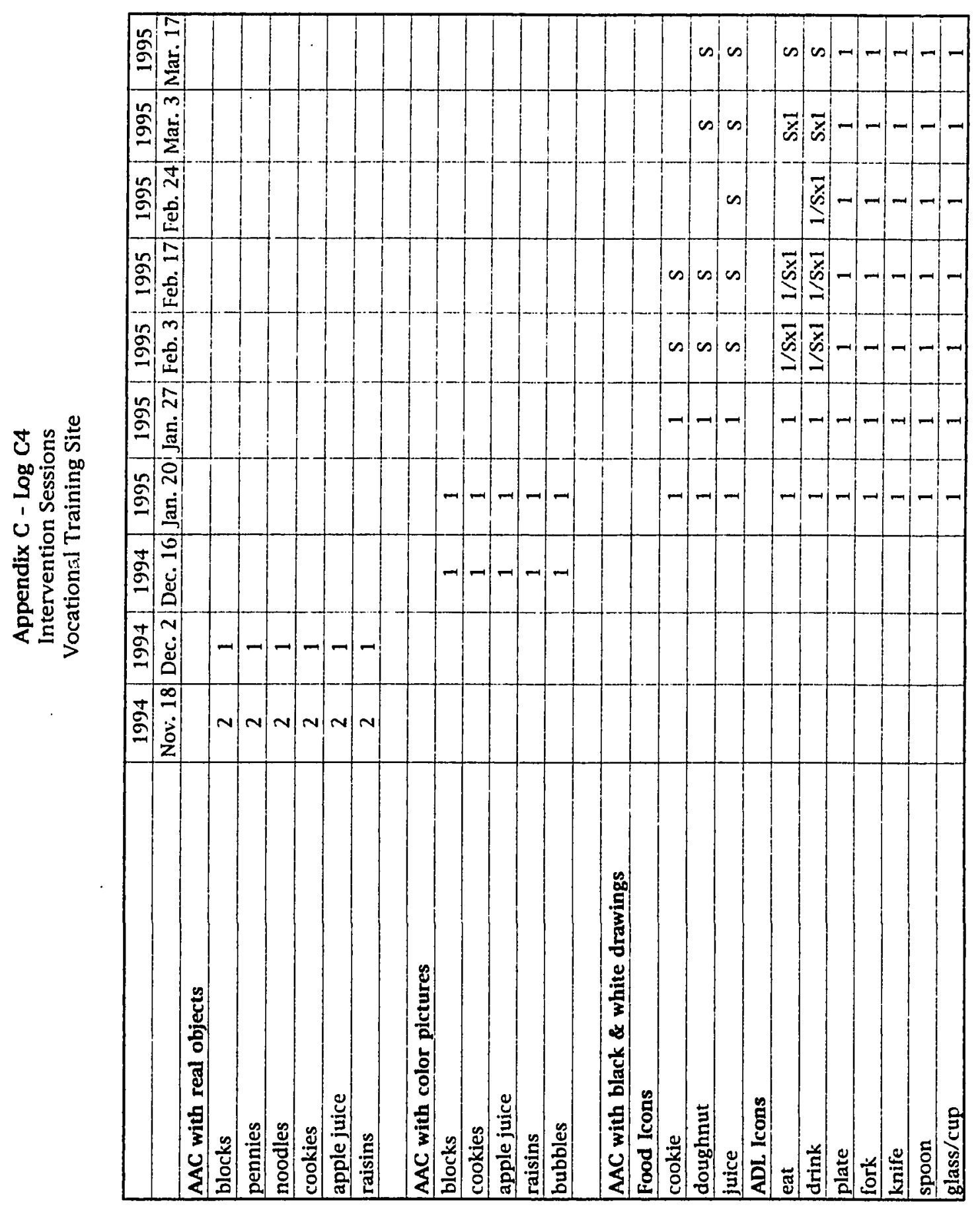




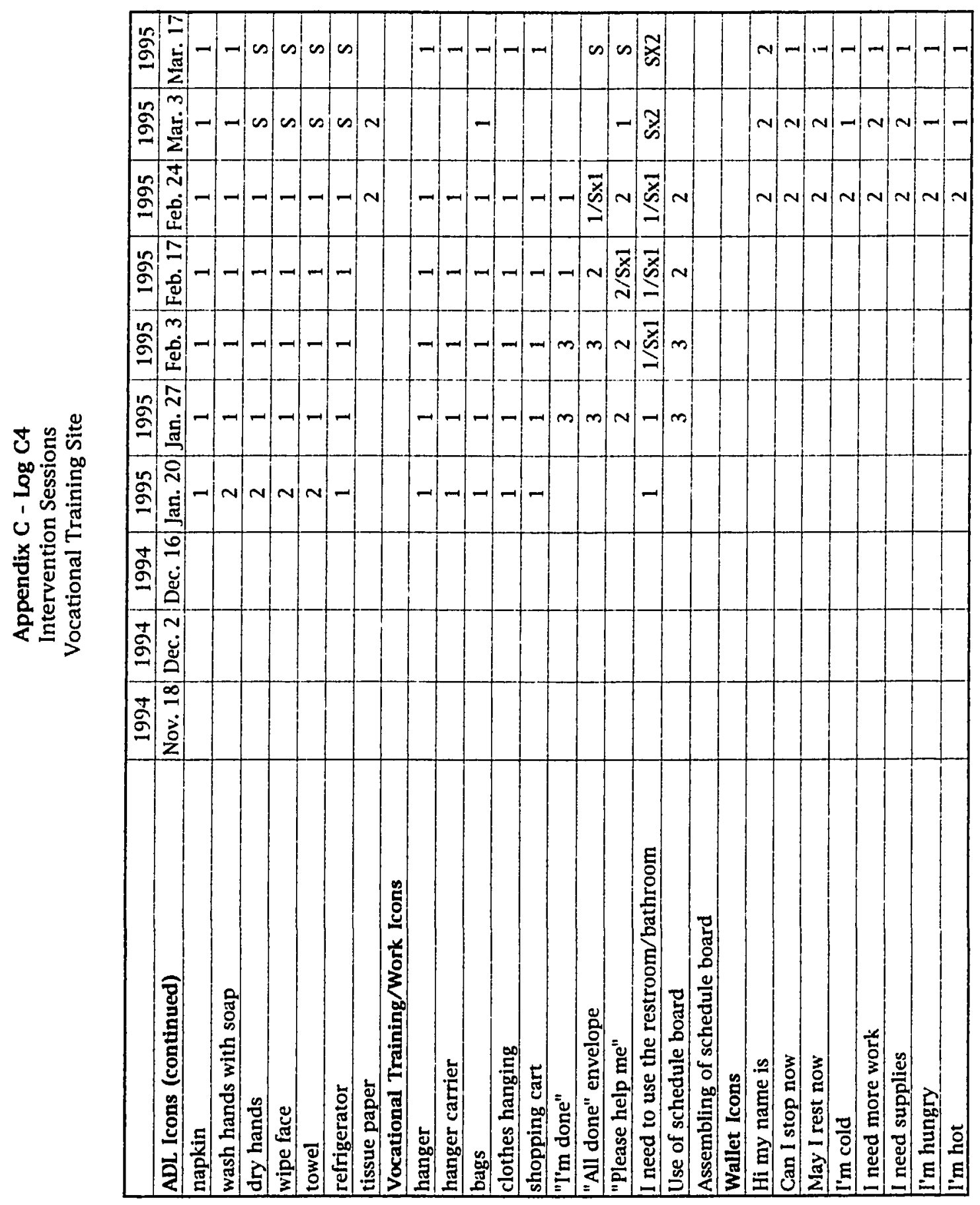




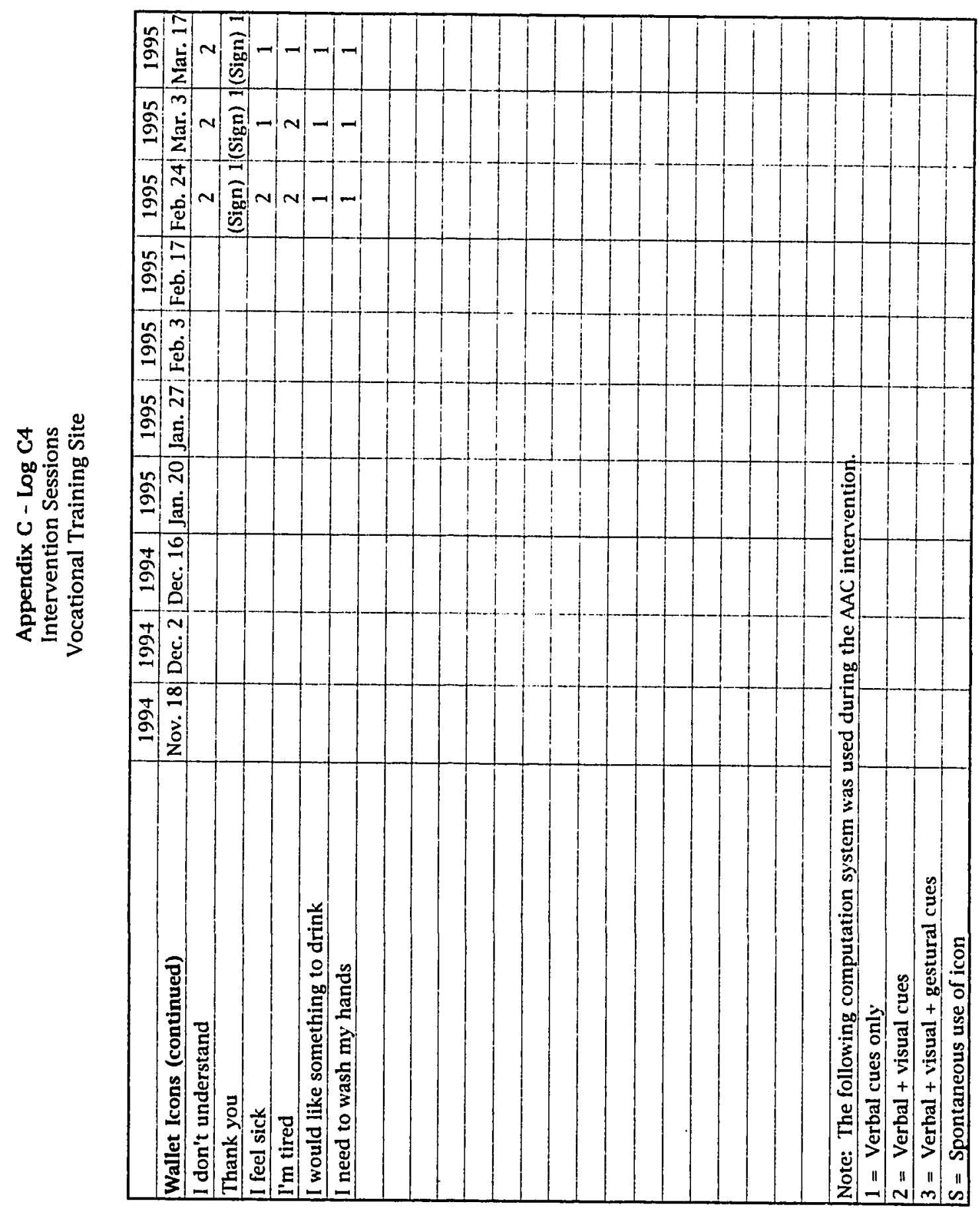




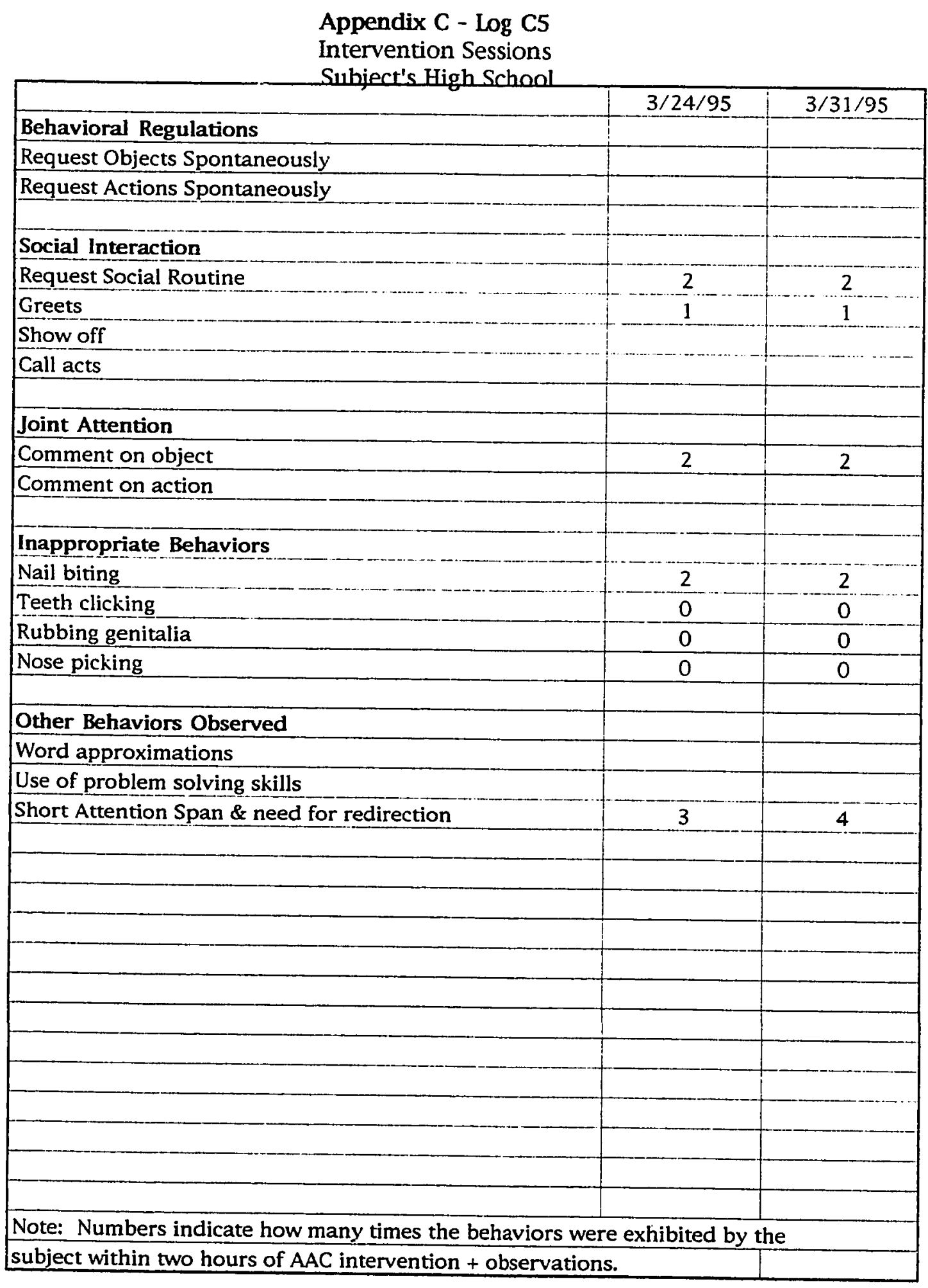




\begin{tabular}{|c|c|c|}
\hline \multirow[t]{2}{*}{$\begin{array}{l}\text { Appendix C - Log C6 } \\
\text { Intervention Sessions } \\
\text { Swhject's High Schoal }\end{array}$} & & \\
\hline & $3 / 24 / 95$ & $3 / 31 / 95$ \\
\hline \multicolumn{3}{|l|}{ AAC Intervention } \\
\hline \multicolumn{3}{|l|}{ Schedule Board Black \& White Icons } \\
\hline matching shapes & 1 & $S$ \\
\hline matching colors & 1 & $S$ \\
\hline matching numbers & 1 & $S$ \\
\hline cutting & 1 & $\mathrm{~s}$ \\
\hline sorting & 1 & $S$ \\
\hline workshop & 1 & $S$ \\
\hline book & 1 & $S$ \\
\hline system 80 & 1 & $s$ \\
\hline "I'm done" & 1 & 1 \\
\hline "please help me" & 1 & 1 \\
\hline I need to use the restroom/bathroom & Sx1 & Sx1 \\
\hline "all done" envelope & 1 & $1 / \mathrm{S} \times 3$ \\
\hline & & \\
\hline & & \\
\hline & & \\
\hline & & \\
\hline & & \\
\hline & & \\
\hline & & \\
\hline & & \\
\hline & & \\
\hline & & \\
\hline & & \\
\hline & & \\
\hline & & \\
\hline & & \\
\hline & & \\
\hline & & \\
\hline & & \\
\hline Note: The following computation system was used duri & AAC inter & \\
\hline $1=$ Verbal cues only & & \\
\hline$S=$ Spontaneous use of icon & & \\
\hline
\end{tabular}




\begin{tabular}{|c|c|c|c|}
\hline \multicolumn{4}{|c|}{$\begin{array}{c}\text { Appendix C - Log C7 } \\
\text { Post-Assessment Sessions } \\
\text { Vocational Training Site }\end{array}$} \\
\hline & $4 / 7 / 95$ & $4 / 28 / 95$ & $5 / 12 / 95$ \\
\hline \multicolumn{4}{|l|}{ Behavioral Regulations } \\
\hline \multicolumn{4}{|l|}{ Request Objects Spontaneously } \\
\hline \multicolumn{4}{|l|}{ Request Actions Spontaneously } \\
\hline \multicolumn{4}{|l|}{ Social Interaction } \\
\hline \multicolumn{4}{|l|}{ Request Social Routine } \\
\hline Greets & 1 & 1 & 1 \\
\hline \multicolumn{4}{|l|}{ Show off } \\
\hline \multicolumn{4}{|l|}{ Call acts } \\
\hline \multicolumn{4}{|l|}{ Joint Attention } \\
\hline Comment on object & 2 & 1 & 2 \\
\hline Comment on action & 1 & 0 & 1 \\
\hline \multicolumn{4}{|l|}{ Inappropriate Behaviors } \\
\hline Nail biting & 2 & 1 & 1 \\
\hline Teeth clicking & 0 & 0 & 0 \\
\hline Rubbing genitalia & 0 & 0 & 0 \\
\hline Nose picking & 1 & 4 & 0 \\
\hline \multicolumn{4}{|l|}{ Other Behaviors Observed } \\
\hline \multicolumn{4}{|l|}{ Word approximations } \\
\hline Use of problem solving skills & 1 & & \\
\hline Distracted $=$ task interrupted & 3 & 8 & 5 \\
\hline & & & \\
\hline & & & \\
\hline & & & \\
\hline & & & \\
\hline & & & \\
\hline & & & \\
\hline & & & \\
\hline & & & \\
\hline & & & \\
\hline & & & \\
\hline & & & \\
\hline Note: Numbers indicate how & ehaviors we & xhibited by & subject \\
\hline within two hours of Post-AAC & servations. & & \\
\hline
\end{tabular}




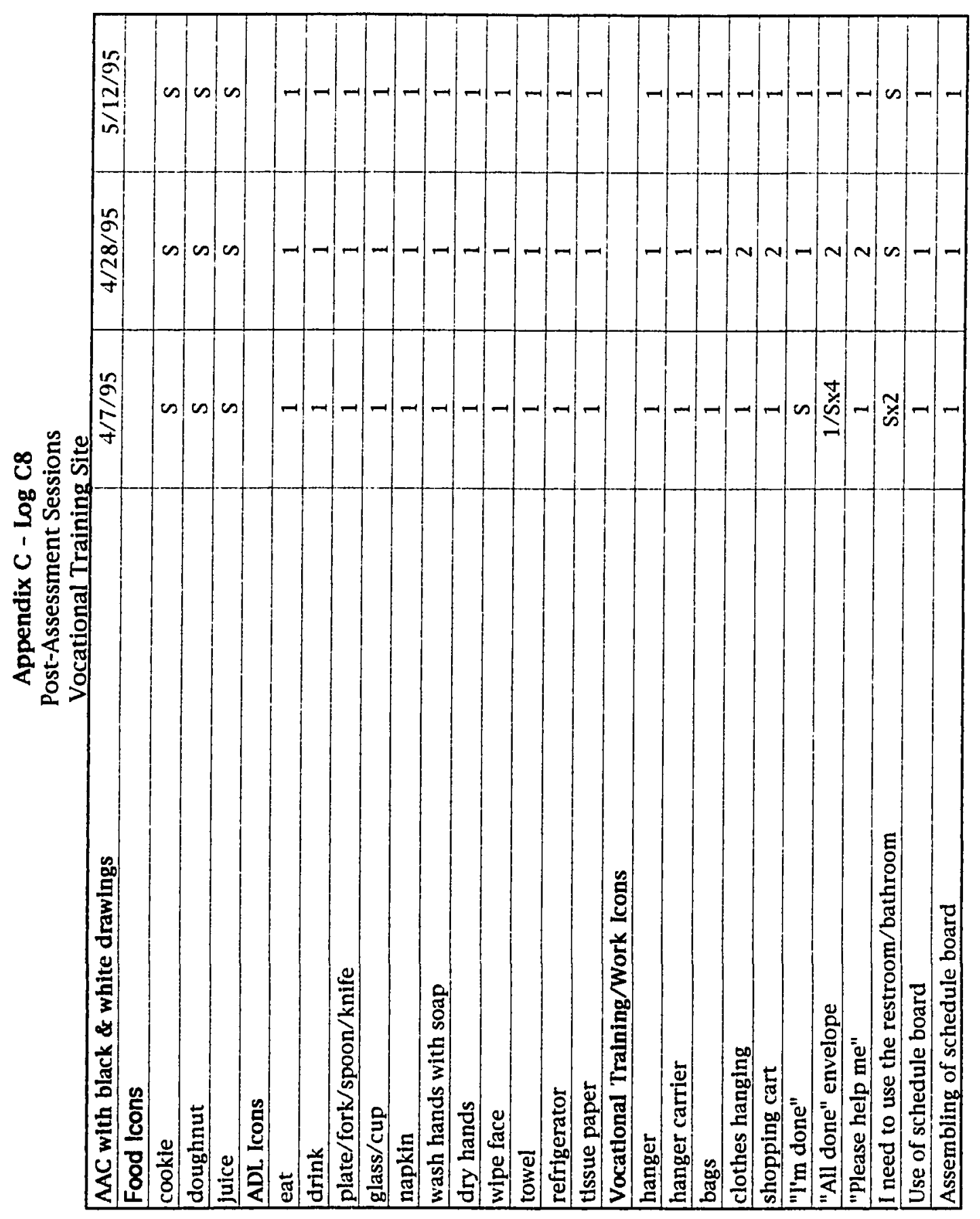




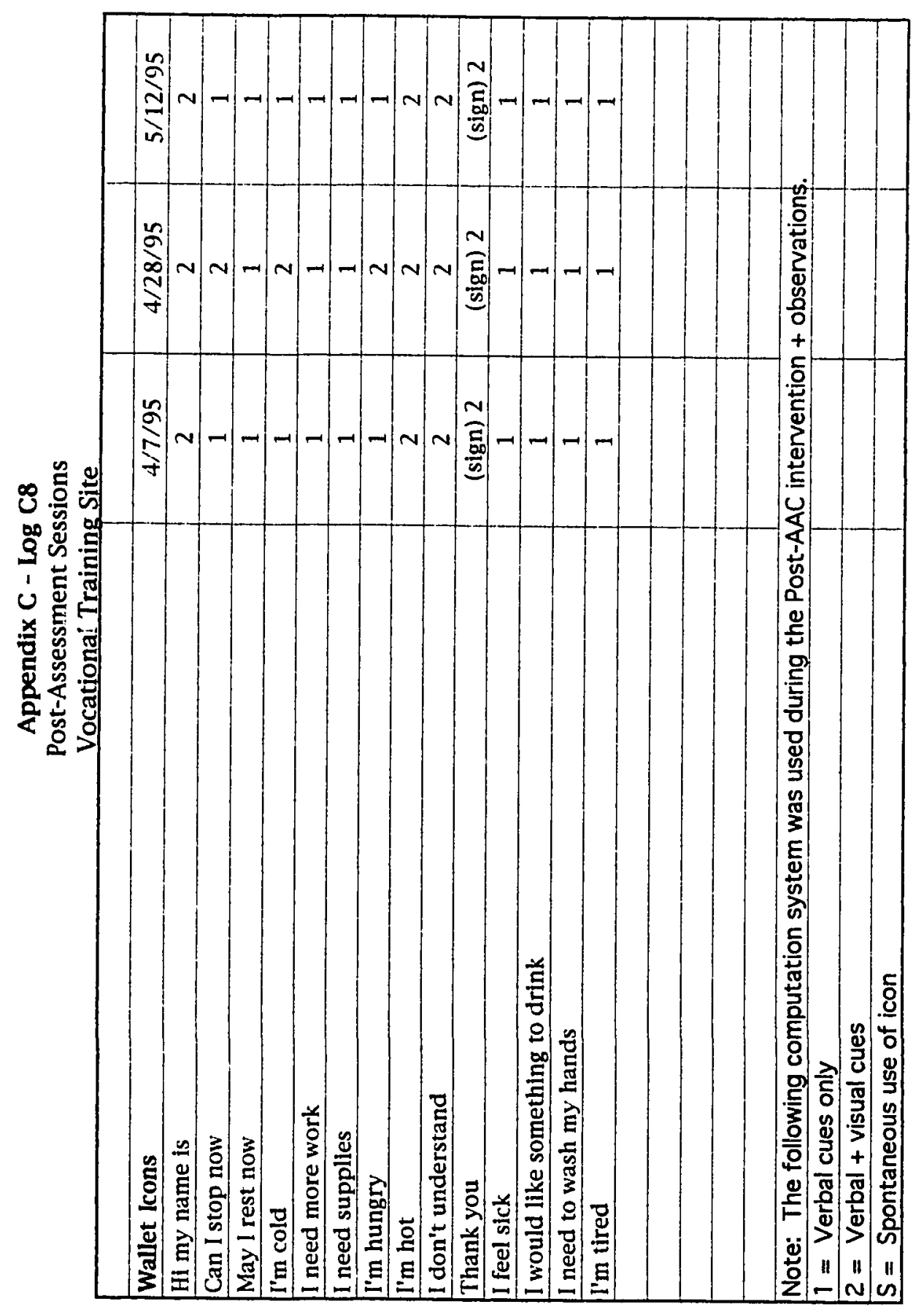




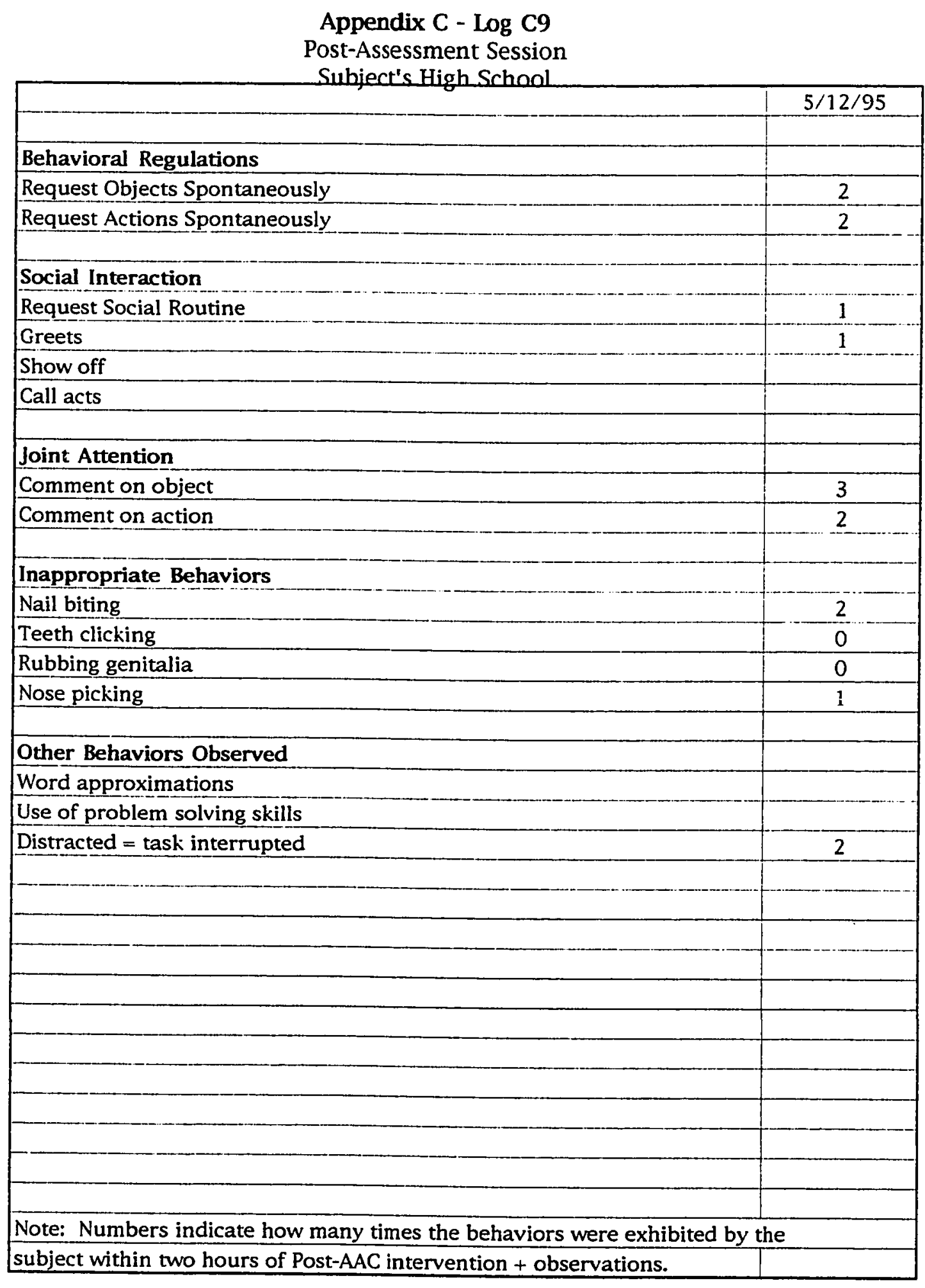




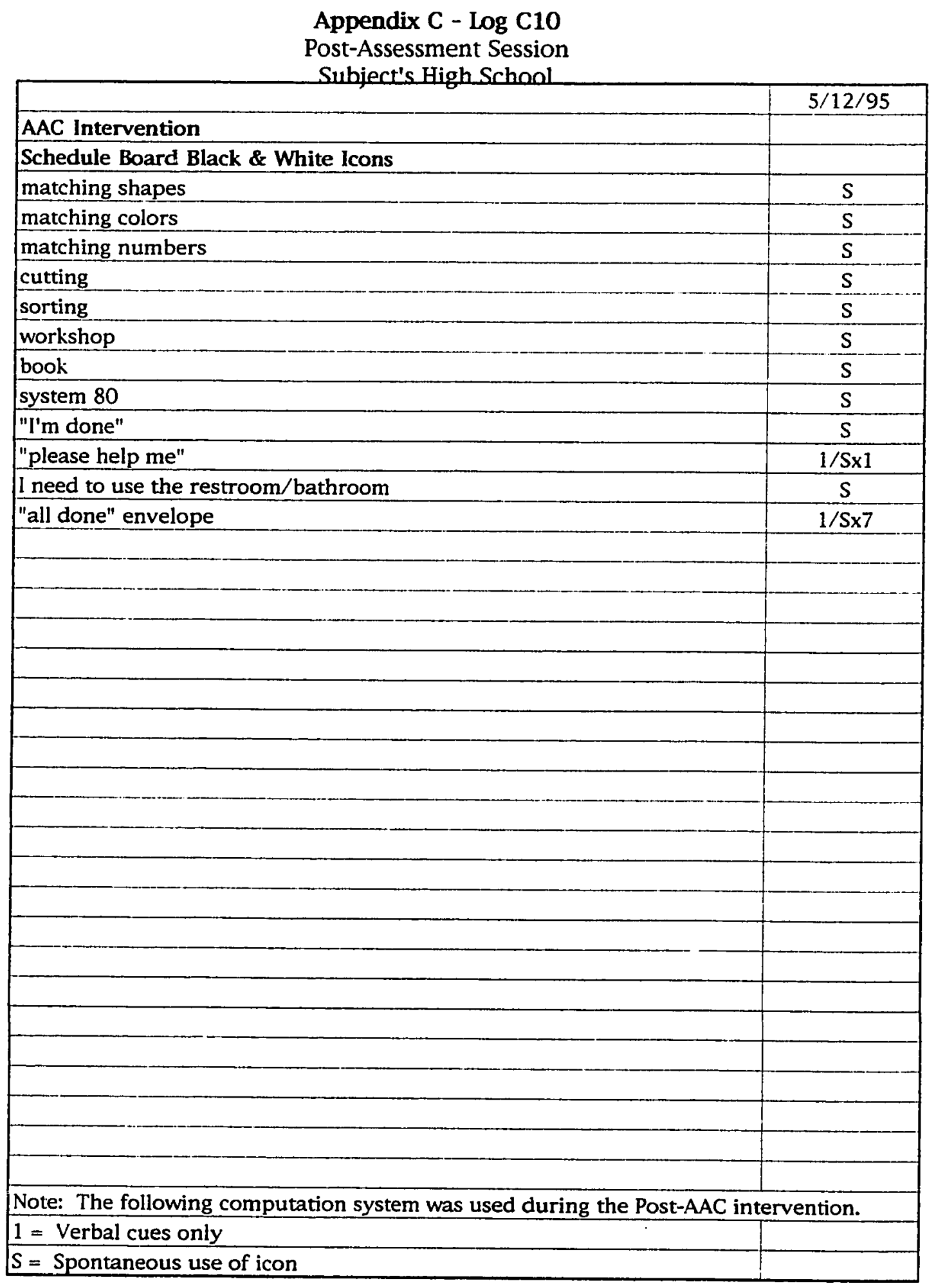




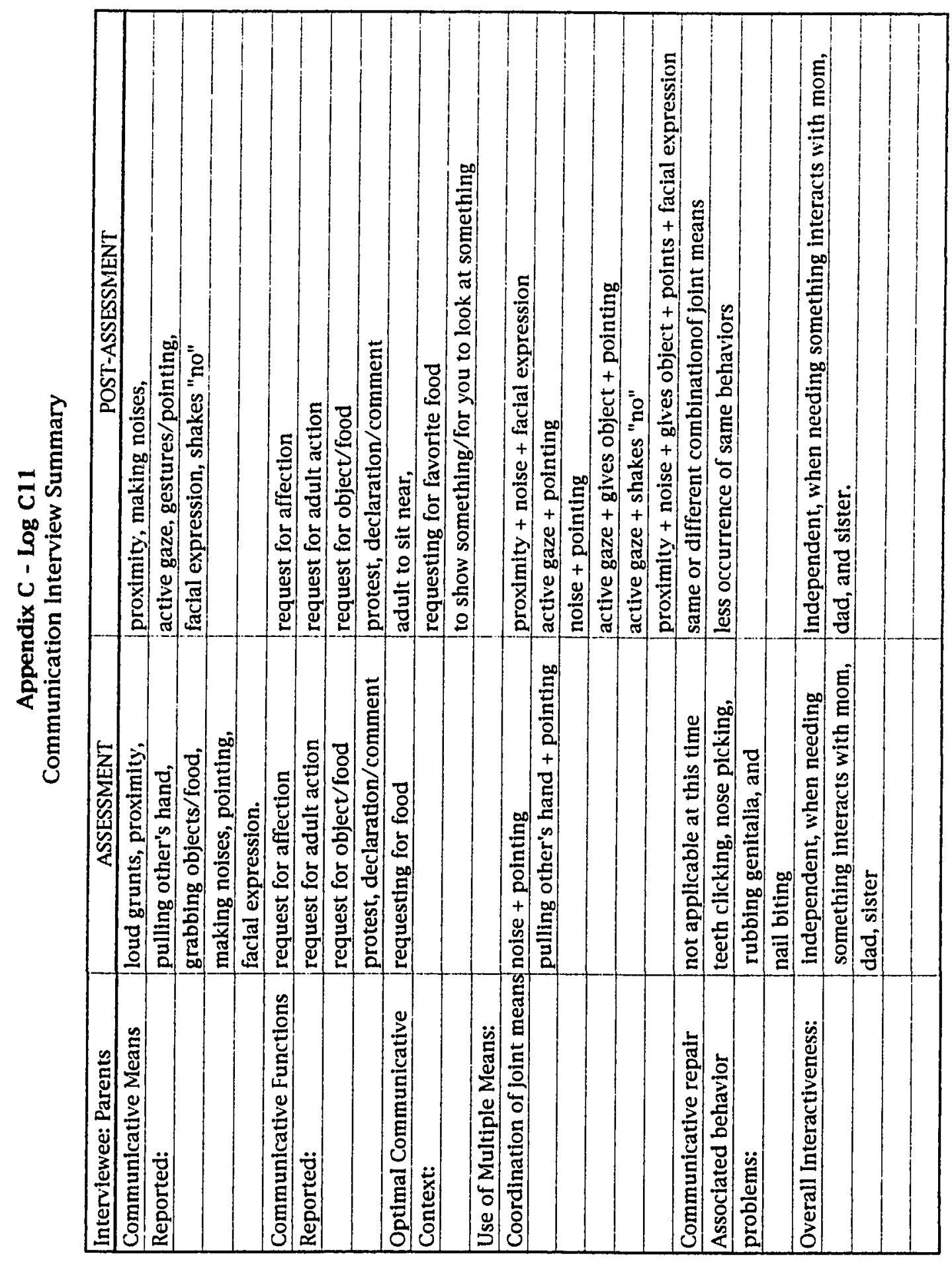




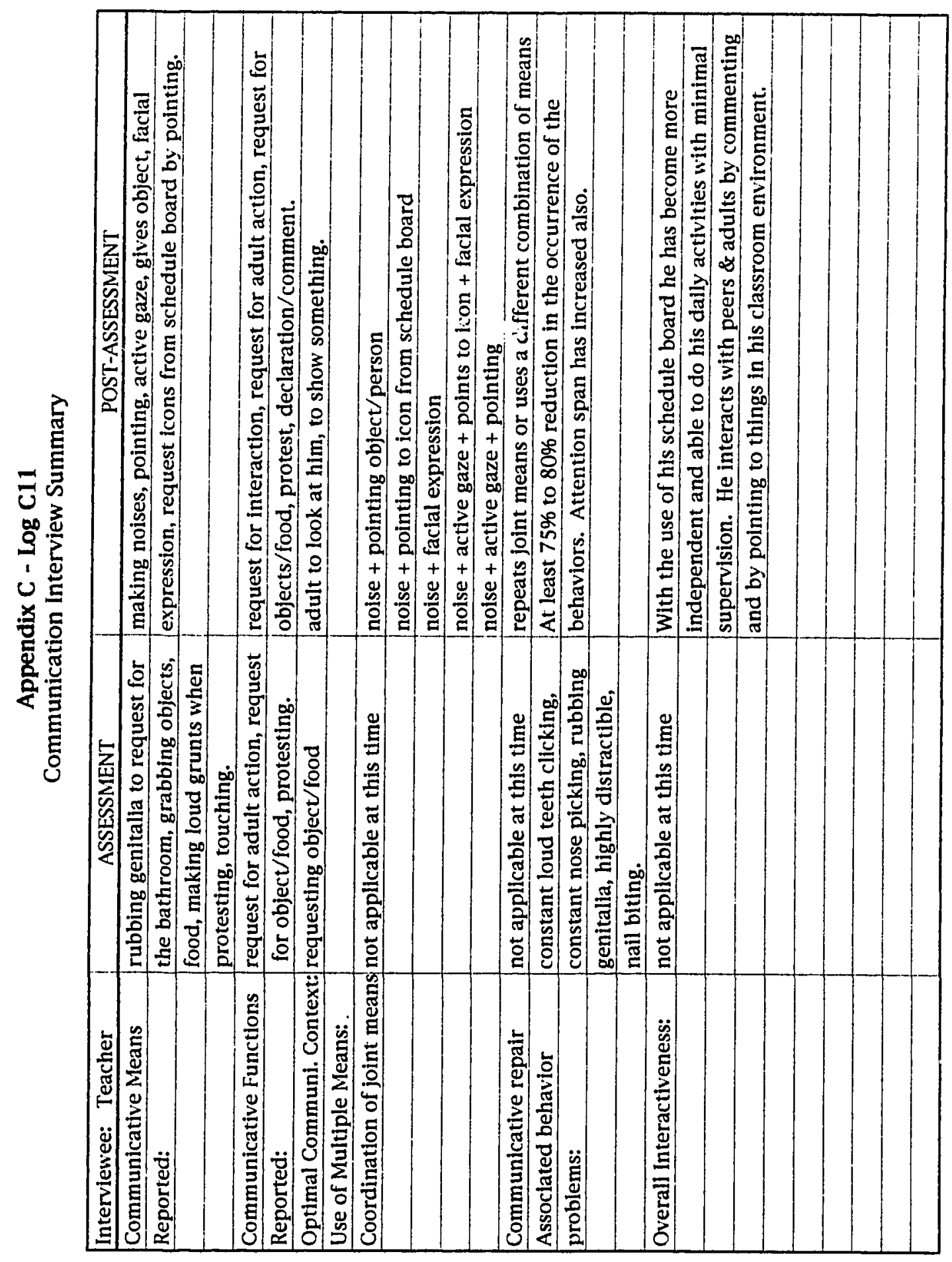




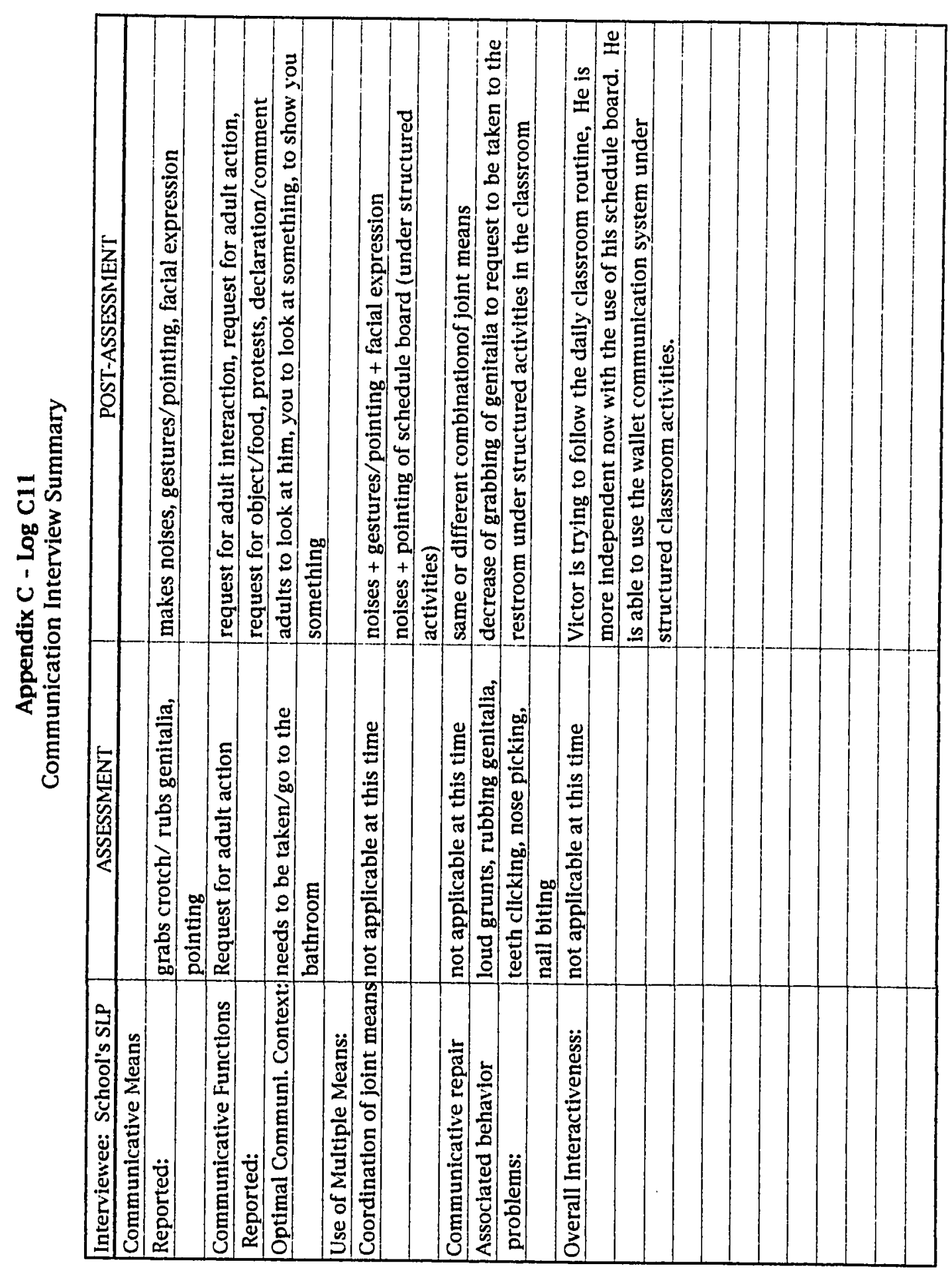




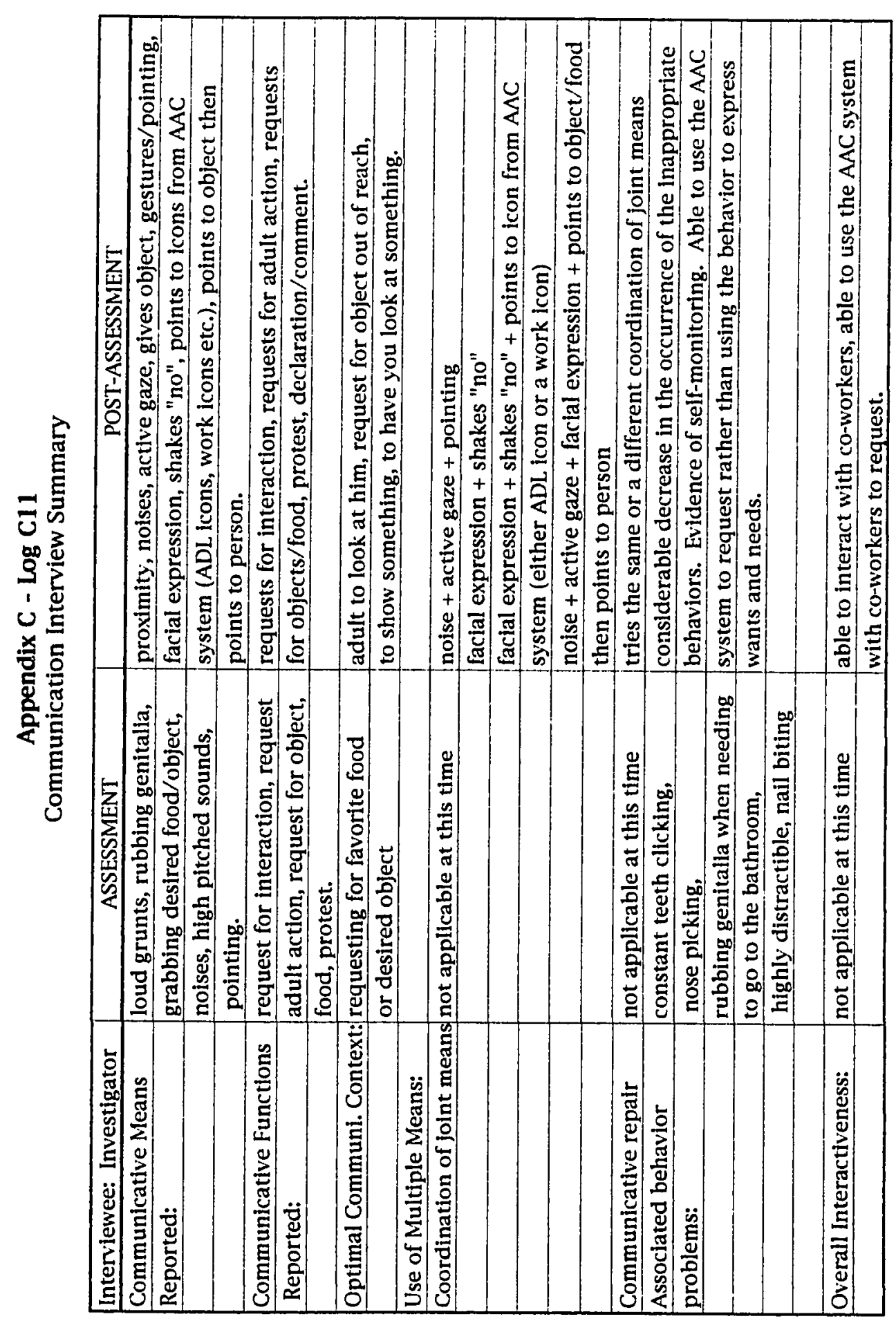


APPENDIX D

Philosophical Assumptions and Practical Considerations

(Adapted from Baumgart, Johnson, \& Helmstetter, 1990)

The the ten philosophic assumptions considered were as follows:

1. Chronological Age.- Victor's chronological age was taken into account to develop appropriate vocabulary that will allow him to participate in activities, communicate with his peers, make choices and send appropriate messages to other peers of his same chronological age. Victor's mental age was considered when deciding how to instruct him, the types of instruction and the complexity of the prompts to be used.

2. Functionality.- The AAC system's was designed to allow Victor the means to express his choices in all of the activities that he would participate in on a routine basis.

3. Interactions.- The interactions that Victor was going to take part in were considered so that the system would allow him to send and receive messages with a variety of people who were English and Spanish speaking.

4. Inclusion with Zero Exclusion.- Based on this belief it was determined that Victor would benefit from the AAC intervention. 
5. Social Significance.- The use of the AAC system would allow Victor to be integrated into society by meeting appropriate communicative social standards.

6. Requisite Skills.- These skills should not be deemed as prerequisites to communication or taught prior to increasing the opportunities for interactions. Therefore, it was determined that skills not possessed by Victor would be taught concurrently with the AAC intervention.

7. Pluralism.- Attention to the pluralistic use of the system was given so that Victor could use the same system and meet his communicative needs with English and Spanish speaking audiences. To ensure success it was necessary to remain flexible and accept the means of communication that Victor was using via body language, gesturing, head nodding, etc.

8. Natural Environment.- It was neccessary to conduct the AAC intervention in a natural environment to provide Victor with instructional and/or structured opportunities to communicate.

9. Preferences.- Victor's preferences in regard to his ADL's choices, wants and needs were taken into account when assembling the system.

10. Parent-School Partnership.- Maintaining a parent-school-job training site partnership would allow Victor to learn faster and generalize and maintain more easily all of the newly acquired communicative skills. 
The five practical considerations taken into account were as follows:

1. Portability.- The systems to be used included a portable communication board and a wallet size communication book.

2. Audience.- Victor's peers, co-workers, teachers, and family members were considered as his audience.

3. Expansion.- Keeping in mind the system's ease of expansion as to allow any other interventionist to continue adding more communicative means and functions once the initial system was established.

4. Maintenarice.- Ease of maintenance was considered to guarantee that the system would remain in good condition and be long lasting.

5. Comprehensive and Integrated Assessment.- The following were carefully considered: Victor's tracking and scanning abilities, hand preference, basic receptive English and Spanish language skills, comprehension skills (degree of abtraction/iconicity). 